UNIVERSIDADE DE SÃO PAULO

FACULDADE DE FILOSOFIA, CIÊNCIAS E LETRAS DE RIBEIRÃO PRETO DEPARTAMENTO DE FÍSICA

MARCELO ANTONIASSI

\title{
$\mathrm{O}$ espalhamento Compton de raios $\mathrm{X}$ no diagnóstico de neoplasias mamárias
}

RIBEIRÃO PRETO 


\section{O espalhamento Compton de raios X no diagnóstico de neoplasias mamárias}

Tese apresentada à Faculdade de Filosofia Ciências e Letras de Ribeirão Preto da Universidade de São Paulo, para obtenção do título de Doutor em Ciências

Área de concentração: Física Aplicada à Medicina e Biologia

Orientador: Prof. Dr. Martin Eduardo Poletti

RIBEIRÃO PRETO 
AUTORIZO A REPRODUÇÃO E DIVULGAÇÃO TOTAL OU PARCIAL DESTE TRABALHO POR QUALQUER MEIO CONVENCIONAL OU ELETRÔNICO, PARA FINS DE ESTUDO E PESQUISA, DESDE QUE CITADA A FONTE.

Antoniassi, Marcelo

O espalhamento Compton de raios $\mathrm{X}$ no diagnóstico de neoplasias mamárias / Marcelo Antoniassi; Orientação: Prof. Dr. Martin Eduardo Poletti, Ribeirão Preto: FFCLRP / USP, 2012.

Tese (Doutorado) apresentada à Faculdade de Filosofia, Ciências e Letras de Ribeirão Preto - Universidade de São Paulo.
1. Espalhamento Compton.
3. Radiologia.

2. Câncer de mama. 
À minha querida mãe (in memoriam) 


\section{AGRADECIMENTOS}

A Deus, por dar sentido ao trabalho, esforço e dedicação empregados neste trabalho.

A minha mãe Helena, por todo amor concedido.

A meu irmão Márcio, por todo apoio, incentivo e ajuda incondicional.

A minha noiva Nayara, pelo amor, compreensão e companheirismo nos momentos de conquista e de perda.

Ao professor Martin Eduardo Poletti, pelo excelente trabalho de orientação e pela amizade em todos estes anos de convivência.

Aos companheiros do grupo de Física Radiológica e Dosimetria Alessandra, André, Diego, Marina e Wender pela amizade e sabedoria compartilhada.

Aos técnicos Eldereis de Paula e José Luiz Aziani pela valiosa ajuda prestada na montagem dos arranjos experimentais e manutenção técnica do Laboratório de Física Radiológica e Dosimetria (LFRD).

Aos professores do Departamento de Física da Faculdade de Filosofia Ciências e Letras de Ribeirão Preto que tanto contribuíram para minha formação, desde a minha graduação até a pós-graduação em meu mestrado e doutorado.

Ao Departamento de Patologia da Faculdade de Medicina de Ribeirão Preto por fornecer as amostras de tecidos mamários utilizadas neste trabalho.

Ao pessoal das secretarias da Faculdade de Filosofia Ciências e Letras de Ribeirão Preto e do Departamento de Física, em especial a secretária Nilza Marina Leone Marino pela sempre presente boa vontade nos atendimentos.

À FAPESP, pela concessão da bolsa ao projeto "O espalhamento Compton de raios X no diagnóstico de neoplasias mamárias". 


\section{RESUMO}

ANTONIASSI, M. O espalhamento Compton de raios X no diagnóstico de neoplasias mamárias. [tese]. Ribeirão Preto: Faculdade de Filosofia Ciências e Letras de Ribeirão Preto, Universidade de São Paulo; 2012. 102p.

Neste trabalho foram realizadas medidas de espalhamento elástico e inelástico em tecidos mamários normais e neoplásicos (benignos e malignos) usando uma energia de 17,44 keV (radiação $K \alpha-M o)$ e um ângulo de espalhamento de $90^{\circ}\left(x=0,99 \AA^{-1}\right)$ com o objetivo de determinar as densidades eletrônicas $\left(\rho_{e}\right)$, número atômico efetivo $\left(Z_{e f}\right)$ e largura a meia altura $(L M A)$ do pico de espalhamento inelástico destes tecidos. Também foram estudadas por meio de simulações computacionais imagens obtidas por técnica de tomografia de espalhamento Compton. As metodologias experimentais foram verificadas através da análise de materiais de referência. Os valores de densidades eletrônicas e números atômicos efetivos obtidos foram comparados com dados experimentais e teóricos previamente publicados, mostrando uma boa concordância com estes (diferenças menores que 5\%). Os valores de LMA obtidos indicam a possibilidade de uso deste parâmetro para obter informação sobre composição dos tecidos e se mostraram correlacionados com os valores de $Z_{e f}$. Os resultados também mostram que existem diferenças de $\rho_{e}, Z_{e f}$ e $L M A$ entre os grupos de tecidos, as quais estão associadas à composição e à histologia dos tecidos investigados. Por fim, os resultados do estudo técnica de imagem por espalhamento Compton permitiu avaliar a influência de diferentes fatores relacionados ao feixe de radiação, à geometria e à amostra, que determinam a qualidade das imagens obtidas.

Palavras-chave: Espalhamento Compton. Câncer de mama. Radiologia. 


\begin{abstract}
ANTONIASSI, M. The Compton scattering of X-rays in the diagnosis of breast neoplasia. [thesis]. Ribeirão Preto: Faculdade de Filosofia Ciências e Letras de Ribeirão Preto, Universidade de São Paulo; 2012. 102p.

In this work we have been measured elastic and inelastic scattering from normal and neoplastic (benign and malignant) breast tissues using a photon energy of $17.44 \mathrm{keV}$ ( $\mathrm{K \alpha}$ radiation - Mo) and a scattering angle of $90^{\circ}$ in order to determine the electron densities $\left(\rho_{e}\right)$, effective atomic number $\left(Z_{e f}\right)$ and full width at half maximum $(F W H M)$ of inelastic peak of these tissues. Compton scattering imaging techniques was also studied using computational simulation. The experimental methods were checked by analyzing of standard reference materials. The values of electron densities and effective atomic numbers obtained were compared with theoretical and experimental data previously published, showing good agreement between them (differences smaller than 5\%). The values of $F W H M$ indicate the possibility of using the $F W H M$ for obtain information about the composition of tissues showing correlation with the values of $Z_{e f}$. The results also show that there are differences of $\rho e, Z_{e f}$ and $F W H M$ between groups of tissues which are associated with the composition and histology of the investigated tissues. Finally, the results of the study of the Compton scattering imaging technique allowed assessing the influence of various factors, related to the radiation beam, geometry sample, which determine the image quality.
\end{abstract}

Keywords: Compton scattering. Breast cancer. Radiology. 


\section{SUMÁRIO}

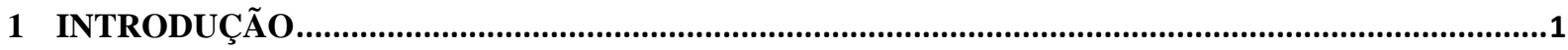

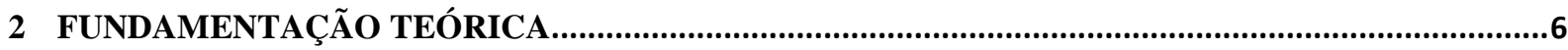

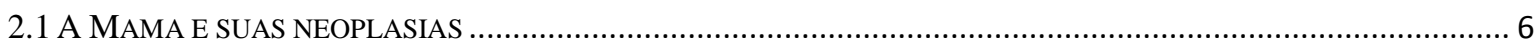

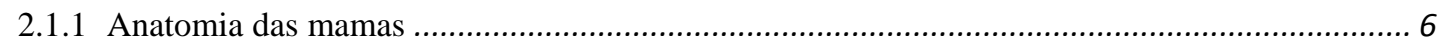

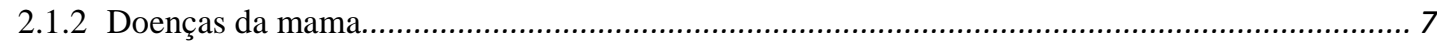

2.1.2.1 Doenças não neoplásicas .................................................................................................

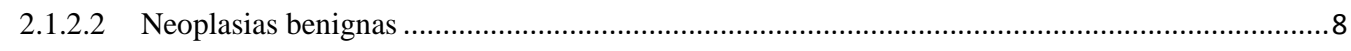

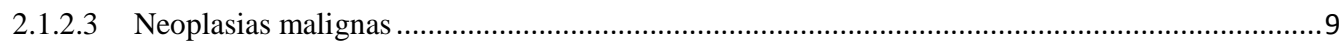

2.2 PROCESSOS DE INTERAÇÃO DA RADIAÇÃO COM A MATÉRIA .............................................................. 11

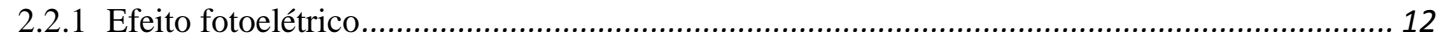

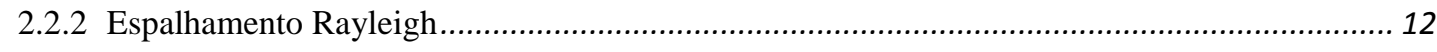

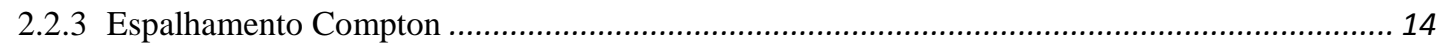

2.2.3.1 Distribuição angular dos fótons espalhados........................................................................16

2.2.3.2 Distribuição em energia dos fótons espalhados .....................................................................18

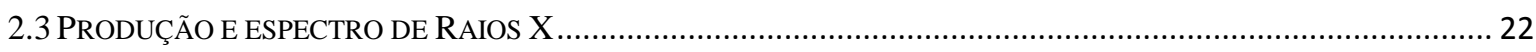

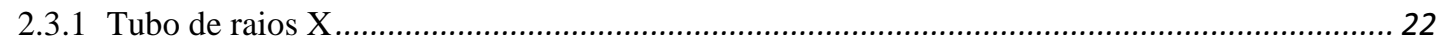

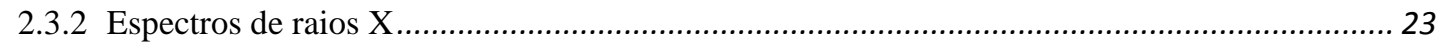

2.3.2.1 Espectro contínuo de emissão.............................................................................................23

2.3.2.2 Espectro característico de emissão ……............................................................................23

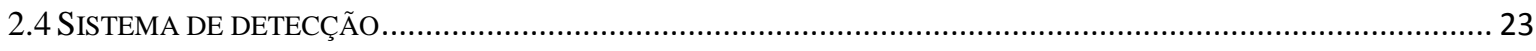

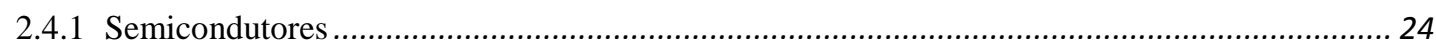

2.4 .2 Detecção da radiação.............................................................................................. 26

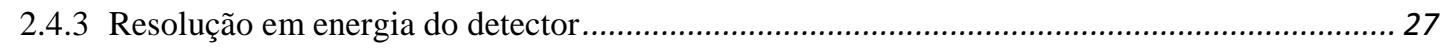

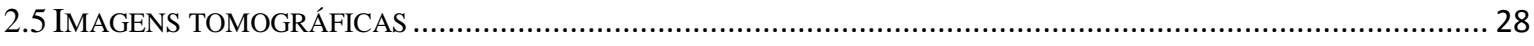

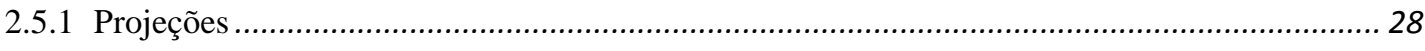

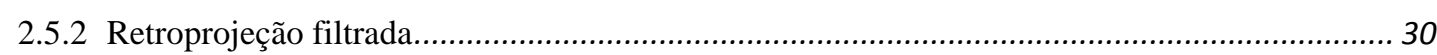

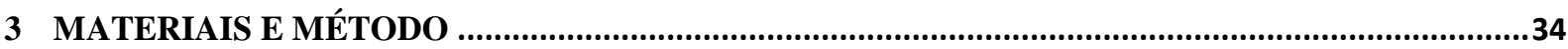

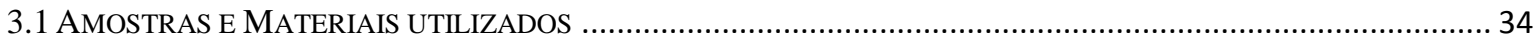

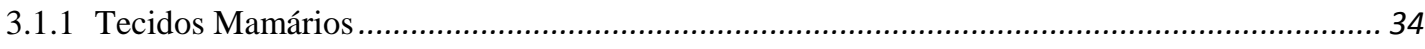

3.1.1.1 Coleta e Preparação das Amostras de tecidos...........................................................................34

3.1.1.2 Classificação Histológica dos Tecidos ...............................................................................34

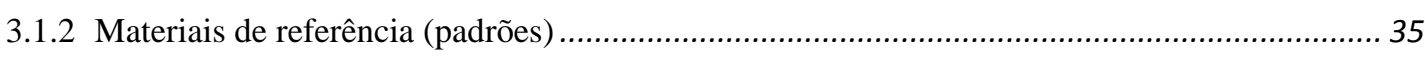

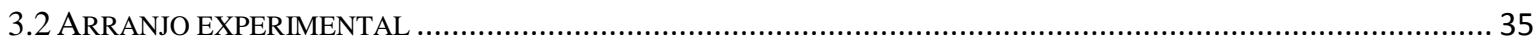

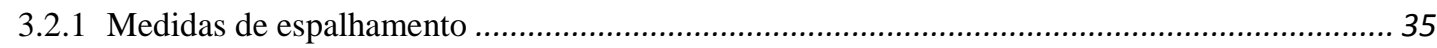




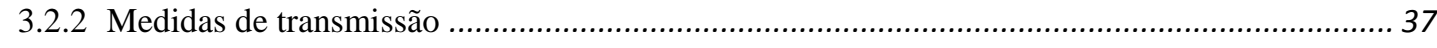

3.3 EXPLORANDO A DISTRIBUIÇÃO ANGULAR (INTENSIDADE) DOS FÓTONS ESPALHADOS .............................. 38

3.3.1 Determinação das densidades eletrônicas usando a distribuição angular (intensidade) dos

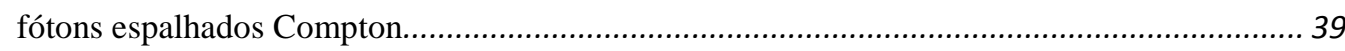

3.3.1.1 Fator de atenuação A .................................................................................................. 41

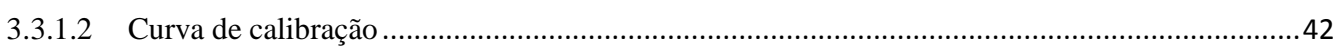

3.3.1.3 Validação do método para determinação das densidades eletrônicas ....................................... 43

3.3.2 Determinação do número atômico efetivo dos tecidos mamários usando a razão $\mathfrak{R}$ entre as intensidades de espalhamento Rayleigh e Compton........................................................... 44

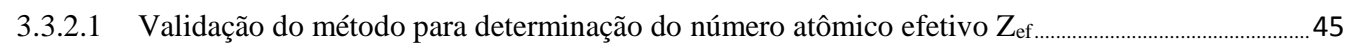

3.4 EXPLORANDO A DISTRIBUIÇÃO EM ENERGIA (FORMA DO ESPECTRO) DOS FÓTONS ESPALHADOS ................ 46

3.4.1 Determinação das larguras a meia altura (LMA) usando a distribuição em energia dos fótons

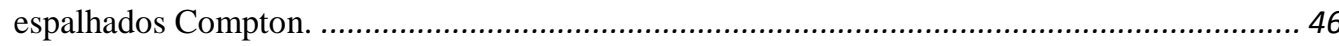

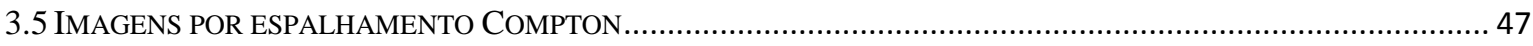

3.5.1 Arranjo esquemático das simulações tomográficas ........................................................... 47

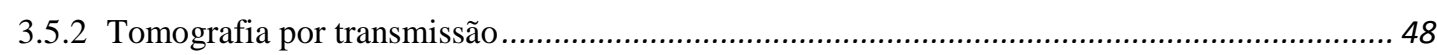

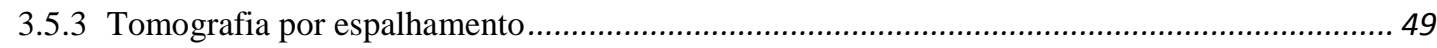

3.5.4 Estrutura do programa usado na simulação de espalhamento Compton................................ 53

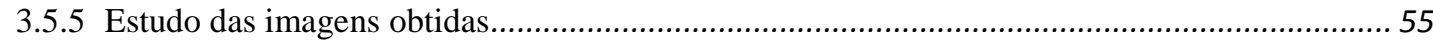

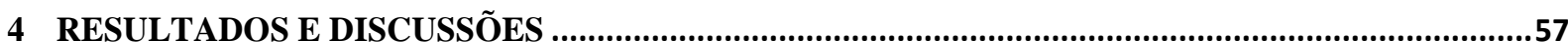

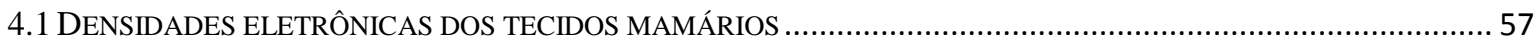

4.1.1 Resultados do teste de acurácia para as densidades eletrônicas ........................................ 57

4.1.2 Resultados de densidades eletrônicas dos tecidos mamários ............................................ 58

4.1.3 Comparação dos valores de densidades eletrônicas obtidos com os presentes na literatura ..... 59

4.1.4 Comparações estatísticas entre as distribuições de densidades eletrônicas .............................60

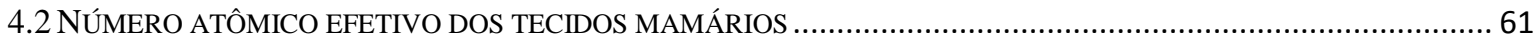

4.2.1 Resultados da validação do método de determinação do número atômico efetivo usando a razão

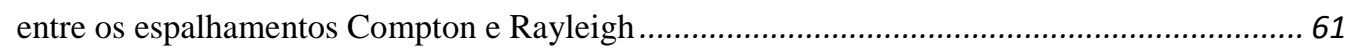

4.2.2 Resultados de número atômico efetivo dos tecidos mamários ............................................ 62

4.2.3 Comparação dos valores de número atômico efetivo obtidos com os presentes na literatura ...63

4.2.4 Comparações estatísticas entre as distribuições de número atômico efetivo...........................66

4.3 LARGURA A MEIA ALTURA DAS CURVAS DE ESPALHAMENTO COMPTON DOS TECIDOS MAMÁRIOS ............. 64

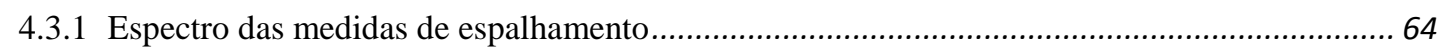

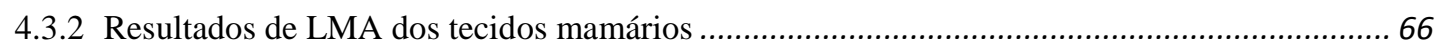

4.3.3 Comparações estatísticas das distribuições de LMA ......................................................6 66

4.4 RELAÇÕES ENTRE OS RESULTADOS DE $\rho_{\mathrm{E}}, \mathrm{Z}_{\mathrm{EF}}$ E LMA OBTIDOS E HISTOLOGIA DOS TECIDOS MAMÁRIOS..... 68

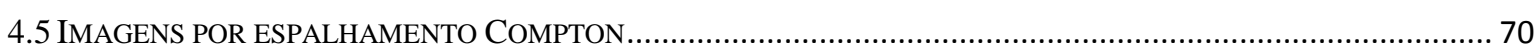

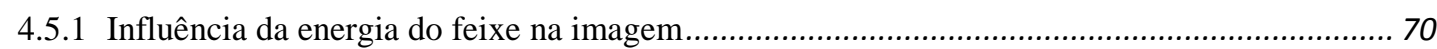


4.5.2 Influência da espessura e composição do objeto na imagem ........................................... 71

4.5.2.1 Dimensão do objeto ............................................................................................................

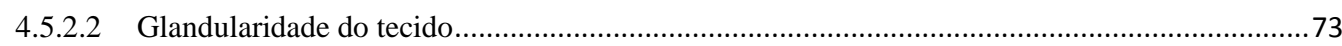

4.5.3 Influência das condições geométricas de irradiação e detecção .......................................... 75

4.5.3.1 Tamanho do feixe de irradiação .................................................................................................. 75

4.5.3.2 Ruído estatístico nas contagens ..............................................................................................76

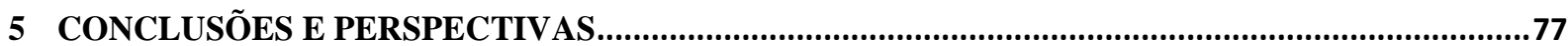

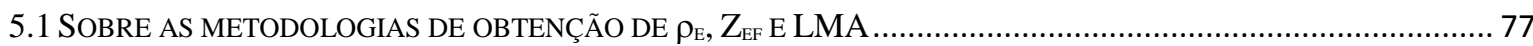

5.2 Dos RESULTADOS DE $\mathrm{P}_{\mathrm{E}}, \mathrm{Z}_{\mathrm{EF}}$ E LMA OBTIDOS E POTENCIALIDADES DAS TÉCNICAS................................ 77

5.3 DOS RESULTADOS DAS SIMULAÇÕES DE IMAGENS POR ESPALHAMENTO COMPTON ................................ 78

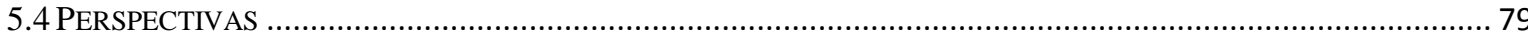

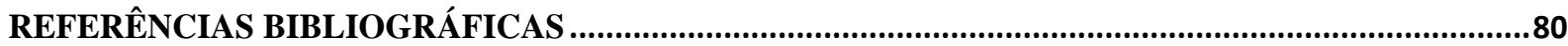

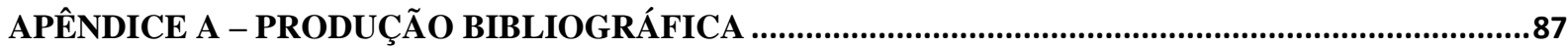

ANEXO A - APROVAÇÃO PELO COMITÊ DE ÉTICA E PESQUISA DO HC-FMRP........................90 


\section{Lista de Figuras}

Figura 2.1: Estrutura anatômica da mama (adaptado de Patrick J. Lynch)

Figura 2.2: Doenças da mama..

Figura 2.3: (a) Fator de forma $F(x, Z)$ e (b) secção de choque diferencial elástica para o átomo de oxigênio.

Figura 2.4: Esquema das medidas realizadas por Compton. .14

Figura 2.5: Esquema da interação Compton .15

Figura 2.6: Função de espalhamento incoerente na aproximação de Waller e Hartree para os elementos hidrogênio, carbono, nitrogênio e oxigênio.

Figura 2.7: (a) Perfis Compton e (b) secção de choque diferencial dupla para os elementos hidrogênio, carbono, nitrogênio e oxigênio.

Figura 2.8: Comparação das secções de choque diferenciais inelásticas nas aproximações de KleinNishina, Waller e Hartree e de Impulso do elemento carbono para 69,5 keV.

Figura 2.9: Produção de raios $X$ em um tubo. .22

Figura 2.10: Espectro de um tubo de raios $X$ de anodo de tungstênio... .23

Figura 2.11: Classificação dos materiais em termos da estrutura de bandas. .24

Figura 2.12: Esquema simplificado de um detector semicondutor.

Figura 2.13: Projeção paralela de um objeto em um ângulo $\theta$.

Figura 2.14: Retroprojeção de uma das projeções filtradas $\mathrm{Q}_{\theta}(\mathrm{t})$.

Figura 3.1: Arranjo experimental utilizado nas medidas de espalhamento. .36

Figura 3.2: Arranjo experimental utilizado nas medidas transmissão.

Figura 3.3: Comparação entre os fatores de atenuação A obtidos pela solução analítica e pela simulação usando os parâmetros experimentais de irradiação e geometria.

Figura 3.4: Curva $\mathrm{Y} v s \mu$ usada para determinação dos parâmetros $\mathrm{k}$ e $L$.

Figura 3.5: Razão $\mathfrak{R}$ entre os espalhamentos Rayleigh e Compton em função do número atômico efetivo. Símbolos representam os pontos de $f_{0,99},(Z)$ calculados teoricamente para elementos puros ( $Z$ inteiro) enquanto a linha contínua representa a função contínua $f_{0,99}(Z e f)$, resultado do ajuste polinomial.

Figura 3.6: Seção de choque total em função do número atômico efetivo. Símbolos representam os pontos obtidos teoricamente para elementos puros ( $Z$ inteiro) enquanto a linha contínua representa o resultado do ajuste polinomial de ordem 6 ......

Figura 3.7: Arranjo esquemático usado nas simulações de tomografia por espalhamento.................. .48

Figura 3.8: Estrutura do programa usado nas simulações de tomografia por espalhamento.

Figura 3.9: Definição de alguns parâmetros que influenciam as características das imagens reconstruídas. 
Figura 4.1: Densidade eletrônica experimental versus calculada para os materiais de referência........57

Figura 4.2: Box plot das densidades eletrônicas dos diferentes tipos de tecidos .............................58

Figura 4.3: Box plot de $Z_{e f}$ dos diferentes tipos de tecidos ..............................................62

Figura 4.4: Espectro médio normalizado dos vários tipos de tecidos estudados. ...........................64

Figura 4.5: Secções de choques diferenciais duplas dos tecidos mamários....................................65

Figura 4.6: Box plot das LMA dos diferentes tipos de tecidos ...................................................66

Figura 4.7: Distribuição das $L M A$ versus $Z_{e f}$ das amostras usadas no teste de correlação.................67

Figura 4.8: Histologia e composição dos tecidos comparadas com os valores obtidos de $L M A$ e $Z_{e f .} .69$

Figura 4.9: Imagens de espalhamento e valores de $\mu_{i n}$, reais e reconstruídos, ao longo da linha central para $D=2 \mathrm{~cm}, d=0,5 \mathrm{~cm}$, tecido 1: adiposo, tecido 2: carcinoma, $n=200, m=180$, filtro: Shepp-Logan e diferentes energias incidentes $E_{i}$ (a) $17,44 \mathrm{keV}$, (b) $30 \mathrm{keV}$ e (c) $60 \mathrm{keV}$........70

Figura 4.10: Diferenças $\%$ entre os valores de $\mu_{\text {in }}$ reais e obtido pela reconstrução tomográfica para diferentes energias incidentes.

Figura 4.11: Imagens de espalhamento e valores de $\mu_{\text {in }}$, reais e reconstruídos, ao longo da linha central para $E_{i}=60 \mathrm{keV}$, tecido 1: adiposo, tecido 2: carcinoma, $n=200, m=180$, filtro: SheppLogan e diferentes diâmetro da amostra D (a) $8 \mathrm{~cm}$, (b) $4 \mathrm{~cm}$ e (c) $2 \mathrm{~cm}$.

Figura 4.12: Diferenças \% entre os valores de $\mu_{\text {in }}$ reais e reconstruídos para diferentes diâmetro de amostra. .73

Figura 4.13: Imagens de espalhamento para $E_{i}=60 \mathrm{keV}, \mathrm{D}=2 \mathrm{~cm}, \mathrm{~d}=0,5 \mathrm{~cm}$, tecido 1: adiposo/fibroglandular, tecido 2: carcinoma, $n=200, m=180$, filtro: Shepp-Logan e diferentes glandularidades do tecido 1 (a) $0 \%$, (b) $30 \%$, (c) $50 \%$ e (d) $80 \%$

Figura 4.14: Imagens de espalhamento para $E_{i}=60 \mathrm{keV}, D=8 \mathrm{~cm}, d=2 \mathrm{~cm}$, tecido 1: adiposo, tecido 2: carcinoma, $n=200, m=180$, filtro: Shepp-Logan e diferentes larguras do feixe $b$ (a) $0,05 \mathrm{~cm}(\mathrm{~b}) 0,1 \mathrm{~cm} \mathrm{(c)} 0,2 \mathrm{~cm} \mathrm{e} \mathrm{(d)} 0,5 \mathrm{~cm}$.

Figura 4.15: Imagens de espalhamento para $E_{i}=60 \mathrm{keV}, D=2 \mathrm{~cm}, d=0,5 \mathrm{~cm}$, tecido 1: adiposo, tecido 2: carcinoma, $n=200, m=180$, filtro: Hamming e diferentes níveis de ruído (a) sem ruído (b) ruído $\sim 1 \%$ (c) ruído $\sim 3 \%$ .76 


\section{Lista de Tabelas}

Tabela 3.1: Composições químicas e densidade física dos materiais de referência utilizados neste trabalh

Tabela 3.2: Coeficientes de atenuação linear determinados na experiência com 17,44 keV, calculados através da regra das misturas e a diferença relativas entre esses valores

Tabela 4.1: Densidades eletrônicas reais e experimentais, utilizadas para verificar a acurácia do procedimento experiment .58

Tabela 4.2: Valores experimentais (média e desvio padrão) e teóricos de densidades eletrônicas de tecidos mamários presentes na literatura. .59

Tabela 4.3: Resultado do teste de comparação múltipla de Dunn...... .60

Tabela 4.4: Comparação entre os valores de $Z_{e f}$ determinados pelo método proposto (espalhamento) e pelo método convencional (transmissão) e respectiva exatidão relativa.

Tabela 4.5: Intervalo dos valores médios de $Z_{e f}$ dos tecidos mamários .62

Tabela 4.6: Resultado do teste de comparação múltipla de Bonferroni. .64

Tabela 4.7: Composição química (porcentagem em massa) de carbono e oxigênio de tecidos mamários na literatura .68 


\section{INTRODUÇÃO}

O câncer de mama é o segundo tipo de câncer mais frequente no mundo e o mais comum em mulheres, sendo uma das principais causas de morte entre elas. A cada ano, cerca de $23 \%$ dos casos de câncer em mulheres são de mama (INCA, 2011). Estudos do Instituto Nacional de Câncer sobre a incidência do câncer de mama estimam que o número de novos casos de câncer de mama no Brasil no ano de 2012 será de 52680, com um risco de 52 casos para cada 100 mil mulheres (INCA, 2011).

A detecção precoce do câncer de mama é fundamental para o combate a essa doença, possibilitando a utilização de tratamentos menos agressivos, com maiores chances de cura dos pacientes. Várias são as técnicas utilizadas para detecção do câncer de mama, sendo o exame clínico e a mamografia as principais utilizadas, podendo ser complementadas por exames de ultra-sonografia, cintilografia, ressonância magnética e por diversas técnicas de biópsia (punção aspirativa por agulha fina, biopsia de fragmento e mamotomia) (MAUTNER; SCHMIDT; BRENNAN, 2000).

A mamografia (radiografia da mama), assim como a radiografia convencional, é baseada no uso das diferenças de coeficientes de atenuação linear dos diversos tipos de tecidos que compõem a mama. A radiação transmitida pela mama impressiona um receptor de imagem (filme mamográfico) gerando um padrão de contraste, permitindo a detecção de estruturas de diferentes densidades e formas (JOHNS; CUNNINGHAM, 1983). Apesar de sua grande eficiência e importância, a mamografia apresenta limitações basicamente relacionadas às pequenas diferenças radiológicas (coeficientes de atenuação linear) entre os diversos tecidos mamários e a perda de contraste ocorrida devido aos efeitos do espalhamento da radiação (POLETTI, 1997). Tais limitações explicam a grande dificuldade em diferenciar alterações benignas de malignas (estima-se que 75\% das lesões suspeitas ou indeterminadas mamograficamente levadas à biopsia são benignas) (MAUTNER; SCHMIDT; BRENNAN, 2000). Estas razões têm motivado estudos de novas técnicas que possibilitem a melhoria do diagnóstico da doença, diminuindo a necessidade de biópsias, cujos procedimentos são invasivos, altamente especializados e dispendiosos.

A utilização da radiação espalhada, antes tida como um problema em radiologia, vem se mostrando uma solução promissora ao problema apresentado. Este tipo de radiação carrega informações sobre a estrutura eletrônica do material espalhador, não contidas na radiação primária, que forma a imagem de transmissão. Uma vez que as composições elementares e, 
por conseguinte, as estruturas eletrônicas dos vários tecidos (normais ou alterados) que compõem a mama são diferentes, essas informações podem ser úteis, por exemplo, para diferenciar tecido normal de alterado, ou ainda, tecidos neoplásicos benignos de malignos.

A radiação espalhada é composta de fótons espalhados elasticamente (espalhamento coerente), cuja energia não é alterada no processo de interação com a matéria e por fótons espalhados inelasticamente (espalhamento incoerente ou Compton), que são aqueles fótons que transferem parte da energia no processo de interação (JOHNS; CUNNINGHAM, 1983). Ambos os processos de espalhamento podem ser utilizados para obter informações sobre tecidos biológicos permitindo classificá-los (ANTONIASSI; CONCEIÇÃO; POLETTI, 2010; 2011; CESAREO et al., 1992; CONCEIÇÃO; ANTONIASSI; POLETTI, 2010; POLETTI; GONÇALVES; MAZZARO, 2002b; SPELLER, 1999; TARTARI et al., 1992; THEODORAKOU; FARQUHARSON, 2008)

Estudos de espalhamento elástico permitem obter as distribuições eletrônicas espaciais dos centros espalhadores (átomos ou moléculas) dando informações detalhadas sobre as correlações eletrônicas no material. Estes estudos vêm sendo aplicados para diferentes tecidos como mama (CONCEIÇÃO; ANTONIASSI; POLETTI, 2009; FERNANDEZ et al., 2002; LEWIS et al., 2000; POLETTI; GONÇALVES; MAZZARO, 2002b; RYAN; FARQUHARSON, 2007), cérebro (SIU et al., 2005), rim (CASTRO; BARROSO; LOPES, 2005), útero (CASTRO; BARROSO; LOPES, 2005) e músculo (ELSHEMEY; ELSAYED; EL-LAKKANI, 1999).

Estudos envolvendo o espalhamento inelástico, por sua vez, podem ser divididos em dois grupos de técnicas: $(i)$ técnicas que exploram a intensidade (número) de fótons espalhados e (ii) técnicas que exploram a forma do espectro dos fótons espalhados (perfil de espalhamento Compton).

O primeiro grupo de técnicas utiliza a intensidade da radiação espalhada inelasticamente para obter informação sobre a densidade eletrônica do material analisado, relacionando a intensidade com o número de elétrons por unidade de volume da amostra espalhadora. Dessa forma, medidas de espalhamento Compton permitem determinar as densidades eletrônicas de materiais, fato que tem sido explorado com êxito em diversas aplicações clínicas tais como densitometria óssea (CLARKE; VANDYK, 1973; WEBBER; KENNETT, 1976), pulmonar (HANSON et al., 1984; WEBBER; COATES, 1982) e de mama (AL-BAHRI; SPYROU, 1998; ANTONIASSI; CONCEIÇÃO; POLETTI, 2010; RYAN; FARQUHARSON; FLINTON, 2005) no diagnóstico de osteoporose, edema pulmonar e neoplasias mamárias respectivamente. Além disso, a intensidade de fótons espalhados 
inelasticamente, combinada com a intensidade de fótons espalhados elasticamente, também permite determinar o número atômico efetivo do material espalhador (DUVAUCHELLE; PEIX; BABOT, 1999), uma grandeza que é independente da densidade e da atenuação da radiação dentro da amostra, cuja determinação é de grande importância em radiologia, no estudo das imagens médicas (particularmente em sistemas tomográficos), e em dosimetria (SHIVARAMU, 2002). Esta técnica está baseada no fato de a razão entre as intensidades de espalhamento Rayleigh e Compton ser uma função do número atômico dos elementos presentes na amostra espalhadora (BRADLEY; GHOSE, 1984; DUVAUCHELLE; PEIX; BABOT, 1999), e quando comparada com técnicas convencionais de transmissão, sensíveis ao coeficiente de atenuação linear $(\mu)$, é especialmente útil em casos onde as variações de $\mu$ são pequenas e as variações de número atômico são mais significantes. Esta técnica tem sido bastante empregada na detecção de alterações na composição de tecidos moles (PUUMALAINEN; SIKANEN; OLKKONEN, 1979), de fígado (PUUMALAINEN; OLKKONEN; SIKANEN, 1977) e de osso (KERR et al., 1980; PUUMALAINEN et al., 1982), sendo, no entanto, pouco empregada na caracterização de tecidos mamários (ANTONIASSI; CONCEIÇÃO; POLETTI, 2011; RYAN; FARQUHARSON, 2010)

O segundo grupo de técnicas analisa a forma da curva da distribuição em energia dos fótons espalhados relacionando-as à distribuição de momento dos elétrons do material espalhador (COOPER, 1985; DUMOND, 1929; RIBBERFORS, 1975). Essa distribuição de momento, própria dos elementos que constituem o material, pode ser usada para caracterizálo. Particularmente, na caracterização de tecidos biológicos ou de materiais de interesse radiológico, Holt et al. (1983) mostraram diferenças na forma da curva Compton entre diferentes amostras de tecidos de fígado. Gatti, Rehak e Kemmer (1986) sugeriram um método para determinar as composições dos tecidos ajustando os perfis experimentais como soma dos perfis dos átomos livres. Matschenko e Carlsson (1989) analisaram o espectro de quatro materiais (berílio, lucite, alumínio e polietileno) mostrando que as diferenças entre suas formas eram devidas às diferenças na distribuição de momento dos elétrons que compõem os materiais. Mackenzie (1990) propôs que a parte de alta energia do perfil de espalhamento Compton em geometria de retroespalhamento pode ser usada para avaliar a concentração de minerais em ossos. Tartari et al. (1992; 1994) resumiram as informações contidas nos perfis Compton em uma razão entre contagens de duas regiões específicas da curva, mostrando qualitativamente uma correlação entre o número atômico efetivo da amostra e essa razão. Mais recentemente Rao et al. (2004) calcularam a largura da curva dos perfis de 
espalhamento Compton para moléculas, plásticos, tecidos biológicos e materiais biológicos na região de energia dos raios $\mathrm{X}$.

Uma importante e promissora aplicação das técnicas de espalhamento apresentadas é a possibilidade de obterem-se imagens, isto é, a distribuição espacial de parâmetros físicos, como a densidade eletrônica, número atômico efetivo (CESAREO et al., 2001; CESAREO et al., 2002; DUVAUCHELlE; PEIX; BABOT, 2000; HARDING, 1997; HARDING; HARDING, 2010; LENTI, 2008; VANUYTVEN; PISTORIUS; GORDON, 2008), com as quais estruturas possam ser visualmente reconhecidas. Isto permite obter informações espaciais, como por exemplo, no caso do câncer de mama, o contorno de massas sólidas, existência de infiltração, etc., que somadas ao contraste obtido pela técnica podem úteis para o diagnóstico desta doença.

Com base no apresentado, o presente trabalho pretende dar uma sequência natural aos estudos de classificação histopatológica de tecidos mamários usando radiação espalhada Compton, com o objetivo de aperfeiçoar as metodologias empregadas e estender o estudo de densitometria Compton anteriormente realizado por Antoniassi (2008), baseada na intensidade de espalhamento, à análise completa do espectro de espalhamento, elástico e inelástico, buscando obter outros parâmetros como, o número atômico efetivo e a largura a meia altura do pico inelástico, que permitam a caracterização e classificação dos tecidos mamários, além de estudar técnicas de imagens tomográficas por espalhamento com aplicação ao diagnóstico do câncer de mama.

A divisão dos capítulos desta tese obedece à seguinte sequência:

No capítulo 2 serão apresentados os fundamentos teóricos em que este trabalho está baseado. Inicialmente será apresentado um estudo da anatomia e doenças da mama. Posteriormente serão abordados o efeito fotoelétrico e o espalhamento elástico (Rayleigh) seguido de um estudo detalhado do espalhamento Compton onde serão descritas a distribuição angular dos fótons espalhados através da secção de choque diferencial inelástica e a distribuição em energia (espectro) de espalhamento Compton com base na secção de choque diferencial dupla segundo a Aproximação de Impulso. Por fim serão apresentados os conceitos referentes à produção de raios $\mathrm{X}$ por um tubo de raios $\mathrm{X}$, à detecção de radiação e à reconstrução de imagens através de técnica tomográfica.

No capítulo 3 serão descritos os tecidos estudados, o arranjo experimental, os modelos e metodologias experimentais envolvidos na determinação da densidade eletrônica $\left(\rho_{e}\right)$, número atômico efetivo $\left(Z_{e f}\right)$ e largura a meia altura $(L M A)$ da curva de espalhamento 
Compton. Também será apresentada a metodologia usada nas simulações computacionais para obtenção de imagens de espalhamento Compton.

No capítulo 4 serão apresentados os resultados dos testes de acurácia e validação das metodologias experimentais para determinação de $\rho_{e}, Z_{e f}$ e $L M A$. Os resultados desses parâmetros para os diferentes tipos de tecidos serão comparados com dados presentes na literatura e analisados estatisticamente. Os resultados obtidos também serão discutidos em relação à composição e histologia dos tecidos mamários. Por fim serão apresentados os resultados do estudo das imagens de espalhamento Compton para diversas condições espectrais, de tamanho e composição do objeto, geométricas de irradiação e detecção.

O capítulo 5 será dedicado às conclusões e perspectivas do trabalho. 


\section{FUNDAMENTAÇÃO TEÓRICA}

\subsection{A MAMA E SUAS NEOPLASIAS}

Para a perfeita compreensão dos processos patológicos de um órgão, é necessário conhecer sua estrutura e função. Nesta subseção serão apresentadas as estruturas anatômicas e fisiológicas de uma mama normal. Posteriormente serão estudadas as principais patologias da mama, classificadas em doenças benignas não neoplásicas, neoplasias benignas e neoplasias malignas.

\subsubsection{Anatomia das mamas}

Na figura 2.1 podemos observar as diversas estruturas anatômicas que compõem mama.

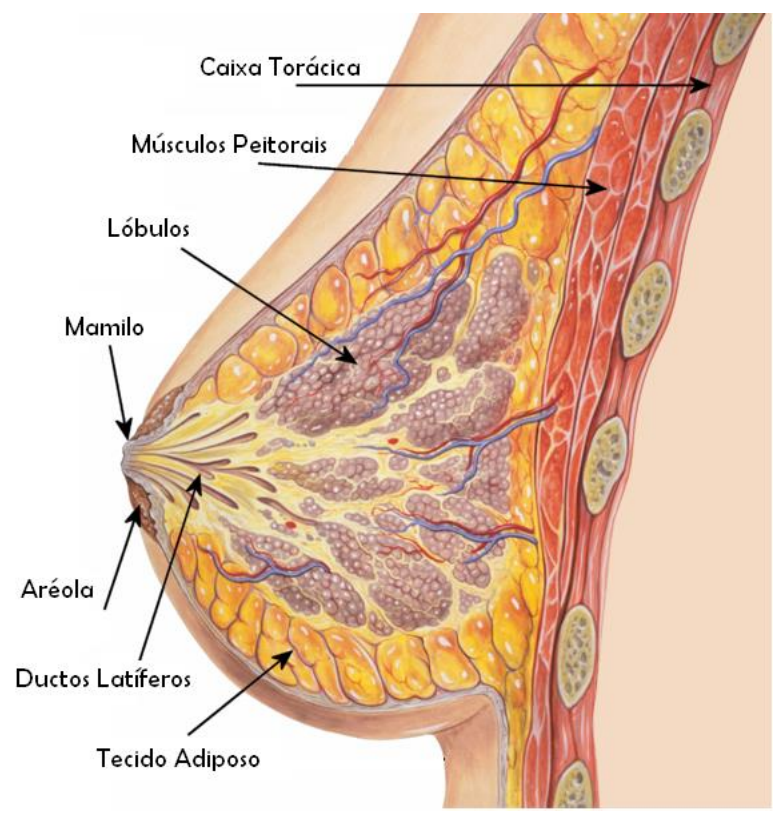

Figura 2.1: Estrutura anatômica da mama (adaptado de Patrick J. Lynch).

As mamas situam-se na superfície anterior ao tórax e se sobrepõem aos músculos peitorais. Durante a puberdade da mulher, as mamas se desenvolvem e as áreas rosadas da pele ao redor dos mamilos, chamadas aréolas, aumentam. Os ductos lactíferos são canais que dão origem a botões que formam 15 a 20 lóbulos de tecido glandular, constituindo a glândula mamária. Cada lóbulo é imerso em tecido conjuntivo intralobular frouxo e muito celularizado. 
Já o tecido conjuntivo interlobular, que separa os lóbulos, é mais denso e menos celularizado (JUNQUEIRA; CARNEIRO, 2004), rico em fibras e colágeno, constituindo a armação da mama. Abundante tecido adiposo está presente no tecido conjuntivo denso dos espaços interlobulares. O contorno arredondado (gordura subcutânea) e maior parte do volume das mamas são constituídos de tecido adiposo, exceto durante a gravidez e a lactação, quando as glândulas mamárias crescem de tamanho.

Resumidamente, o tecido mamário pode ser dividido em três diferentes tipos:

(i) Tecido Glandular: composto pelo conjunto de ductos e lóbulos;

(ii) Tecido Fibroso: tecido conjuntivo responsável pela sustentação do tecido glandular;

(iii) Tecido Adiposo: presente na gordura subcutânea e nos espaços interlobulares.

\subsubsection{Doenças da mama}

$\mathrm{Na}$ figura 2.2 é apresentado um organograma agrupando os principais tipos de doenças da mama, que num primeiro nível podem ser separadas em doenças não neoplásicas e neoplásicas, sendo estas últimas, alvo de estudo desse trabalho:

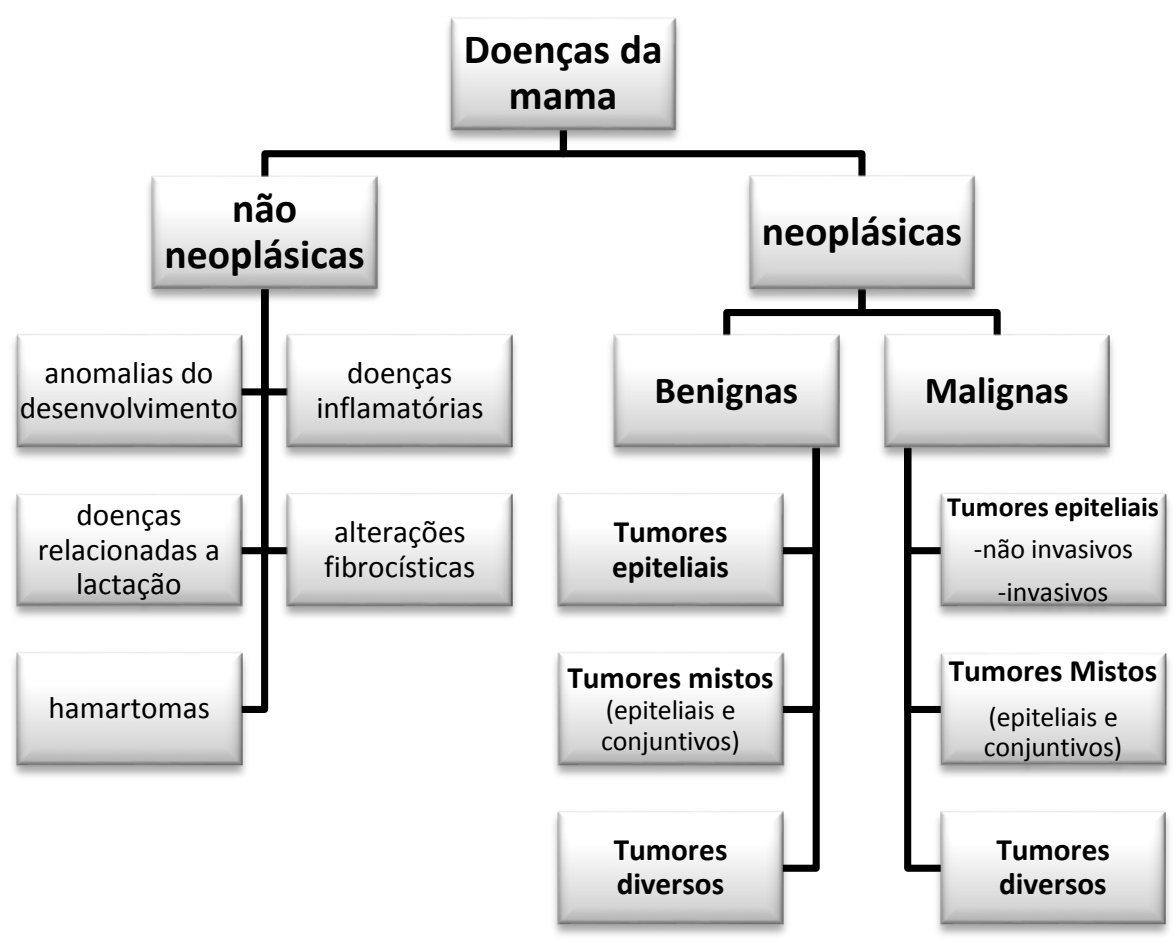

Figura 2.2: Doenças da mama 


\subsubsection{Doenças não neoplásicas}

As doenças benignas não neoplásicas da mama podem ser classificadas em diferentes grupos de doenças: (i) anomalias do desenvolvimento, (ii) doenças inflamatórias, (iii) doenças relacionadas a lactação, (iv) alterações fibrocísticas e (v) hamartomas (SCHMITT, 2000). Um grupo que pode ser destacado por sua elevada frequência em mulheres, pela falta de uniformização de sua nomenclatura e por algumas delas constituírem lesões precursoras do câncer mamário é o das alterações fibrocísticas mamárias (AFM).

As alterações fibrocísticas constituem um conjunto de modificações dinâmicas verificadas na mama feminina, cujas manifestações clínicas são caracterizadas por mastalgia e graus variados de espessamento e nodularidade do parênquima mamário. Histopatológicamente as AFM são representadas pelo termo genérico de displasias mamárias que se caracteriza pela presença em graus variados de proliferação epitelial, fibrose e cistos (BARROS, 2004).

\subsubsection{Neoplasias benignas}

As neoplasias benignas, como seu nome sugere, não apresenta grande risco a saúde de seus portadores. Caracterizam-se por um crescimento lento e seu tecido de sustentação (estroma), é semelhante ao de tecidos normais, não ocorrendo invasão tecidual nem metástases. Dentre as diversas neoplasias benignas mamárias, destacam-se o fibroadenoma e o tumor filóides

\section{(a) Fibroadenoma}

Constituem as neoplasias mais comuns da mama, acometendo principalmente mulheres com menos de 30 anos de idade. Trata-se de uma lesão do lóbulo mamário, sendo formada pela proliferação de tecido conjuntivo e epitélio. $\mathrm{O}$ tecido conjuntivo é composto por células fusiformes contendo por vezes elementos mesenquimais como gordura, músculo liso, cartilagem e osso. Em alguns casos, ao redor dos ductos o estroma é mais celular e mitoses são mais comuns, sugerindo interação epitélio-estroma (SCHMITT, 2000). Apresentam características típicas, são bem limitados, indolores, móveis e de contornos arredondados. 
(b) Tumor filoides

Trata-se de um tumor de origem histológica mista (epitelial e conjuntiva), como o fibroadenoma. No entanto o tumor filoides tem comportamento biológico variado, podendo ser totalmente benigno, localmente agressivo ou até fracamente maligno. Macroscopicamente é um tumor firme, com superfície de corte heterogênia e contendo fendas foliáceas. Histologicamente é caracterizado por maior celularidade do estroma e crescimento excessivo do tecido conjuntivo em relação ao epitélio. Os limites do tumor não são tão definidos como nos fibroadenomas e frequentemente observam-se na sua periferia projeções neoplásicas para o parênquima mamário vizinho.

\subsubsection{Neoplasias malignas}

As neoplasias malignas, também indicadas como câncer, são formadas por células geneticamente alteradas apresentando um volume maior e invadindo os tecidos adjacentes. Em alguns casos o tecido cresce tão rapidamente que não há suporte sanguíneo necessário, provocando necroses. Mecanismos de interação entre as células neoplásicas e o endotélio vascular, propiciam o aparecimento em órgãos distantes das chamadas metástases, na maioria das vezes, causadoras do óbito em pacientes.

A maioria dos casos de câncer de mama ocorre nos ductos ou nos lóbulos, sendo denominados respectivamente ductais e lobulares. Caso a doença rompa os ductos ou lóbulos atingindo os tecidos vizinhos, é dita infiltrativa ou invasora. A doença que está contida dentro dos ductos e lóbulos é denominada "in situ".

Os carcinomas são a maioria das neoplasias malignas da mama, sendo o carcinoma ductal invasor (infiltrante), o tipo mais comum. O carcinoma de mama surge na unidade lobular-ductal terminal. Aqui serão descritos os tipos histológicos mais comuns e importantes na classificação da Organização Mundial da Saúde (OMS) e os principais fatores prognósticos associados ao carcinoma de mama. 
(a) Carcinoma Ductal in situ

O carcinoma ductal in situ (CDIS) consiste de células epiteliais malignas confinadas aos ductos mamários, sem evidências microscópicas de invasão dos tecidos adjacentes. Existem cinco subtipos histológico de CDIS: comedo, papilífero, micropapilífero, cribriforme e sólido.

(b) Carcinoma Lobular in situ

Carcinoma lobular in situ (CLIS) se inicia a partir de ductos terminais em mamas atróficas pós-menopausa ou do complexo lobular do ducto terminal em mulheres pré menopausadas. As células neoplásicas substituem o epitélio normal dos ductos intralobulares. Os lóbulos apresentam-se distendidos completamente ou parcialmente por células relativamente uniformes, redondas, pequenas ou médias. A falta de coesão é característica das células neoplásicas do CLIS (EISENBERG; KOIFMAN, 2000).

\section{(c) Carcinoma Ductal invasor}

Macroscopicamente, o carcinoma ductal invasor (CDI) caracteriza-se pela formação de um nódulo sólido ou uma área de condensação no parênquima, de coloração acinzentada ou branquicenta, em geral endurecidos, com consistência de pêra verde ao corte (carcinoma cirroso), o que depende da quantidade de fibrose de estroma, da elastose peritumoral e da presença de necrose e de calcificações relativamente grosseiras. As lesões podem ser espiculadas ou circunscritas. Aproximadamente um terço dos carcinomas apresenta margens circunscritas (na mamografia ou na macroscopia), e esses costumam ter melhor prognóstico.

Histologicamente, o tumor é formado pela proliferação de elementos epiteliais com atipias citológicas relativamente acentuadas, com uma tendência diversa a formar estruturas pseudoglandulares ou semelhantes aos ductos, e com atividade mitótica variável.

A avaliação histológica destas características (formação de túbulos, atipias nucleares e índice mitótico) serve para graduar o CDI: bem diferenciado (G1), médio grau de diferenciação (G2) e pouco diferenciado (G3), conforme o critério de classificação de Bloom e Richardson (BLOOM; RICHARDSON, 1957).

As características citológicas variam muito, podendo ser encontradas desde células pequenas com núcleos homogêneos até células grandes com núcleos irregulares e 
hipercromáticos. Nas margens da massa tumoral, as células neoplásicas infiltram-se para dentro do estroma e do tecido adiposo e, com frequência, há uma invasão dos espaços perivasculares e perineurais, bem como dos vasos sanguíneos e linfáticos.

\section{(d) Carcinoma Lobular Invasor}

Trata-se de um tipo de câncer relativamente incomum. As células tumorais são pequenas, relativamente uniformes, dispostas em fila ou de uma maneira concêntrica em torno dos lóbulos envolvidos por carcinoma lobular in situ. Falta coesão entre as células, não existindo formação glandular. O estroma geralmente é abundante podendo exibir infiltrado inflamatório (EISENBERG; KOIFMAN, 2000).

Outros tipos de Câncer de Mama menos frequentes são: tipo medular, mucinoso, tubular e papilar, correspondendo a menos de $10 \%$ de todos os casos. A Doença de Paget é um tipo raro de carcinoma in situ que se inicia nos ductos do mamilo.

\subsection{PROCESSOS DE INTERAÇÃO DA RADIAÇÃO COM A MATÉRIA}

A interação da radiação com a matéria ocorre através de processos de absorção e espalhamento. O processo de absorção da radiação consiste na absorção total da energia do fóton incidente enquanto os processos de espalhamento resultam na alteração de sua direção e/ou energia.

Inicialmente, nesta subsecção será abordado de forma sucinta o efeito fotoelétrico (processo de absorção) e posteriormente o processo de espalhamento elástico (Rayleigh) através do estudo da secção de choque diferencial Rayleigh que descreve a probabilidade de um fóton espalhar em um determinado ângulo (distribuição angular). Por fim será abordado o processo de espalhamento inelástico (Compton) cujo estudo será feito através da $(i)$ secção de choque diferencial inelástica (distribuição angular) para um átomo e da (ii) secção de choque diferencial dupla, que descreve a distribuição angular e em energia dos fótons espalhados. 


\subsubsection{Efeito fotoelétrico}

Neste processo de interação um fóton de energia incidente $\hbar \omega$ interage com um elétron orbital cedendo toda sua energia a ele. Neste caso o elétron é ejetado com energia cinética bem definida $T=\hbar \omega-U$, onde $U$ é a energia de ligação do elétron ao átomo (ATTIX, 1986). Após a ejeção do elétron da camada do átomo a vacância é preenchida através de um rearranjo eletrônico sendo o excesso de energia liberado na forma de raios $\mathrm{X}$ característicos ou de elétrons Auger.

A probabilidade de ocorrência do efeito fotoelétrico está relacionada com a secção de choque de interação fotoelétrica $(\tau)$ que para energias $\hbar \omega<100 \mathrm{keV}$ tem-se aproximadamente (ATTIX, 1986):

$$
\tau \propto \frac{Z^{4}}{(\hbar \omega)^{3}}
$$

onde $Z$ é o número atômico do material.

Da equação 2.1 é possível observar que a probabilidade de ocorrência do efeito fotoelétrico é maior para materiais de elevado número atômico $Z$ e para fótons de baixa energia.

\subsubsection{Espalhamento Rayleigh}

O espalhamento elástico de fótons por um átomo livre, chamado espalhamento Rayleigh em homenagem ao cientista que o discutiu para a luz visível John William Strutt (Lorde Rayleigh), ocorre quando os fótons incidentes em um determinado material são espalhados pelos elétrons ligados aos átomos, não sofrendo variação energia, apenas variação de momento. As ondas espalhadas por cada elétron sofrem interferência construtiva devido à diferença de caminho óptico percorrido no átomo. A secção de choque diferencial para o espalhamento Rayleigh (elástico) pode ser expressa na seguinte forma (CESAREO et al., 1992): 


$$
\left(\frac{d \sigma}{d \Omega}\right)_{e l}=F^{2}(x, Z)\left(\frac{d \sigma}{d \Omega}\right)_{T h}
$$

onde $(d \sigma / d \Omega)_{T h}$ é a secção de choque diferencial de espalhamento Thomson, $x=$ $\lambda^{-1} \operatorname{sen}(\theta / 2)$ é proporcional ao momento transferido $K$ na interação do fóton com o átomo, a relação entre $x$ e $K$ é dada por $x=20,607744 \hbar K, Z$ é o número atômico e $F(x, Z)$ é chamado fator de forma atômico.

A função $F(x, Z)$ é a transformada de Fourier da distribuição espacial das cargas do átomo a qual pode ser decomposta na soma dos fatores de forma individuais de cada camada eletrônica do átomo (HUBBELL et al., 1975). O fator de forma $F(x, Z)$ está representado na figura 2.3a para o átomo de Oxigênio $(Z=8)$. A forma da secção de choque diferencial $(d \sigma / d \Omega)_{e l}$ está representada na figura 2.3b para o mesmo átomo.
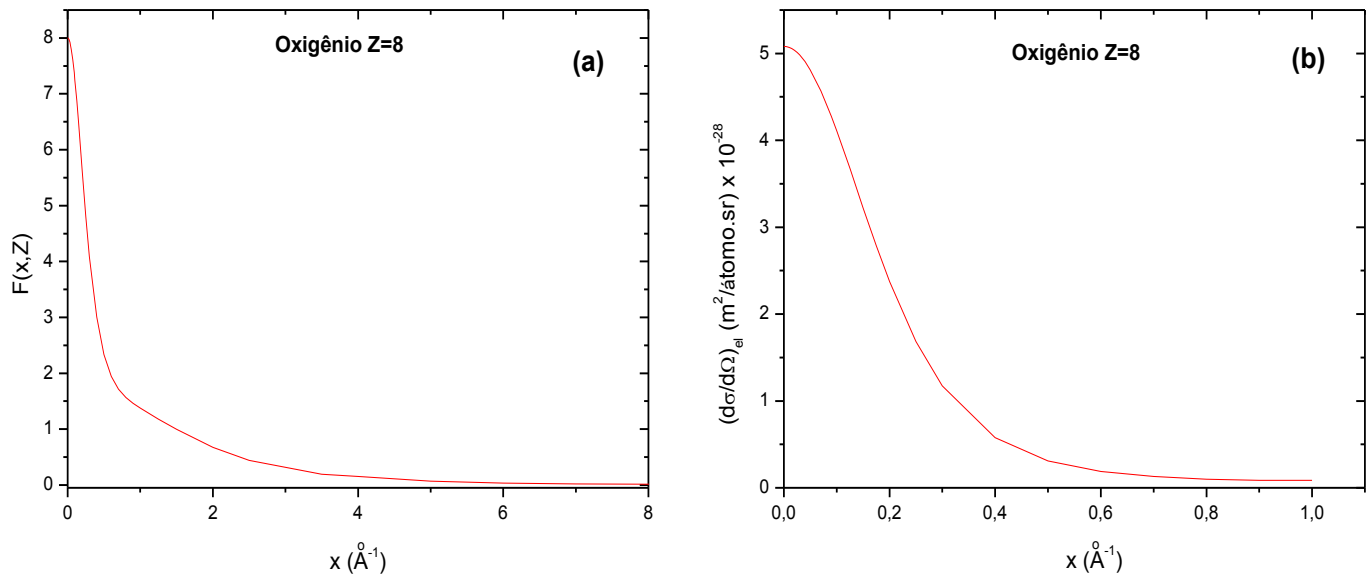

Figura 2.3: (a) Fator de forma $F(x, Z)$ e (b) secção de choque diferencial elástica para o átomo de oxigênio.

A partir da figura 2.3 pode-se notar que para baixos valores de momento transferido $x$, isto é $x \rightarrow 0, F(x, Z) \rightarrow Z$ (interferência construtiva). Para altos valores de $x(x \rightarrow \infty), F(x, Z) \rightarrow 0$ (interferência destrutiva). 


\subsubsection{Espalhamento Compton}

A verificação dos princípios quânticos e as evidências mais diretas de propriedades corpusculares da luz foram obtidas por Compton (COMPTON, 1923), observando o espalhamento de raios $\mathrm{X}$ monocromáticos por um alvo de grafite. Compton verificou, através da análise do espectro dos raios $\mathrm{X}$ espalhados, a presença de uma componente de mesma energia (mesmo comprimento de onda) dos fótons incidentes e outra componente de energia menor (comprimento de onda maior), cujo valor variava com o ângulo de espalhamento. A figura 2.4 esquematiza seu experimento e os espectros obtidos:

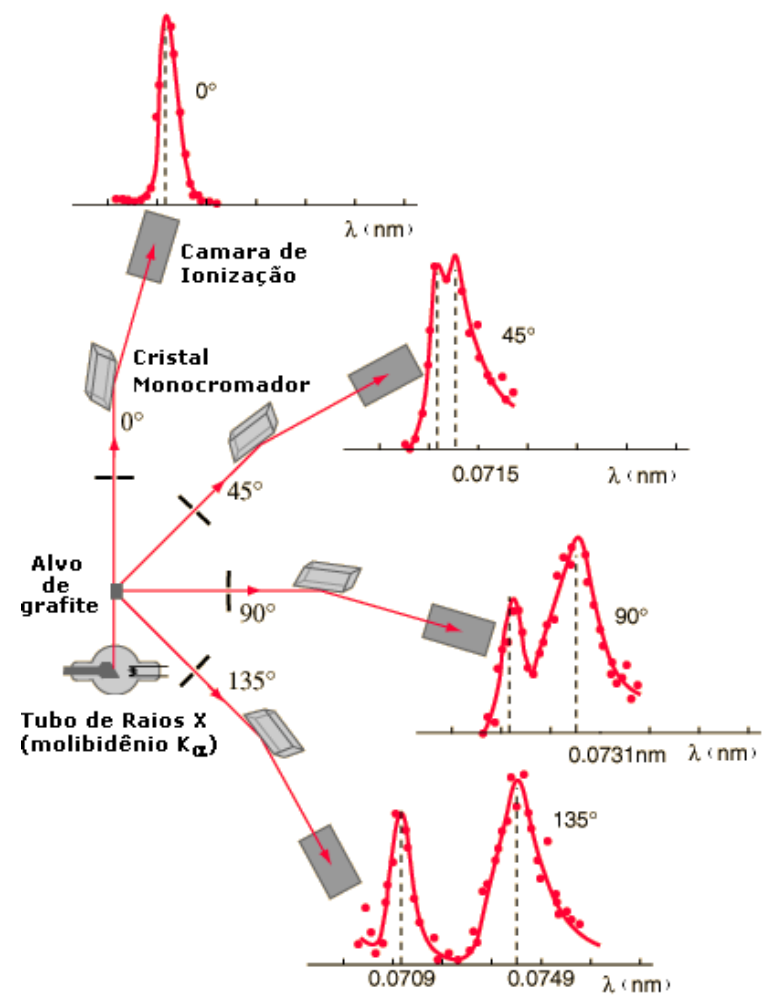

Figura 2.4: Esquema das medidas realizadas por Compton

Para explicar seus resultados, Compton levou às últimas consequências as hipóteses de Einstein, tratando os raios $\mathrm{X}$ como fótons, ou seja, como partículas, explicando, então, o espalhamento como a colisão entre um fóton e um elétron livre e em repouso.

O espalhamento inelástico ou Compton, como ficou conhecido, tem como consequência a diminuição da energia do fóton incidente devido à transferência de energia para o elétron no processo de interação. Consideremos o caso particular em que um fóton interage com um elétron livre em repouso: 


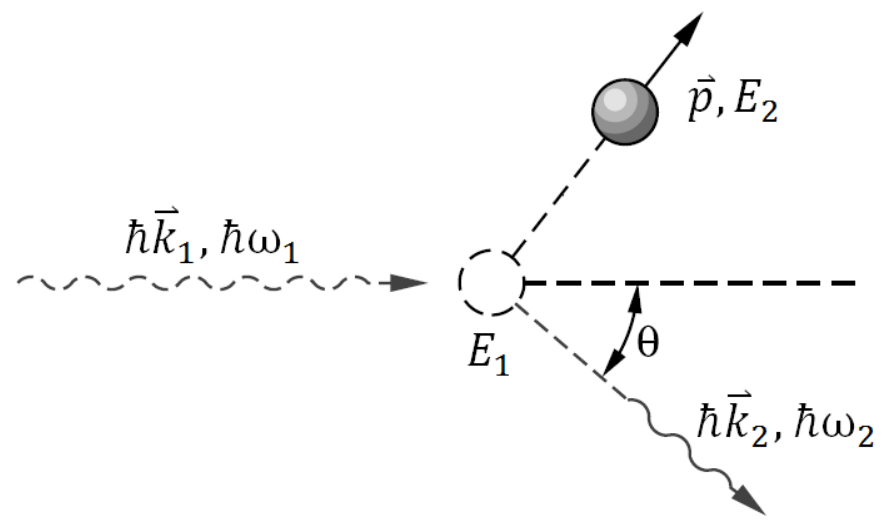

Figura 2.5: Esquema da interação Compton

$\mathrm{Na}$ figura 2.5, o fóton é caracterizado pelo seu momento $\hbar \vec{k}$ e por sua energia $\hbar \omega$, ou simplesmente $\vec{k}$ e $\omega$ em unidades atômicas $\left(e=\hbar=m_{0}=1 ; c=137\right)$, onde $m_{o}$ é a massa de repouso do elétron, $e$ a carga fundamental e $c$ a velocidade da luz no vácuo. Os sub-índices 1 e 2 referem-se respectivamente ao fóton incidente e espalhado. O elétron, inicialmente em repouso, é caracterizado por sua energia relativística $E_{1}=m_{0} c^{2}$ e após a colisão por seu momento $\vec{p}_{2}$ e sua energia $E_{2}=\left(m_{0}^{2} c^{4}+p^{2} c^{2}\right)^{\frac{1}{2}}$, o ângulo de espalhamento é $\theta$. Define-se o vetor $\vec{K}=\vec{k}_{1}-\vec{k}_{2} \cdot$, como vetor de espalhamento.

As seguintes relações de conservação podem ser escritas:

(i) Conservação do momento:

$$
\vec{k}_{1}=\vec{k}_{2}+\vec{p}
$$

(ii) Conservação da energia:

$$
\omega_{1}+E_{1}=\omega_{2}+E_{2}
$$

E como consequência delas, é possível obter a expressão que relaciona a energia do fóton espalhado com a energia do fóton incidente e o ângulo de espalhamento:

$$
\omega_{2}=\frac{\omega_{1}}{1+\frac{\omega_{1}}{m_{0} c^{2}}(1-\cos \theta)}
$$




\subsubsection{Distribuição angular dos fótons espalhados}

A probabilidade dos fótons serem espalhados inelasticamente em um dado ângulo de espalhamento é expressa através da secção de choque diferencial inelástica (Compton) $(d \sigma / d \Omega)_{\text {in }}$ obtida pelo produto de dois fatores, um dado pela secção de choque KleinNishina $(d \sigma / d \Omega)_{K N}($ KLEIN; NISHINA, 1929), que representa a probabilidade de um fóton ser espalhado por um elétron livre em repouso através de um determinado ângulo de espalhamento e outro dado pela função de espalhamento incoerente $S(x, Z)$, que representa a probabilidade de um elétron atômico, tendo recebido momento $K$, consiga deixar o átomo. Esta função leva em conta que os elétrons estão ligados aos átomos, sendo necessária certa quantidade de energia para liberá-los, reduzindo assim a probabilidade de ocorrência de interação Compton para baixos momentos transferidos (seja por fótons incidentes de baixa energia ou por pequenos ângulos de espalhamento) (JOHNS; CUNNINGHAM, 1983).

Assim a secção de choque diferencial inelástica é dada por:

$$
\left(\frac{d \sigma}{d \Omega}\right)_{i n}=S(x, Z)\left(\frac{d \sigma}{d \Omega}\right)_{K N}
$$

onde a secção de choque diferencial Klein-Nishina é obtida, para radiação não polarizada, como:

$$
\left(\frac{d \sigma}{d \Omega}\right)_{K N}=\frac{r_{0}^{2}}{2}\left(\frac{\omega_{2}}{\omega_{1}}\right)\left(\frac{\omega_{1}}{\omega_{2}}+\frac{\omega_{2}}{\omega_{1}}-\operatorname{sen}^{2} \theta\right)
$$

onde $r_{0}=\frac{1}{4 \pi \varepsilon_{0}} \frac{e^{2}}{m_{0} c^{2}}$ é o raio clássico do elétron, $e$ a carga fundamental e $\varepsilon_{0}$ a permissividade elétrica do vácuo. A expressão análoga à expressão Klein-Nishina para feixe polarizado é dada por:

$$
\left(\frac{d \sigma}{d \Omega}\right)_{K N}=\frac{r_{0}^{2}}{2}\left(\frac{\omega_{2}}{\omega_{1}}\right)\left(\frac{\omega_{1}}{\omega_{2}}+\frac{\omega_{2}}{\omega_{1}}-2 \operatorname{sen}^{2} \theta \cos ^{2} \eta\right)
$$

em que $\eta$ é o ângulo entre o plano definido pela direção do fóton incidente com a direção de seu campo elétrico e o plano de espalhamento.

O cálculo teórico de $S(x, Z)$ é feito de forma não relativística, segundo a teoria de Waller e Hartree (1929), onde: 


$$
S(x, Z)=\sum_{m=1}^{Z} \sum_{n=1}^{Z}\left\langle\psi_{0}\left|\exp \left(i \vec{K} \cdot\left(\vec{r}_{m}-\vec{r}_{n}\right)\right)\right| \psi_{0}\right\rangle-\left|\left\langle\psi_{0}\left|\exp \left(i \vec{K} \cdot \vec{r}_{m}\right)\right| \psi_{0}\right\rangle\right|^{2}
$$

onde $\psi_{0}$ é a função de onda para o estado atômico inicial, e $\vec{r}_{n}$ e $\vec{r}_{m}$ são as posições respectivas do enésimo e emésimo elétron num átomo de número atômico $Z$. Funções de onda de Hartree-Fock para elétrons atômicos foram usadas por Cromer e Mann (1967) e por Cromer (1969) para obtenção da função de espalhamento incoerente, designada como $S^{W H}(x, Z)$, onde o índice $W H$ remete a teoria de Waller e Hartree (1929) empregada. Valores de $S^{W H}(x, Z)$ foram extensivamente tabulados para diferentes valores de $x$ e $Z$ por Hubbell et al. (1975) e mais recentemente por Wang et al. (1993).

Na figura 2.6 estão representadas as funções de espalhamento incoerente $S^{\mathrm{WH}}(x, Z)$, para os átomos de hidrogênio $(Z=1)$, carbono $(Z=6)$, nitrogênio $(Z=7)$ e oxigênio $(Z=8)$, elementos de grande interesse biológico:

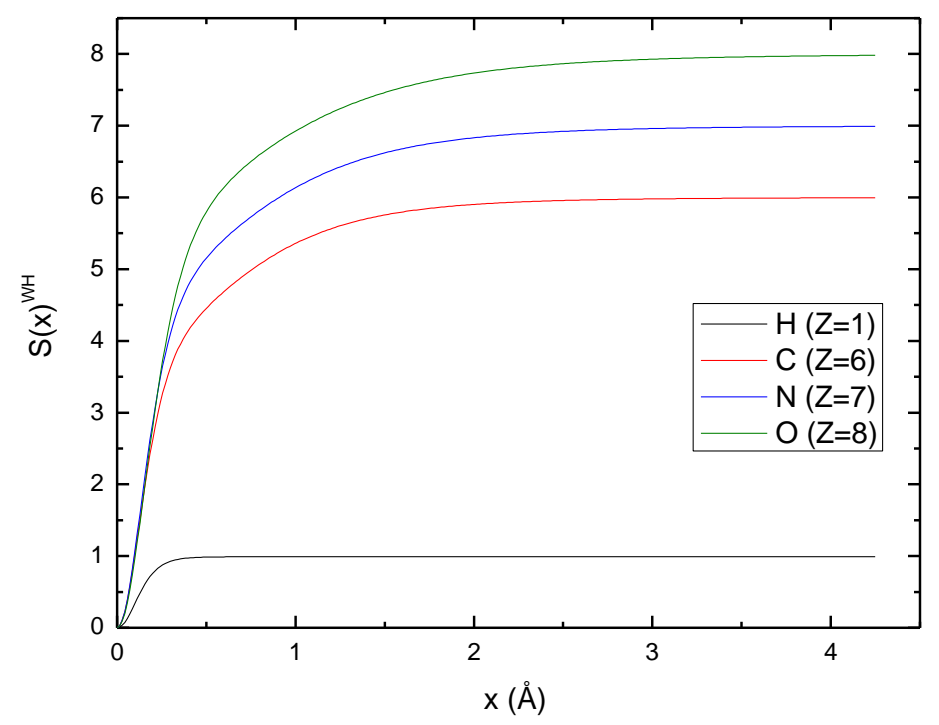

Figura 2.6: Função de espalhamento incoerente na aproximação de Waller e Hartree para os elementos hidrogênio, carbono, nitrogênio e oxigênio.

A figura 2.6 mostra que, para momento transferido $x$ muito baixo (baixa energia do fóton incidente e/ou pequeno ângulo de espalhamento), a probabilidade de ocorrência da interação Compton é diminuída, isto é, quando $x \rightarrow 0, S(x, Z) \rightarrow 0$, pelo fato de a energia transferida pelo fóton ao elétron ser comparável à energia de ligação do elétron ao átomo. Quando $x \rightarrow \infty$, o fóton possui energia alta o suficiente para arrancar qualquer um dos elétrons ligados ao átomo. Nesse caso a probabilidade do fóton interagir com o átomo será 
proporcional ao número de elétrons $Z$ no átomo, ou seja, $S(x, Z) \rightarrow Z$. Nestas condições a secção de choque diferencial inelástica pode ser escrita como $\left(\frac{d \sigma}{d \Omega}\right)_{i n}=Z\left(\frac{d \sigma}{d \Omega}\right)_{K N}$.

\subsubsection{Distribuição em energia dos fótons espalhados}

Segundo a equação 2.5, deduzida desprezando o movimento inicial do elétron, todo fóton que incide com uma determinada energia será espalhado sempre com a mesma energia final em um determinado ângulo de espalhamento. No entanto, em situações reais, onde os elétrons do material estão em movimento, os fótons incidentes ao interagirem com elétrons de diferentes momentos $\vec{p}$ (velocidades) iniciais, adquirirão diferentes energias finais se detectados no mesmo ângulo de espalhamento. A equação 2.10, neste caso, descreve a energia do fóton espalhado em função da energia incidente, do ângulo de espalhamento e do momento $\vec{p}$ inicial do elétron:

$$
\omega_{2}=\frac{\omega_{1}}{1+\frac{\omega_{1}}{m_{0} c^{2}}(1-\cos \theta)}+\frac{\frac{\vec{K} \cdot \vec{p}}{m_{0}}}{\left(1+\frac{\omega_{1}}{m_{0} c^{2}}(1-\cos \theta)\right)}
$$

A distribuição em energia dos fótons espalhados, em um determinado ângulo sólido, que pode ser representada através da secção de choque diferencial dupla $\frac{d^{2} \sigma}{d \omega_{2} d \Omega}$, depende da distribuição $n(p)$ de momento dos elétrons dos átomos do material alvo, ou, mais especificamente, da distribuição $J\left(p_{z}=\frac{\vec{K} \cdot \vec{p}}{K}\right)$ das projeções $p_{z}$ dos momentos dos elétrons na direção do vetor de espalhamento, conhecida como perfil Compton, onde:

$$
J\left(p_{z}\right)=\iint n\left(p_{x}, p_{y}, p_{z}\right) d p_{x} d p_{y}
$$

Sendo o vetor de espalhamento por convenção escolhido como eixo $z$ do sistema de coordenadas cartesianas $x y z$.

A aproximação mais comumente usada para obtenção da seção de choque diferencial dupla é a conhecida como Aproximação de Impulso (AI). Nela considera-se que a interação entre os fótons e os elétrons ligados aos átomos ou moléculas é impulsiva. Os outros elétrons são meros espectadores uma vez que a interação é extremamente rápida, não sendo 
influenciados durante a interação. Em outras palavras, o potencial visto pelos elétrons alvo é o mesmo imediatamente antes e imediatamente depois da interação: o termo que envolve o potencial de energia pode ser cancelado na equação de conservação da energia. Assim, a interação ocorre entre um fóton e um elétron que se apresenta em movimento, mas aproximadamente livre. Para que essa aproximação seja válida a energia transferida ao elétron alvo deve ser muito maior que sua energia de ligação ao átomo, condição fácil de obter para elétrons da camada de condução utilizando-se raios X (COOPER, 1985). De forma não relativística, a expressão para a secção de choque diferencial dupla, nesta aproximação é dada por (RIBBERFORS; BERGGREN, 1982):

$$
\left(\frac{d^{2} \sigma}{d \omega_{2} d \Omega}\right)_{A I}=r_{0}^{2} \frac{m}{K} \frac{\omega_{2}}{\omega_{1}} \frac{1+\cos ^{2} \theta}{2} J\left(p_{z}\right)
$$

onde $J\left(p_{z}\right)$ é obtido através das contribuições dos elétrons de cada camada, dado por:

$$
J\left(p_{z}\right)=\sum_{i} Z_{i} J_{i}\left(p_{z}\right)
$$

onde $Z_{i}$ representa o número de elétrons na iésima camada e $J_{i}\left(p_{z}\right)$ é o perfil Compton de um elétron para esta camada.

De forma relativística, a secção de choque diferencial dupla é dada por (BRUSA et al., 1996):

$$
\left(\frac{d^{2} \sigma}{d \omega_{2} d \Omega}\right)_{A I R}=\frac{r_{0}{ }^{2}}{2} \frac{m}{K} \frac{\omega_{2}}{\omega_{1}}\left[1+\left(\frac{p_{z}}{m c}\right)^{2}\right]^{-\frac{1}{2}} X J\left(p_{z}\right)
$$

onde a quantidade $X$ na equação 2.14 é definida por:

$$
X=\frac{R_{1}}{R_{2}}+\frac{R_{2}}{R_{1}}+2\left(\frac{1}{R_{1}}-\frac{1}{R_{2}}\right)+\left(\frac{1}{R_{1}}-\frac{1}{R_{2}}\right)^{2}
$$

com

$$
R_{1}=\frac{\omega_{1}}{m c^{2}}\left\{\left[1+\left(\frac{p_{z}}{m c}\right)^{2}\right]^{-\frac{1}{2}}+\frac{\omega_{1}-\omega_{2} \cos \theta}{c K} \frac{p_{z}}{m c}\right\}
$$




$$
R_{2}=R_{1}-\frac{\omega_{1} \omega_{2}}{m^{2} c^{4}}(1-\cos \theta)
$$

O efeito de ligação pode ser introduzido no cálculo da secção de choque diferencial dupla restringindo o somatório da equação 2.13 apenas aos casos em que a energia transferida ao elétron, que depende de seu valor de $p_{z}$, seja maior que sua energia de ligação ao átomo $(U)$.

A figura 2.7a mostra os perfis Compton dos átomos de hidrogênio, carbono, nitrogênio e oxigênio, obtidos das tabelas de Biggs, Mendelsohn e Mann (1975) e a figura 2.7b mostra a secção de choque diferencial dupla desses elementos, diretamente relacionada com seus perfis Compton, obtida para um ângulo de $90^{\circ}$ e uma energia incidente de $17,44 \mathrm{keV}$.
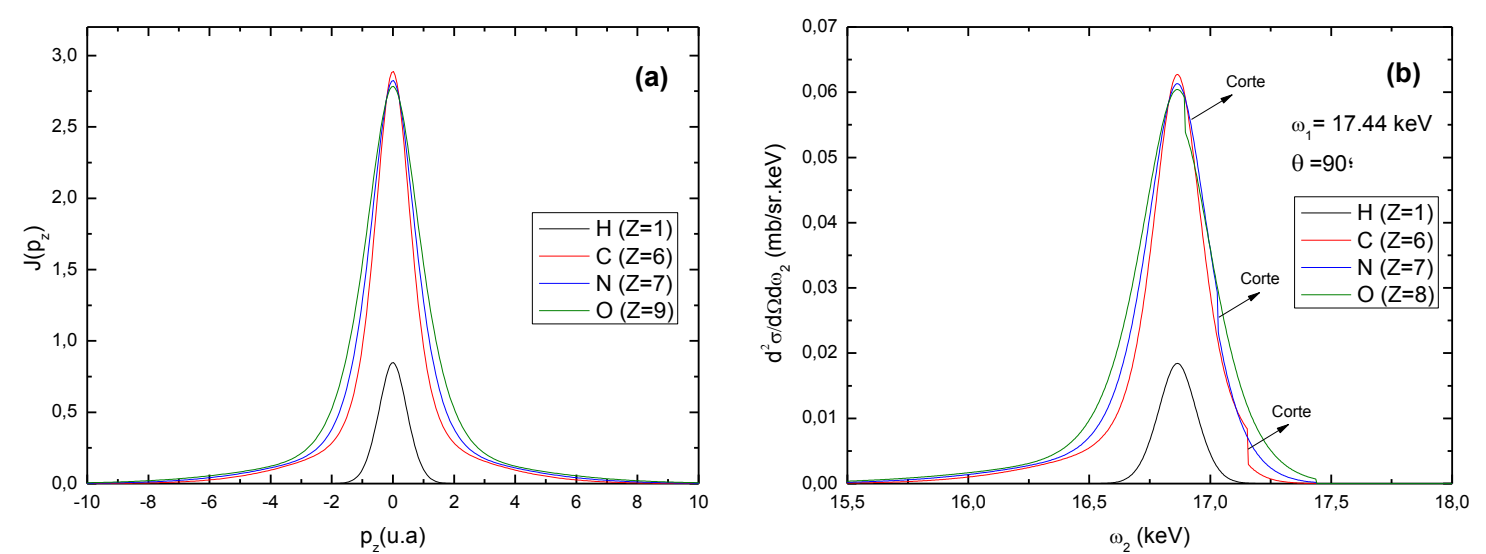

Figura 2.7: (a) Perfis Compton e (b) secção de choque diferencial dupla para os elementos hidrogênio, carbono, nitrogênio e oxigênio.

Pode se observar nas figuras que quanto maior o número atômico do material maior é a largura da curva. Além disso, também se observam regiões descontínuas (cortes) na figura $2.7 b$, resultado do fato de não poder haver fótons com energia maior que a energia de corte $\left(\omega_{\max }=\omega_{1}-U\right)$, pois a energia transferida ao elétron deve ser maior que a energia de ligação da camada a qual pertence.

A aproximação de impulso também permite a obtenção da secção de choque diferencial inelástica (distribuição angular dos fótons espalhados) através da integração na energia de espalhamento da secção de choque diferencial dupla, sendo dada por:

$$
\left(\frac{d \sigma}{d \Omega}\right)_{i n}=\int d \omega_{2}\left(\frac{d \sigma}{d \omega_{2} d \Omega}\right)
$$


De forma análoga à expressão 2.6 podemos escrever a secção de choque diferencial inelástica como:

$$
\left(\frac{d \sigma}{d \Omega}\right)_{i n}=S^{A I}\left(\frac{d \sigma}{d \Omega}\right)_{K N}
$$

Onde a função de espalhamento incoerente, agora na Aproximação de Impulso, é dada por:

$$
S^{A I}=\frac{\int d \omega_{2}\left(d^{2} \sigma / d \omega_{2} d \Omega\right)}{(d \sigma / d \Omega)_{K N}}
$$

A figura 2.8 compara as secções de choque diferenciais inelásticas obtidas segundo as aproximações de Klein-Nishina (KN), Waller e Hartree (WH) e de Impulso (AI), para energia incidente de 69,5 keV, do elemento carbono $(Z=12)$. Como esperado, para pequenos ângulos (baixo momento transferido) verifica-se grande diferença entre os modelos de Klein-Nishina e as outras aproximações que levam em conta a ligação dos elétrons ao átomo. Por outro lado, boa concordância é observada entre as secções de choque diferenciais obtidas nas aproximações de Waller e Hartree e de Impulso, indicando a adequada descrição da distribuição angular dos fótons espalhados por ambos os modelos.

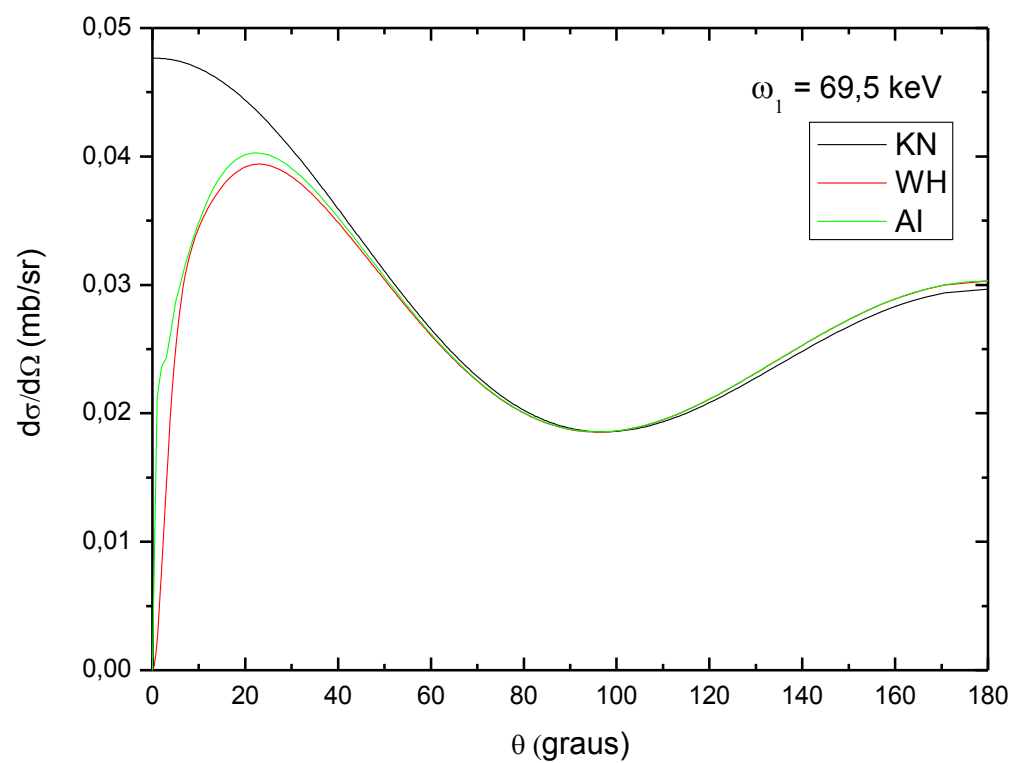

Figura 2.8: Comparação das secções de choque diferenciais inelásticas nas aproximações de KleinNishina, Waller e Hartree e de Impulso do elemento carbono para 69,5 keV. 


\subsection{PRODUÇÃO E ESPECTRO DE RAIOS X}

Os raios $X$ são radiações eletromagnética de comprimento de onda entre $\approx 10^{-5} \AA$ a $\approx 100 \AA$ Å. Esta radiação pode ser produzida por diferentes processos: desaceleração de elétrons de alta energia em trajetórias lineares ou circulares (radiação síncrotron), transições eletrônicas entre níveis atômicos internos de átomos e decaimento radioativo. Nesta seção serão descritos, sucintamente, os processos envolvidos na produção de raios X por um tubo de raios $\mathrm{X}$, fonte de radiação utilizada neste trabalho.

\subsubsection{Tubo de raios $X$}

Em tubos de raios $X$, elétrons liberados por um catodo de filamento aquecido são acelerados por um campo elétrico associado a uma diferença de potencial (da ordem de dezenas de quilovolts) aplicada entre o filamento e o anodo. Os elétrons acelerados pelo campo elétrico incidem no anodo, normalmente de tungstênio ou molibdênio, perdem velocidade e transferem energia aos átomos com os quais interagem (figura 2.9). Como consequência, observa-se a emissão de fótons de raios $\mathrm{X}$ originados no volume irradiado do anodo, cujo espectro pode ser classificado em dois tipos: contínuo (desaceleração) e característico (transições eletrônicas) (ATTIX, 1986).

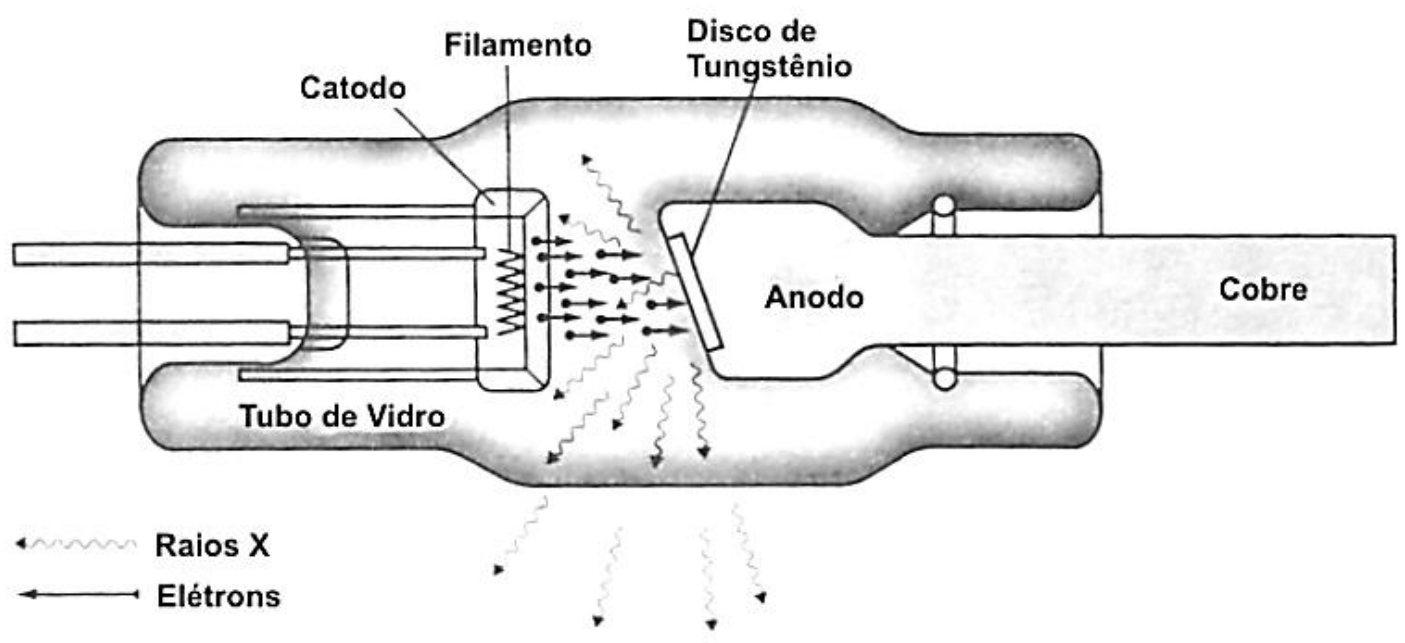

Figura 2.9: Produção de raios $X$ em um tubo. 


\subsubsection{Espectros de raios $\mathrm{X}$}

\subsubsection{Espectro contínuo de emissão}

A perda de velocidade dos elétrons quando penetram no anodo leva à emissão fótons de raios X com espectro contínuo de energia ("Bremsstrahlung”). O valor máximo de energia deste espectro $\left(\hbar \omega_{\max }\right)$ corresponde ao caso extremo no qual um elétron, com energia cinética $E_{c}=e . \Delta V$ (onde $\Delta V$ é o potencial aplicado) perde toda sua energia em uma única interação. A outra parte do espectro contínuo $\left(\hbar \omega<\hbar \omega_{\max }\right)$ corresponde a interações com perda parcial de energia.

\subsubsection{Espectro característico de emissão}

Os tubos de raios $\mathrm{X}$ emitem também fótons com energias bem definidas (características), associadas a transições eletrônicas nos átomos ionizados pelas colisões dos elétrons incidentes no anodo, por exemplo, transições entre as camadas eletrônicas $\mathrm{L} \rightarrow \mathrm{K}$ e $\mathrm{M} \rightarrow \mathrm{K}$, Os raios $\mathrm{X}$ característicos são rotulados pelas letras $\mathrm{K}, \mathrm{L}, \mathrm{M}$ e $\mathrm{N}$ que se referem à camada para a qual o elétron sofreu a transição, seguidas pelas letras gregas $\alpha, \beta, \delta$, que definem a camada de onde se originou a transição. Desta forma um fóton de raios $\mathrm{X} \mathrm{K}_{\alpha}$ é resultado da transição de um elétron da camada $L$ para a $K$, enquanto um fóton $\mathrm{K}_{\beta}$ é originado de uma transição da camada M para a camada K.

$\mathrm{O}$ espectro de emissão de um tubo de raios $\mathrm{X}$ de alvo de tungstênio é mostrado na figura 2.10 onde podem ser observadas as regiões do espectro contínuo e característico.

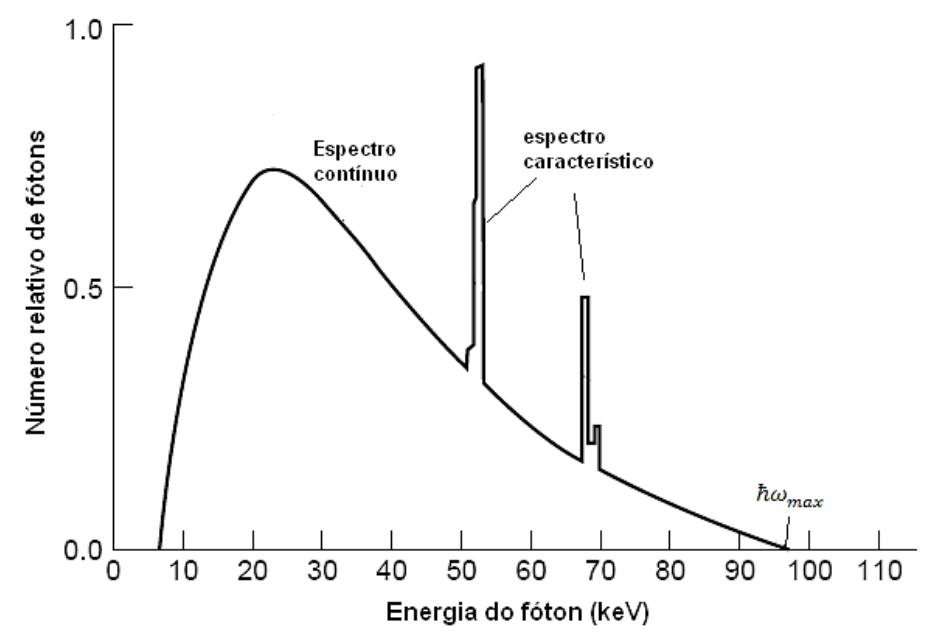

Figura 2.10: Espectro de um tubo de raios $X$ de anodo de tungstênio 


\subsection{SISTEMA DE DETECÇÃO}

São vários os tipos de detectores que podem ser empregados para medidas de radiação $X$, tais como câmaras de ionização, proporcionais, cintiladores e semicondutores. Nesta seção serão tratados estes últimos, que foram os tipos de detectores empregados nas medidas de espalhamento desse trabalho.

\subsubsection{Semicondutores}

Os átomos de um material semicondutor são dispostos em uma rede cristalina. Enquanto em um átomo isolado os níveis de energia acessíveis a um elétron são discretos, quando ordenados na rede os níveis se subdividem (degeneração) a tal ponto que para o cristal pode-se falar em bandas de energia. A chamada banda de valência é ocupada por elétrons ligados aos átomos e a banda de condução contém os elétrons livres para circular pela rede cristalina, sendo que a diferença entre os níveis de energia de uma banda para a outra é característica de cada tipo de cristal e é denominada gap de energia. A região situada entre as bandas de valência e condução é denominada banda proibida, região onde não existem estados permitidos para os elétrons. Esta noção de bandas permite classificar genericamente os materiais como isolantes, condutores e semicondutores, como mostrado na figura 2.11.

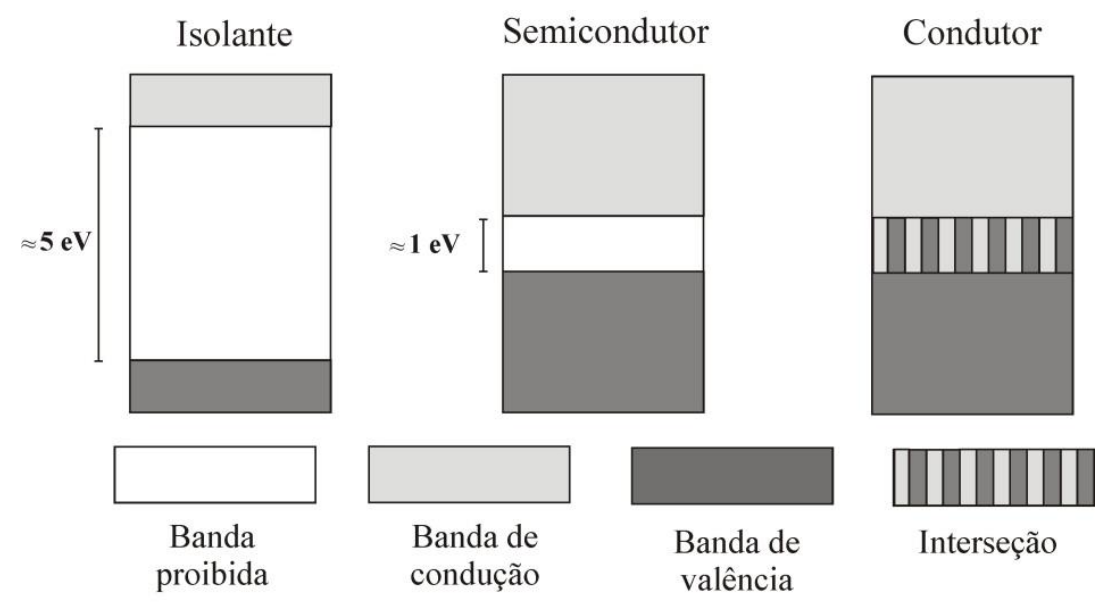

Figura 2.11: Classificação dos materiais em termos da estrutura de bandas.

Num isolante praticamente não há elétrons na banda de condução, e a diferença de energia entre as bandas de condução e valência é relativamente alta, de modo que à temperatura ambiente, um elétron não tem energia suficiente para passar para a banda de condução. Num condutor as bandas se interceptam, e os elétrons podem se mover livremente 
pelos átomos do material. No semicondutor a diferença de energia entre bandas (gap) é pequena, e os elétrons podem facilmente passar para a banda de condução deixando um buraco na banda de valência. A probabilidade da formação de um par elétron-buraco gerado termicamente, nos semicondutores é dada pela seguinte relação (KNOLL, 1989):

$$
p(T)=C T^{3 / 2} \exp \left(\frac{-E_{G}}{2 k T}\right)
$$

Onde:

$p$ : probabilidade de formação;

$T$ : temperatura absoluta $(\mathrm{K})$;

$E_{G}$ : energia da banda proibida (eV);

$k$ : constante de Boltzmann (eV.K $\left.\mathrm{K}^{-1}\right)$;

$C$ : constante de proporcionalidade, característica do material $\left(\mathrm{K}^{-3 / 2}\right)$

Para ser usado como um detector, um material semicondutor deve permitir a coleta do sinal induzido pelo movimento de elétrons e buracos. Aplicando-se um campo elétrico em um semicondutor, os elétrons que se encontram na banda de condução irão se movimentar no sentido oposto ao do campo aplicado. $\mathrm{Na}$ banda de valência um elétron situado próximo em energia a um buraco pode passar para esse buraco ocupando-o, deixando assim outro buraco em sua posição de origem. O movimento sucessivo dos elétrons e dos buracos é análogo a formação de um par de íons nos detectores gasosos, onde os buracos nos semicondutores são equivalentes aos íons positivos nos gases.

Um material semicondutor puro pode ser dopado com uma impureza que tenha um elétron de valência a mais ou a menos. A substituição de um dos átomos da rede cristalina de silício ou germânio, átomos tetravalentes, por um átomo pentavalente equivale a acrescentar um elétron à banda de valência, enquanto a substituição por um átomo trivalente equivale a acrescentar um buraco. Segundo este critério os semicondutores dopados são referidos como tipo- $n$ e tipo-p. Nos semicondutores tipo- $n$ a corrente elétrica é principalmente determinada pelo movimento de elétrons, e nos tipo-p pelo movimento de buracos. As impurezas tipicamente usadas são: fósforo, arsênio, antimônio, gálio índio e boro.

Uma junção pn é obtida quando se fabrica um semicondutor tipo-p justaposto com um tipo- $n$. Na região de interface entre os dois, haverá tendência dos elétrons a migrar para a região tipo-p, e dos buracos a migrar para a região tipo- $n$. Dessa forma a região tipo-n tornase carregada positivamente por haver capturado buracos, e a região tipo-p torna-se carregada 
negativamente por haver capturado elétrons. Um campo elétrico, portanto, se estabelece, implicando uma diferença de potencial elétrico tipicamente da ordem de $1 \mathrm{~V}$.

Um campo elétrico exterior aplicado à junção tende a confinar ainda mais os elétrons ao lado $p$ e os buracos ao lado $n$, aumentando assim a espessura da região entre a junção, denominada depleção.

\subsubsection{Detecção da radiação}

Quando a radiação ionizante interage com um detector, dependendo do processo de interação ocorrido (efeito fotoelétrico, Rayleigh, Compton ou formação de pares) toda ou parte de sua energia é absorvida dentro do volume sensível e a energia transferida pela radiação é usada na geração de pares de elétrons-buracos. A energia média necessária para formar um par elétron buraco é constante e independe da energia e tipo de radiação envolvida (KNOLL, 1989), de forma que o número de pares de elétrons-buracos será proporcional a energia cedida pela radiação ao material. Um campo elétrico aplicado no detector atrai os elétrons para o polo positivo e os buracos para o polo negativo. A capacitância do detector armazena as cargas coletadas gerando um pulso de amplitude $(\Delta V)$, proporcional à energia transferida ao detector, desde que nenhum elétron gerado deixe o volume sensível do detector. A equação 2.22 relaciona a amplitude do pulso $(\Delta V)$ com a energia da radiação cedida ao meio (E):

$$
\Delta V=\varepsilon \frac{n e}{C}=\varepsilon \frac{E \cdot e}{W C}
$$

Onde:

$n$ : número inicial de cargas produzidas;

$e$ : carga fundamental do elétron;

$W$ : energia média para produção de um par elétron-buraco;

$C$ : capacitância do detector;

$\varepsilon$ : eficiência de coleta das cargas produzidas.

A figura 2.12 apresenta um esquema simplificado de um detector semicondutor e o processo de geração de cargas em seu volume sensível com a consequente coleta pelos eletrodos. 


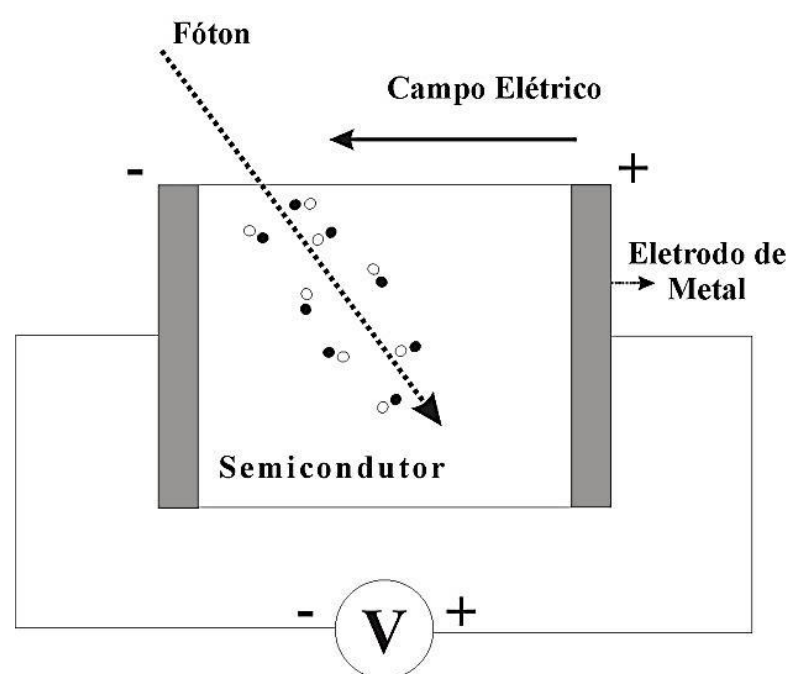

Figura 2.12: Esquema simplificado de um detector semicondutor.

É de se esperar que quanto maior for a quantidade de cargas gerada em uma interação (menor valor de $\mathrm{W}$ ), melhor será o detector quanto à resolução energética e à razão sinal ruído. Entretanto produzir muitas cargas não significa que elas todas serão coletadas. Dependendo, em especial, do grau de pureza dos materiais existe a possibilidade de as cargas serem aprisionadas ou de se recombinarem ainda no volume sensível, com consequente coleta incompleta das cargas produzidas no processo de interação da radiação. Ainda é possível que parte da energia transferida ao detector seja depositada fora do volume sensível. Em ambos os casos a amplitude do pulso torna-se menor, e como consequência, a proporcionalidade entre a amplitude do pulso e a energia da radiação incidente não é mais mantida.

A eletrônica que segue o detector é composta de um pré-amplificador e um amplificador. Após o pulso ser amplificado, ele passa por um analisador multicanal que converte a amplitude do sinal em um sinal digital que posteriormente será disponibilizado em um histograma. O conjunto de todos os sinais produzidos, finalmente, forma o espectro que pode ser interpretado e analisado. Antes da análise é necessário fazer uma calibração da escala de energia do analisador.

\subsubsection{Resolução em energia do detector}

Uma causa para as flutuações na energia que degradam a resolução do detector é o ruído estatístico devido à natureza discreta do sinal medido. Este efeito estará sempre presente, não importando o sistema. O ruído estatístico surge do fato que a carga (Q) gerada no detector pela radiação, a qual se espera ser proporcional a energia incidente, não é uma 
variável contínua, mas representa o número discreto de portadores de carga e está sujeito a flutuações em cada um dos eventos, embora a mesma quantidade de energia seja depositada (KNOLL, 1989). Uma estimativa da quantidade inerente de flutuação pode ser feita supondo que a formação de cada portador de carga segue uma estatística de Poisson. Se um número total $\mathrm{N}$ de portadores de carga é gerado em média, espera-se um desvio padrão igual a $\sqrt{N}$. Assim, a função resposta do detector deve ter uma forma Gaussiana. A função Gaussiana citada, para um número $N$ grande de portadores de carga, pode ser apresentada da seguinte maneira:

$$
G(H)=\frac{A}{\sigma \sqrt{2 \pi}} \exp \left(-\frac{\left(H-H_{0}\right)^{2}}{2 \sigma^{2}}\right)
$$

onde os parâmetros $H_{0}$ e A são, respectivamente, o centroide e a área da gaussiana e $\sigma$, o desvio padrão, que determina o valor de sua largura a meia altura $(\Delta R)$ através da seguinte relação (KNOLL, 1979):

$$
\Delta R=2,35 \sigma
$$

\subsection{IMAGENS TOMOGRÁFICAS}

Nesta subseção será abordada a reconstrução de imagens a partir de projeções paralelas. Este estudo se faz importante para entender o processo de obtenção de imagens tomográficas tanto por técnicas de transmissão de raios $\mathrm{X}$ (como é o caso da tomografia computadorizada) quanto por técnicas de espalhamento.

\subsubsection{Projeções}

Uma integral de linha representa a integral de um parâmetro de um objeto ao longo de uma linha. No caso de um feixe de raios X propagando-se através de um objeto, podemos considerar que o objeto seria modelado pela distribuição bidimensional dos coeficientes de atenuação linear e a integral de linha representaria a atenuação sofrida pelo feixe ao atravessar o objeto. A figura 2.13 mostra a secção transversal de um objeto, representado pela função $f(x, y)$, no plano $x y$ : 


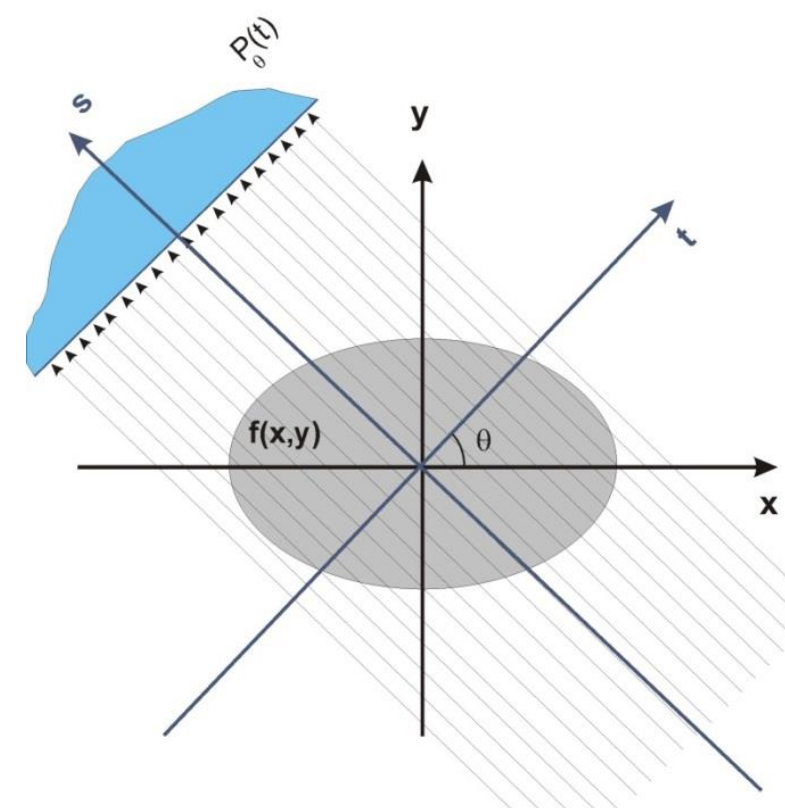

Figura 2.13: Projeção paralela de um objeto em um ângulo $\theta$.

A projeção $P_{\theta}(t)$ pode ser escrita como a integral de linha:

$$
P_{\theta}(t)=\int f(x, y) d s
$$

O sistema de coordenadas $(t, s)$ mostrado na figura 2.13 corresponde à rotação do sistema de coordenadas $(x, y)$ de um ângulo $\theta$ :

$$
\left[\begin{array}{l}
t \\
s
\end{array}\right]=\left[\begin{array}{cc}
\cos \theta & \operatorname{sen} \theta \\
-\operatorname{sen} \theta & \cos \theta
\end{array}\right]\left[\begin{array}{l}
x \\
y
\end{array}\right]
$$

Assim sendo podemos escrever a projeção $P_{\theta}(t)$, onde $t=x \cos \theta+y \operatorname{sen} \theta$, como:

$$
P_{\theta}(t)=\int_{-\infty}^{\infty} \int_{-\infty}^{\infty} f(x, y) \delta(x \cos \theta+y \operatorname{sen} \theta-t) d x d y
$$

A equação 2.27 é conhecida como a transformada de Randon da função $f(x, y)$.

A aquisição de projeções para diferentes ângulos $\theta$ permite a reconstrução da imagem original, isto é, permite obter a função $f(x, y)$. Para tanto são utilizados diferentes métodos de reconstrução como (i) método da transformada de Fourier, (ii) método da retroprojeção, (iii) método da retroprojeção filtrada, (iv) métodos iterativos (HENDEE; RITENOUR, 2002). 
Dentre os métodos citados o método da retroprojeção é um dos mais usados e será descrito na próxima subseção por ser o método utilizado nas técnicas de imagens deste trabalho.

\subsubsection{Retroprojeção filtrada}

O método da retroprojeção filtrada tem como fundamento o "Teorema da fatia central" que se baseia nas transformadas de Fourier unidimensional e bidimensional definidas respectivamente pelas equações 2.28 e 2.29 :

$$
\begin{gathered}
F(\omega)=\int_{-\infty}^{\infty} f(t) e^{-i 2 \pi \omega t} d t \\
F(u, v)=\int_{-\infty}^{\infty} \int_{-\infty}^{\infty} f(x, y) e^{-i 2 \pi(u x+v y)} d x d y
\end{gathered}
$$

A transformada bidimensional para o caso particular em que $v=0$ é dada pela seguinte expressão:

$$
F(u, 0)=\int_{-\infty}^{\infty} \int_{-\infty}^{\infty} f(x, y) e^{-i 2 \pi u x} d x d y
$$

que pode ser reescrita como:

$$
F(u, 0)=\int_{-\infty}^{\infty}\left[\int_{-\infty}^{\infty} f(x, y) d y\right] e^{-i 2 \pi u x} d x
$$

A integral dentro dos colchetes é um caso particular da equação 2.27 correspondendo a projeção da função $f(x, y)$ para o ângulo $\theta=0^{\circ}$ :

$$
P_{0}(x)=\int_{-\infty}^{\infty} f(x, y) d y
$$


Desta forma a transformada de Fourier bidimensional $F(u, 0)$, da função $f(x, y)$, é igual a transformada unidimensional de Fourier $\mathrm{S}(\mathrm{u})$ da projeção $P_{0}(x)$ :

$$
F(u, 0)=S_{0}(u)=\int_{-\infty}^{\infty} P_{0}(x) e^{-i 2 \pi u x} d x
$$

A equação 2.33 pode ser estendida para o caso geral, correspondente ao teorema da fatia central: a transformada de Fourier unidimensional de uma projeção formando um ângulo $\theta$ com o eixo $x$ é igual aos valores da transformada bidimensional do objeto ao longo de uma linha radial subtendendo o mesmo ângulo $\theta$ com o eixo $u$.

$$
F(\omega, \theta)=S_{\theta}(\omega)=\int_{-\infty}^{\infty} P_{\theta}(t) e^{-i 2 \pi \omega t} d t
$$

A transformada de Fourier inversa bidimensional é dada pela equação:

$$
f(x, y)=\int_{-\infty}^{\infty} \int_{-\infty}^{\infty} F(u, v) e^{i 2 \pi(u x+v y)} d u d v
$$

Transformando a equação 2.35 de coordenadas cartesianas $(u, v)$ para coordenadas polares $(\omega, \theta)$ temos:

$$
f(x, y)=\int_{0}^{2 \pi} \int_{0}^{\infty} F(\omega, \theta) e^{i 2 \pi \omega(x \cos \theta+y \operatorname{sen} \theta)} \omega d \omega d \theta
$$

Separando os limites da integral da equação 2.36 de 0 a $\pi$ e de $\pi$ a $2 \pi$ :

$$
\begin{aligned}
f(x, y)=\int_{0}^{\pi} \int_{0}^{\infty} F(\omega, \theta) e^{i 2 \pi \omega(x \cos \theta+y \operatorname{sen} \theta)} \omega d \omega d \theta \\
\quad+\int_{0}^{\pi} \int_{0}^{\infty} F(\omega, \theta+\pi) e^{i 2 \pi \omega[x \cos (\theta+\pi)+y \operatorname{sen}(\theta+\pi)]} \omega d \omega d \theta
\end{aligned}
$$


e usando a propriedade:

$$
F(\omega, \theta+\pi)=F(-\omega, \theta)
$$

A expressão 2.36 pode ser reescrita como:

$$
f(x, y)=\int_{0}^{\pi}\left[\int_{-\infty}^{\infty} F(\omega, \theta)|\omega| e^{i 2 \pi \omega t} d \omega\right] d \theta
$$

onde $t=x \cos \theta+y \operatorname{sen} \theta$.

Substituindo a transformada de Fourier bidimensional $F(\omega, \theta)$ pela transformada de Fourier unidimensional das projeções em um ângulo $\theta, S_{\theta}(\omega)$, de acordo com o teorema da fatia central (equação 2.34), obtemos:

$$
f(x, y)=\int_{0}^{\pi}\left[\int_{-\infty}^{\infty} S(\omega, \theta)|\omega| e^{i 2 \pi \omega t} d \omega\right] d \theta
$$

Esta equação 2.40 pode ser reescrita como:

$$
f(x, y)=\int_{0}^{\pi} Q_{\theta}(x \cos \theta+y \operatorname{sen} \theta) d \theta
$$

onde:

$$
Q_{\theta}(t)=\int_{-\infty}^{\infty} S(\omega, \theta)|\omega| e^{i 2 \pi \omega t} d \omega
$$

Assim a função $f(x, y)$ pode ser obtida a partir da transformada de Fourier unidimensional das projeções $S_{\theta}(\omega)$. A equação 2.42 apresenta uma operação de filtragem das projeções pela função $|\omega|$. Desta forma a função $Q_{\theta}(t)$ é chamada projeção filtrada. A equação 2.41 representa a operação de retroprojeção das projeções filtradas $Q_{\theta}(t)$ que pode ser observada na figura 2.14 . 


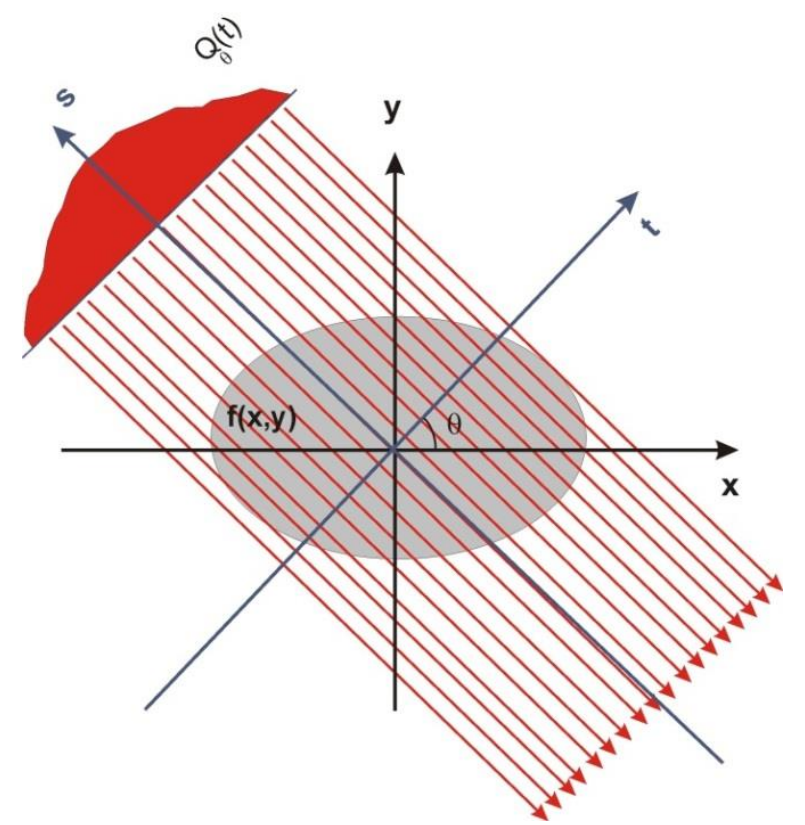

Figura 2.14: Retroprojeção de uma das projeções filtradas $Q_{\theta}(t)$.

O valor $f(x, y)$ de um determinado ponto de coordenadas $(x, y)$ da imagem original será dado pelo somatório (ou integral) dos diversos valores $\mathrm{Q}_{\theta}(x \cos \theta+y \operatorname{sen} \theta)$, para os diversos ângulos $\theta$ em que as projeções foram adquiridas. 


\section{MATERIAIS E MÉTODO}

\subsection{AMOSTRAS E MATERIAIS UTILIZADOS}

\subsubsection{Tecidos Mamários}

\subsubsection{Coleta e Preparação das Amostras de tecidos}

As amostras de tecidos mamários estudadas foram obtidas no Departamento de Patologia do Hospital das Clínicas da Faculdade de Medicina de Ribeirão Preto (DPHCFMRP). O material colhido para análise correspondia a uma fração dos tecidos retirados em procedimentos cirúrgicos de mastectomia (cirurgia para retirada de parte da mama invadida por tumores) e mastoplastia (cirurgia plástica para redução da mama). $\mathrm{O}$ volume de tecido colhido era determinado de forma a ter-se uma amostra homogênea e em quantidade suficiente para apresentar um sinal razoável. Depois de colhidas, as amostras eram armazenadas à temperatura ambiente em recipientes plásticos contendo solução de formol tamponado (10\%).

\subsubsection{Classificação Histológica dos Tecidos}

As amostras de tecidos mamários foram classificadas como tecidos normais (adiposo e fibroglandular), neoplasias benignas (fibroadenomas) e neoplasias malignas (carcinomas ductais invasores de grau I, II e III, conforme o critério de classificação de Bloom e Richardson (1957), carcinoma ductal in situ, carcinoma mucinoso e carcinoma comedo). A classificação histológica foi realizada através da análise das lâminas de tecido por médicos patologistas DP-HCFMRP e posteriormente confirmada por um docente especialista em patologias mamárias do DP-HCFMRP.

Foi utilizado um total de 109 amostras de tecidos mamários que consistiam de tecidos normais (49 adiposos e 16 fibroglandulares), neoplasias benignas (10 fibroadenomas) e neoplasias malignas (34 carcinomas dos tipos ductais invasores de grau I, II e III (29), carcinoma ductal in situ (2), carcinoma mucinoso (1) e carcinoma comedo (2)). 
Este estudo foi aprovado pelo comitê de ética e pesquisa do HCFMRP (processo $\mathrm{n}^{\circ}$ 4306/2009) conforme documento apresentado no anexo A desta tese.

\subsubsection{Materiais de referência (padrões)}

A tabela 3.1 apresenta os materiais de referência (padrões) utilizados neste trabalho com suas respectivas fórmulas químicas e densidades físicas. Esses materiais foram utilizados para a construção da curva de calibração usada na determinação das densidades eletrônicas dos tecidos mamários e para teste de acurácia dos experimentos de determinação da densidade eletrônica e do número atômico efetivo. Eles foram escolhidos por apresentarem características de atenuação e espalhamento similares aos tecidos mamários (AL-BAHRI; SPYROU, 1998).

Tabela 3.1: Composições químicas e densidade física dos materiais de referência utilizados neste trabalho

\begin{tabular}{lcc}
\hline Materiais de referência & Fórmula Química & $\boldsymbol{\rho}\left(\mathbf{g} / \mathbf{c m}^{\mathbf{3}}\right)$ \\
\hline Água & $\mathrm{H}_{2} \mathrm{O}$ & 1,00 \\
Etanol & $\mathrm{C}_{2} \mathrm{H}_{6} \mathrm{O}$ & 0,79 \\
Isopropanol & $\mathrm{C}_{3} \mathrm{H}_{8} \mathrm{O}$ & 0,78 \\
Glicerol & $\mathrm{C}_{3} \mathrm{H}_{8} \mathrm{O}_{3}$ & 1,26 \\
Dimetilsulfóxido & $\mathrm{C}_{2} \mathrm{H}_{6} \mathrm{SO}$ & 1,10 \\
Dimetilformamida & $\mathrm{C}_{3} \mathrm{H}_{7} \mathrm{NO}$ & 0,95 \\
Acrílico & $\left(\mathrm{C}_{6} \mathrm{H}_{8} \mathrm{O}_{2) \mathrm{n}}\right.$ & 1,19 \\
Nylon & $\left(\mathrm{C}_{6} \mathrm{H}_{11} \mathrm{NO}\right)_{\mathrm{n}}$ & 1,15 \\
Polipropileno & $\left(\mathrm{C}_{3} \mathrm{H}_{6}\right)_{\mathrm{n}}$ & 0,89 \\
Poliacetal & $\left(\mathrm{CH}_{2} \mathrm{O}\right)_{\mathrm{n}}$ & 1,42 \\
\hline
\end{tabular}

\subsection{ARRANJO EXPERIMENTAL}

\subsubsection{Medidas de espalhamento}

As medidas de espalhamento foram realizadas no laboratório do Grupo de Física Radiológica e Dosimetria (GFRD) do Departamento de Física da Faculdade de Filosofia Ciências e Letras de Ribeirão Preto (DF-FFCLRP). O arranjo experimental utilizado nas medidas é esquematizado na figura 3.1: 


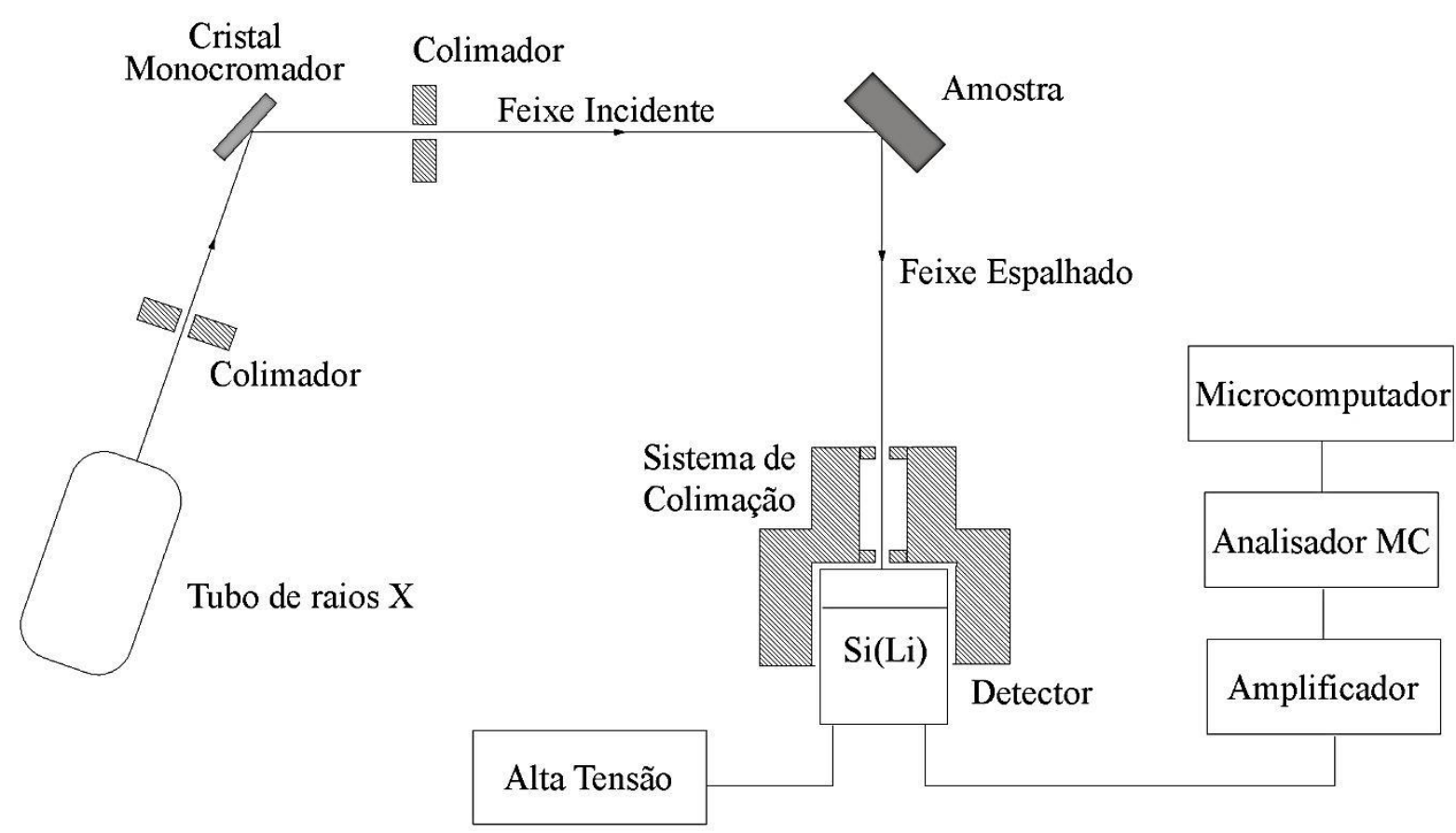

Figura 3.1: Arranjo experimental utilizado nas medidas de espalhamento.

O tubo de raios $\mathrm{X}$ utilizado para realização das medidas possuía anodo de molibdênio $\left(\mathrm{K}_{\alpha}=17,479 \mathrm{keV}\right.$ e $\left.\mathrm{K}_{\beta}=19,602 \mathrm{keV}\right)$ e era acoplado a um gerador de alta tensão Philips de 4kW, modelo PW3830. A energia escolhida para as medidas foi a de 17,44 keV, monocromatizada por meio de um cristal monocromador pirolítico de grafite e pela utilização de um filtro de zircônio ( $\mathrm{Zr}, Z=40$ ), este último utilizado para atenuar o pico $\mathrm{K}_{\beta}$ do Mo. A geometria utilizada foi de reflexão em um ângulo de espalhamento $(\theta)$ de $90^{\circ}$ correspondendo a um valor de momento transferido $x=0,99 \AA^{-1}$.

A área do feixe sobre a amostra (diâmetro $\approx 1,5 \mathrm{~mm}$ ) era limitada pelo colimador colocado na saída do monocromador. Os colimadores, o porta-amostra e seu suporte, além de uma mesa para fixação giratória do suporte do porta-amostra, foram especificamente planejados e construídos na oficina do Departamento de Física (DF-FFCLRP), para realização das medidas. O alinhamento do feixe com os eixos centrais fonte-amostra e amostra-detector e sua área de incidência foram verificados por meio de imagens radiográficas de filmes colocados na posição da amostra. Antes de atingir o detector o feixe espalhado pela amostra passava por um sistema de colimação. O porta-amostra, cilíndrico de acrílico (diâmetro de $13,85 \pm 0,05 \mathrm{~mm}$ e altura de $6,9 \pm 0,05 \mathrm{~mm}$ ) foi posicionado a uma distância de $51 \pm 1 \mathrm{~mm}$ do detector e a $47 \pm 1 \mathrm{~mm}$ do cristal monocromador.

As amostras foram recobertas por uma fina camada de kapton, de forma a deixar suas superfícies regulares e homogêneas, além de permitir as medidas com os padrões líquidos. As 
dimensões dos colimadores, espessura das amostras assim como as distâncias utilizadas nesta experiência foram tais que permitissem um caminho da radiação na amostra suficiente para maximizar a intensidade espalhada proveniente da mesma e minimizar o múltiplo espalhamento (HARDING, 1997; KANE et al., 1986) e a dispersão angular (BRUNETTI et al., 2004).

O sistema de detecção consistiu de um detector de $\mathrm{Si}(\mathrm{Li})$ da Canberra modelo SL30165, com resolução em energia de $\approx 0,31 \mathrm{keV}$ em 17,44 keV acoplado a um analisador multicanal, que permitia a discriminação dos picos de espalhamento elástico e inelástico. $\mathrm{O}$ tempo de aquisição (entre 1000s-2000s) dependia do tipo de tecido ou material de referência medido e era determinado pela contagem de fótons espalhados no detector de forma a obter incertezas percentuais nas contagens de ambos os processos de espalhamento em torno $1 \%$.

\subsubsection{Medidas de transmissão}

Medidas de transmissão, necessárias para obtenção dos coeficientes de atenuação linear utilizados para determinação das densidades eletrônicas e do número atômico efetivo (método convencional de transmissão), foram realizadas alinhando-se o detector com o feixe de incidente $\left(\theta=0^{\circ}\right)$, conforme figura 3.2:

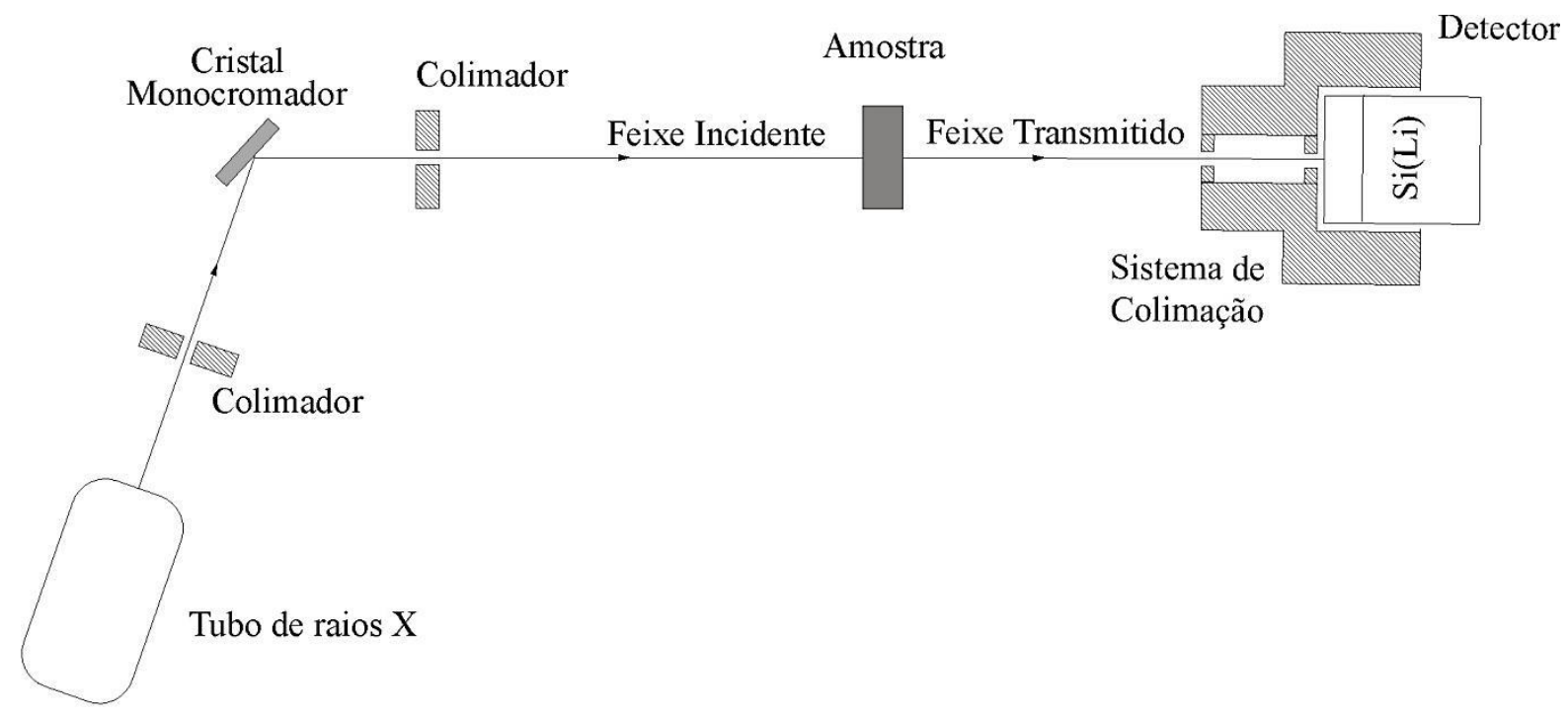

Figura 3.2: Arranjo experimental utilizado nas medidas transmissão.

O porta-amostra utilizadofoi posicionado perpendicularmente ao feixe a uma distância de $(18,0 \pm 0,5) \mathrm{cm}$ do monocromador e a $(14,0 \pm 0,05) \mathrm{cm}$ do detector. As medidas das 
espessuras das amostras eram feitas antes e depois das medidas de transmissão utilizando-se um relógio comparador (precisão de $\pm 0,02 \mathrm{~mm}$ ). Cada medida de transmissão de um tecido era seguida de uma medida com o porta-amostra vazio (feixe incidente). O tempo de aquisição, em média de 200s para o feixe incidente e 700s para os tecidos, permitia manter as incertezas estatísticas nas contagens abaixo de $0,35 \%$.

\subsection{EXPLORANDO A DISTRIBUIÇÃO ANGULAR (INTENSIDADE) DOS FÓTONS ESPALHADOS}

Nesta subseção serão apresentados os modelos e as metodologias experimentais empregados para determinação das densidades eletrônicas $\left(\rho_{e}\right)$ e do número atômico efetivo $\left(Z_{e f}\right)$ dos tecidos mamários a partir do número de fótons espalhados (distribuição angular).

O número de fótons espalhados (elasticamente e inelasticamente) foi obtido determinando-se a área da curva de espalhamento Rayleigh e Compton nos espectros obtidos experimentalmente. Uma vez que nas condições de momento transferido experimental há sobreposição das curvas de espalhamento elástico e inelástico foi usado um programa de ajuste de curvas, com o qual foram ajustadas gaussianas para os picos elásticos e inelásticos e uma função linear para as contagens de fundo (DUVAUCHELLE; PEIX; BABOT, 2000). Os valores de coeficiente de determinação $\mathrm{R}^{2}$ obtidos para os ajustes de curvas foram sempre superiores a 0,98 .

Os coeficientes de atenuação linear $(\mu)$ dos tecidos mamários, utilizados para determinação das $\rho_{e}$ e do $Z_{e f}$ (método convencional de transmissão), foram obtidos a partir das medidas de transmissão usando a equação 3.1 (CONNER et al., 1970; TOMAL et al., 2010):

$$
\mu=-\frac{1}{t} \ln \left(\frac{N_{t}}{N_{0}}\right)
$$

onde $N_{0}$ e $N_{t}$ são respectivamente o número de fótons incidentes e transmitidos através da amostra de espessura $t$. É importante salientar que a validade do modelo experimental, expresso através da equação 3.1, pressupõe a utilização de geometria de feixe estreito para realização das medidas, situação experimental que exige um feixe de radiação bem colimado e um sistema de detecção que garanta a detecção de fótons na energia incidente, condições satisfeitas nos experimentos de transmissão realizados neste trabalho. 
A validação do método de determinação dos coeficientes de atenuação linear foi feita comparando-se os valores obtidos (tabela 3.2) para os materiais de referência estudados neste trabalho com valores teóricos calculados pelo programa XCOM (BERGER et al., 1998) utilizando a regra das misturas $\mu_{m i s}=\rho_{m i s} \sum_{i} \omega_{i}(\mu / \rho)_{i}$, onde $\omega_{i}$ é a fração do peso do $i$ ésimo elemento constituinte com coeficiente de atenuação mássico $(\mu / \rho)_{i}$ e $\rho_{m i s}$ é a densidade física da mistura. As diferenças entre valores de coeficientes de atenuação linear experimentais e calculados (máxima de 3,9\%), mostradas tabela 3.2, são consideradas satisfatórias, tendo em vista as incertezas experimentais e o fato de os valores calculados serem uma aproximação (regra das misturas).

Tabela 3.2: Coeficientes de atenuação linear determinados na experiência com 17,44 keV, calculados através da regra das misturas e a diferença relativas entre esses valores

\begin{tabular}{lccc}
\hline $\begin{array}{l}\text { Materiais de } \\
\text { referência }\end{array}$ & $\begin{array}{c}\mu\left(\mathrm{cm}^{-1}\right) \\
\text { experimental } \\
17,44 \mathrm{keV}\end{array}$ & $\begin{array}{c}\mu\left(\mathrm{cm}^{-1}\right) \\
\text { NIST } \\
17,44 \mathrm{keV}\end{array}$ & $\begin{array}{c}\text { Acurácia } \\
\text { relativa } \\
(\%)\end{array}$ \\
\hline Água & $1,09 \pm 0,02$ & 1,130 & $-3,5$ \\
Etanol & $0,59 \pm 0,02$ & 0,611 & $-3,4$ \\
Isopropanol & $0,55 \pm 0,02$ & 0,562 & $-2,1$ \\
Glicerol & $1,09 \pm 0,02$ & 1,128 & $-3,4$ \\
Dimetilsulfóxido & $4,82 \pm 0,09$ & 5,016 & $-3,9$ \\
Dimetilformamida & $0,69 \pm 0,02$ & 0,711 & $-2,9$ \\
Acrílico & $0,88 \pm 0,02$ & 0,888 & $-0,9$ \\
Nylon & $0,76 \pm 0,02$ & 0,783 & $-2,9$ \\
Polipropileno & $0,48 \pm 0,01$ & 0,487 & $-1,4$ \\
Poliacetal & $1,24 \pm 0,03$ & 1,288 & $-3,7$ \\
\hline
\end{tabular}

\subsubsection{Determinação das densidades eletrônicas usando a distribuição angular (intensidade) dos fótons espalhados Compton}

O número de fótons espalhados inelasticamente $\left(N_{i n}\right)$ por um material em um ângulo de espalhamento $\theta$ pode ser escrito da seguinte forma (KANE, 1992):

$$
N_{\text {in }}(\theta)=N_{0} n_{a t}\left(\frac{d \sigma}{d \Omega}\right)_{i n} \Delta \Omega_{d e t} \varepsilon V A=N_{0} n_{a t}\left[S(x, Z)\left(\frac{d \sigma}{d \Omega}\right)_{K N}\right] \Delta \Omega_{d e t} \varepsilon V A
$$

onde $N_{o}$ é o número de fótons incidentes por unidade de área, $n_{a t}$ é o número de átomos por unidade de volume do material espalhador, $(d \sigma / d \Omega)_{\text {in }}$ é a secção de choque diferencial inelástica, $S(x, Z)$ é a função de espalhamento incoerente, $(d \sigma / d \Omega)_{K N}$ é a secção de choque 
diferencial de Klein-Nishina, o termo $\Delta \Omega_{\text {det }}$ é o intervalo de ângulo sólido compreendido pelo detector com origem no elemento espalhador; $\varepsilon$ é a eficiência de detecção, $V$ é o volume da amostra com o qual a radiação interage e $A$ é o fator de atenuação dado de uma forma geral por:

$$
A=\frac{1}{V} \int_{V} e^{-\left(\mu_{1} l_{1}+\mu_{2} l_{2}\right)} d V
$$

onde $e^{-\left(\mu_{1} l_{1}+\mu_{2} l_{2}\right)}$ representa a atenuação através das distâncias $l_{l}$ da superfície ao elemento de espalhamento $(d V)$ na amostra e $l_{2}$ deste elemento até a superfície da amostra na direção do detector, sendo $\mu_{1}$ e $\mu_{2}$ respectivamente os coeficientes de atenuação linear na energia incidente e espalhada.

Escrevendo que $n_{a t}=\rho_{e} / Z$ onde $\rho_{e}$ é a densidade eletrônica e $Z$ o número atômico do material podemos reescrever a equação 3.2 como:

$$
N_{\text {in }}(\theta)=N_{0} \rho_{\mathrm{e}}\left(\frac{S}{Z}\right)\left(\frac{d \sigma}{d \Omega}\right)_{K N} \Delta \Omega_{d e t} \varepsilon V A
$$

Existem diferentes procedimentos que podem ser usados para determinar a densidade eletrônica a partir do número de fótons espalhados $N_{i n}(\theta)$, os quais podem ser divididos em métodos absolutos e comparativos. No primeiro caso é necessário o conhecimento dos vários parâmetros que a priori são desconhecidos (como por exemplo, o número de fótons incidentes por unidade de área $\left(N_{0}\right)$, a eficiência de detecção $(\varepsilon)$, o volume sensível da radiação na amostra $(V))$. Métodos comparativos são mais adequados em experimentos onde esses parâmetros são desconhecidos e envolvem o uso de um (AL-BAHRI; SPYROU, 1998) ou vários (ANTONIASSI; CONCEIÇÃO; POLETTI，2010; RYAN; FARQUHARSON; FLINTON, 2005; SHRIMPTON, 1981) materiais de calibração (padrões), onde parâmetros experimentais são obtidos pelo uso de curvas de calibração lineares ou não lineares, obtidas de medidas com os padrões

Curvas de calibração lineares são obtidas quando a razão $S / Z$ e o fator de atenuação $A$ são determinados de forma independente do processo de calibração, ou ainda, em condições experimentais em que os efeitos de ligação dos elétrons aos átomos e de atenuação possam ser desprezados $(S / Z=1$ e $A=1)$. Quando um destes fatores $S / Z$ (RYAN; FARQUHARSON; FLINTON, 2005) ou A (ANTONIASSI; CONCEIÇÃO; POLETTI, 2010) é incluído no 
processo de calibração as densidades eletrônicas são obtidas através de curvas de calibração não lineares. Esta metodologia, utilizada no presente trabalho, será apresentada a seguir.

\subsubsection{Fator de atenuação A}

Considerando todas as condições geométricas das medidas deste trabalho (distâncias fonte-amostra e amostra-detector muito maiores que as dimensões da amostra, pequena área irradiada e feixe aproximadamente paralelo em geometria de reflexão $\left(l_{1}=l_{2}=l\right)$ ), o fator de atenuação $A$, escrito de forma geral pela equação 3.3 , pode ser reescrito como uma integral unidimensional dada por $A=\frac{1}{L} \int_{0}^{L} e^{-\left(\mu_{1}+\mu_{2}\right) l} d l$, aproximação usual para geometria de alvos pequenos. Esta integral possui solução analítica $A=\left(1-e^{-\mu L}\right) / \mu L$ onde $\mu=\mu_{1+} \mu_{2}$ e $L$ representa a distância percorrida pelo feixe incidente na amostra ao longo do caminho de incidência. Apesar de esta aproximação analítica desconsiderar a integral sobre a área irradiada, verifica-se que ela é bastante similar (diferenças menores que $0,5 \%$ ) à solução mais completa, obtida por simulação computacional (integração numérica em todo volume irradiado), conforme pode ser observado na figura 3.3, o que justifica sua utilização neste trabalho.

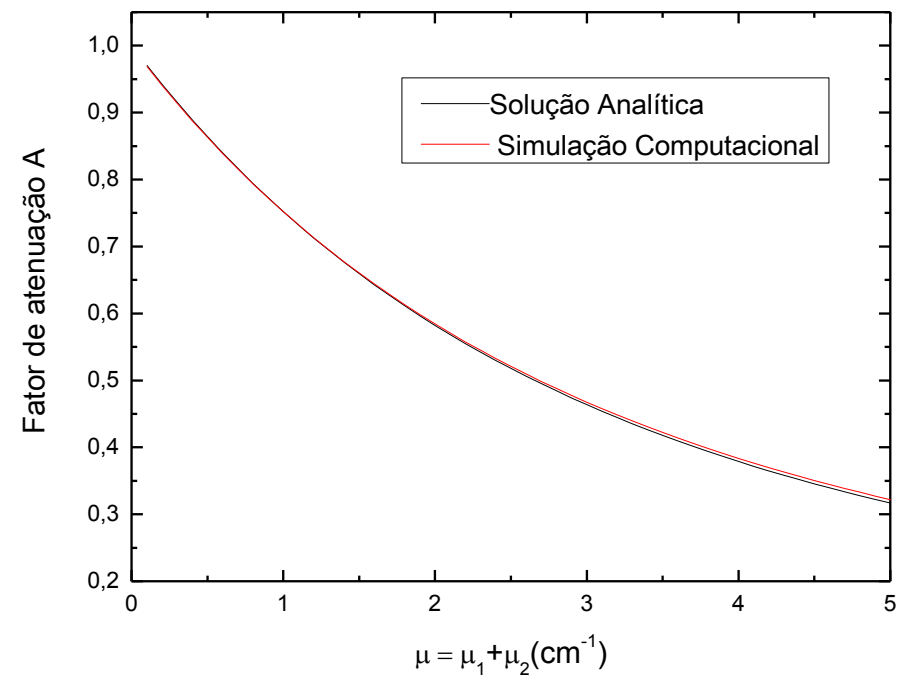

Figura 3.3: Comparação entre os fatores de atenuação A obtidos pela solução analítica e pela simulação usando os parâmetros experimentais de irradiação e geometria. 


\subsubsection{Curva de calibração}

Agrupando os termos constantes no experimento $N_{0},(d \sigma / d \Omega)_{K N}, \Delta \Omega_{d e t}, \varepsilon$ e $V$ da equação 3.4 na constante $k$ e escrevendo o fator de atenuação como $A=\left(1-e^{-\mu L}\right) / \mu L$, temos:

$$
N_{\text {in }}(\theta)=k \rho_{e}\left(\frac{S}{Z}\right) \frac{\left(1-e^{-\mu L}\right)}{\mu L}
$$

Manipulando a equação 3.5 chegamos à expressão 3.6, que fornece o modelo de ajuste da curva $Y$ versus $\mu$, construída a partir de medidas com os materiais de referência, que permite a determinação dos parâmetros experimentais $k$ e $L$.

$$
Y=\frac{k}{L} \frac{\left(1-e^{-\mu L_{0}}\right)}{\mu}
$$

onde $Y=\frac{N}{\rho_{e}}\left(\frac{S}{Z}\right)_{e f}^{-1}$.

No experimento realizado, foram utilizados para construção da curva de calibração cinco materiais de referência (água, isopropanol, acrílico, nylon e poliacetal) presentes na tabela 3.1, cujos coeficientes de atenuação linear compreendem toda faixa de $\mu$ dos tecidos mamários investigados. Os materiais de referência (etanol, glicerol, dimetilsulfóxido, polipropileno), excluídos do processo de calibração, foram utilizados para os testes de acurácia do sistema.

Os valores de $N_{\text {in }}$ e $\mu$ de dos materiais de referências e dos tecidos foram determinados experimentalmente respectivamente por medidas de espalhamento e de transmissão e os valores de $(S / Z)$ para os compostos (tecidos e materiais de referência) foram obtidos através do modelo atômico independente (POLETTI; GONÇALVES; MAZZARO, 2002b), o qual considera que cada átomo do composto espalha de forma independente:

$$
(S / Z)_{e f}=\frac{(S / M)_{e f}}{(Z / M)_{e f}}=\frac{\sum_{i}\left(\omega_{i} / m_{i}\right) S_{i}(x)}{\sum_{i}\left(\omega_{i} / m_{i}\right) Z_{i}}
$$


usando composições elementares de Woodard e White (1986) para tecidos normais e de Poletti, Gonçalves e Mazzaro (2002a) para os tecidos neoplásicos. As funções de espalhamento incoerente foram obtidas de Hubbell et al. (1975).

O gráfico da figura 3.4 apresenta a curva de calibração montada a partir de medidas realizadas com os materiais de referências e o resultado do ajuste não linear (equação 3.6) com os valores de $k$ e $L$ obtidos:

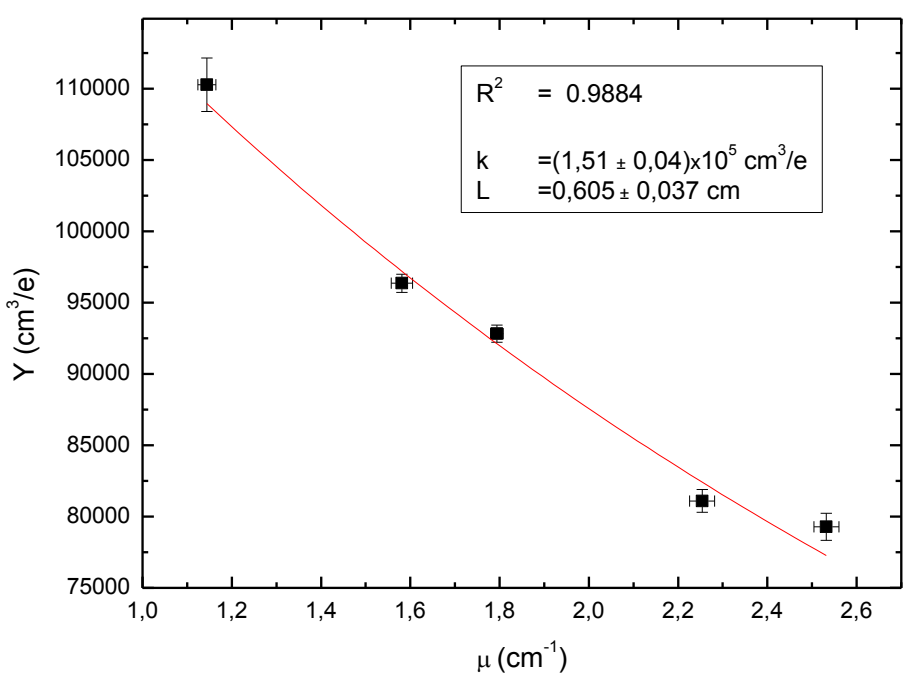

Figura 3.4: Curva Y vs $\mu$ usada para determinação dos parâmetros k e $L$

Os parâmetros $k=(1.51 \pm 0.04) \times 10^{5} \mathrm{~cm}^{3} / e$ e $L=(0.605 \pm 0.037) \mathrm{cm}$, obtidos através da curva de calibração foram usados para determinar as densidades eletrônicas dos tecidos mamários isolando-se o termo $\rho_{e}$ na equação 3.5.

\subsubsection{Validação do método para determinação das densidades eletrônicas}

A acurácia (exatidão) do método experimental proposto para a obtenção das densidades eletrônicas foi verificada comparando-se os valores experimentais de densidades eletrônicas obtidos para o etanol, glicerol, dimetilsulfóxido e polipropileno com os valores reais (calculados a partir de suas composições químicas e densidades físicas). 


\subsubsection{Determinação do número atômico efetivo dos tecidos mamários usando a razão $\mathfrak{R}$ entre as intensidades de espalhamento Rayleigh e Compton}

O número de fótons espalhados elasticamente (Rayleigh), $N_{e l}$, detectados pelo detector em um angulo ângulo de espalhamento $\theta$, pode ser descrito de forma análoga a expressão 3.2, para o espalhamento inelástico, como (KANE et al., 1986):

$$
N_{e l}(\theta)=N_{0} n_{a t}\left(\frac{d \sigma}{d \Omega}\right)_{e l} \Delta \Omega_{d e t} \varepsilon V A_{e l}=N_{0} n_{a t}\left[F^{2}(x, Z)\left(\frac{d \sigma}{d \Omega}\right)_{T h}\right] \Delta \Omega_{d e t} \varepsilon V A_{e l}
$$

onde $F(x, Z)$ é o fator de forma e $(d \sigma / d \Omega)_{T h}$ é a secção de choque diferencial de Thomson.

Assim a razão ( $\mathfrak{R}$ ) entre o número de fótons espalhados elasticamente (equação 3.8) e inelasticamente (equação 3.2) pode ser obtida pela seguinte expressão:

$$
\Re=\frac{N_{i n}}{N_{e l}}=\frac{\left[F^{2}(x, Z)(d \sigma / d \Omega)_{T h}\right] \times A_{e l}}{\left[S(x, Z)(d \sigma / d \Omega)_{K N}\right] \times A_{\text {in }}}
$$

Com o objetivo de obter a Razão $\mathfrak{R}$ entre o espalhamento Rayleigh e Compton independente da atenuação na amostra deve-se escolher uma condição experimental de energia incidente $\left(\hbar \omega_{1}\right)$ e ângulo de espalhamento $(\theta)$ tal que a diferença de energia entre os fótons espalhados elasticamente e inelasticamente seja pequena $\left(\hbar \omega_{1} \approx \hbar \omega_{2}\right)$ para obter-se a razão $A_{e l} / A_{\text {in }} \approx 1$ mas suficiente para permitir uma boa separação entre os picos no espectro medido (DUVAUCHELLE; PEIX; BABOT, 1999). Assim podemos simplificar a expressão 3.9 por:

$$
\Re=\left[\frac{F^{2}(x, Z)}{S(x, Z)}\right] \times\left[\frac{(d \sigma / d \Omega)_{T h}}{(d \sigma / d \Omega)_{K N}}\right]
$$

Considerando um determinado valor experimental fixo de momento transferido $x$ temos que a razão $\Re$ é uma função do número atômico $\Re=f_{x}(Z)$ ou, no caso de compostos ou misturas, é uma função do número atômico efetivo $\Re=f_{x}\left(Z_{e f}\right)$. A linha contínua gráfico da figura 3.5 apresenta a função $\mathfrak{R}=f_{0,99}\left(Z_{e f}\right)$ obtida através de um ajuste polinomial de ordem 6 dos valores teóricos de $\mathfrak{R}$ (símbolos) para elementos químicos de numero atômico $Z$ 
$=1$ a 12, usando-se valores de $F(x, Z)$ de Schaupp et al. (1983) e de $S(x, Z)$ de Hubbell et al. (1975). O valor de $x=0,99 \AA^{-1}$ corresponde ao valor de momento transferido experimental.

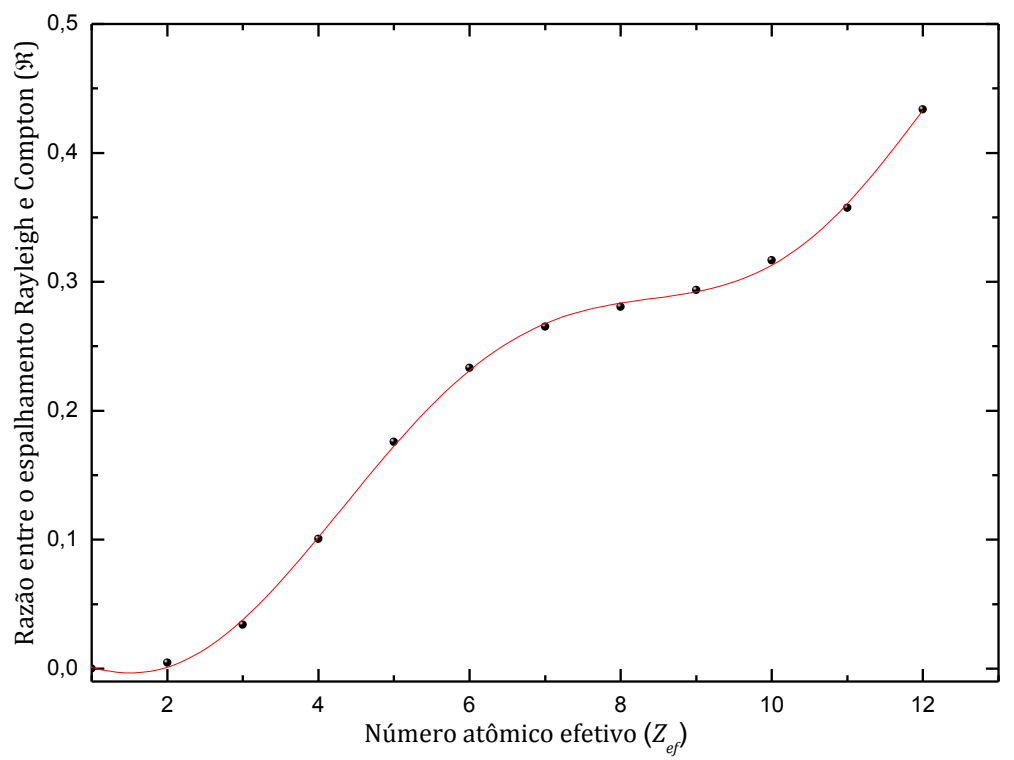

Figura 3.5: Razão $\mathfrak{R}$ entre os espalhamentos Rayleigh e Compton em função do número atômico efetivo. Símbolos representam os pontos de $f_{0,99}(Z)$ calculados teoricamente para elementos puros ( $\mathrm{Z}$ inteiro) enquanto a linha contínua representa a função contínua $f_{0,99}\left(Z_{e f}\right)$, resultado do ajuste polinomial.

Esta função, obtida através do ajuste de curvas, permite determinar os valores de número atômico efetivo de um determinado material ou tecido a partir das razões entre os espalhamentos Rayleigh e Compton obtidas experimentalmente.

\subsubsection{Validação do método para determinação do número atômico efetivo $Z_{\text {ef }}$}

A validação do método foi feita comparando-se valores experimentais de $Z_{e f}$ de diferentes compostos (materiais de referência) determinados usando as razões $\mathfrak{R}$ entre os espalhamentos Rayleigh e Compton (método proposto) e valores experimentais de $Z_{e f}$ obtidos usando um método convencional baseado nos coeficientes de atenuação dos compostos (ou secção de choque total) (KUMAR; REDDY, 1997; SHIVARAMU, 2002). Este último método envolve achar por interpolação o $Z_{e f}$ que corresponda à secção de choque total em um gráfico da seção de choque total para os elementos puros versus número atômico (figura 3.6). 


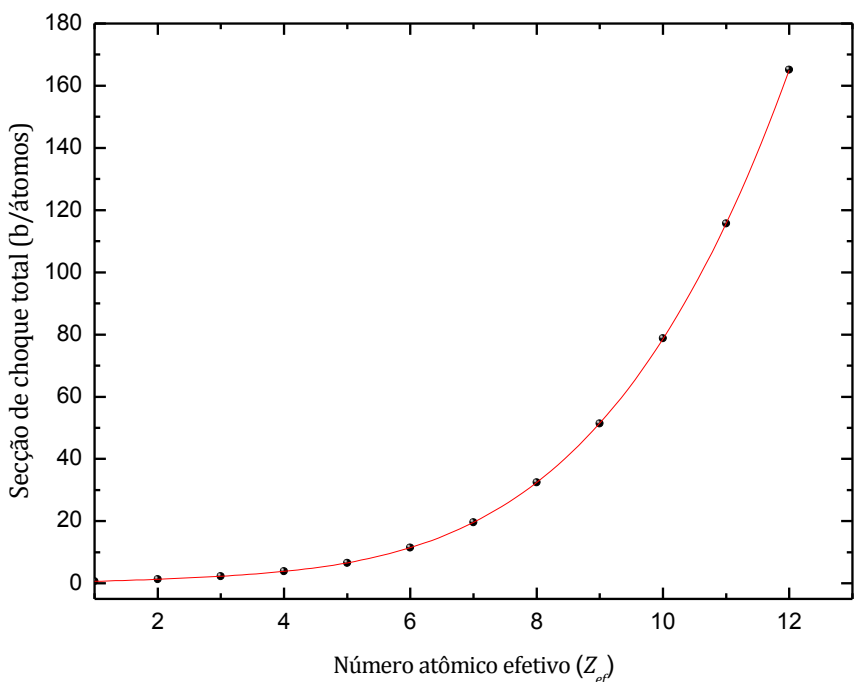

Figura 3.6: Seção de choque total em função do número atômico efetivo. Símbolos representam os pontos obtidos teoricamente para elementos puros ( $Z$ inteiro) enquanto a linha contínua representa $o$ resultado do ajuste polinomial de ordem 6.

A secção de choque total dos materiais de referência foi obtida dividindo o coeficiente de atenuação de massa do composto $\mu \rho$ pelo número de átomos presentes em um grama do material $\left(\sigma=\frac{(\mu / \rho)}{N_{A} \sum_{i} \omega_{i} / M_{i}}\right)$, sendo $N_{A}$ a constante de Avogadro. Os valores de $\mu \rho$ foram obtidos dividindo-se os coeficientes de atenuação linear obtidos experimentalmente pela densidade física dos compostos (presentes na tabela 3.1).

\subsection{EXPLORANDO A DISTRIBUIÇÃO EM ENERGIA (FORMA DO ESPECTRO) DOS FÓTONS ESPALHADOS}

\subsubsection{Determinação das larguras a meia altura (LMA) usando a distribuição em energia dos fótons espalhados Compton.}

$\mathrm{O}$ espalhamento de raios $\mathrm{X}$ monoenergéticos, de energia incidente $\hbar \omega_{1}$, geralmente resulta em dois picos detectados (caso o sistema de detecção discrimine energia): um pico estreito de energia $\hbar \omega_{1}$ que inclui os fótons espalhados elasticamente e um pico largo com energia $\hbar \omega_{2}<\hbar \omega_{1}$ representando os fótons que sofreram perda de energia como produto do espalhamento inelástico no material.

Enquanto a largura do pico de espalhamento Rayleigh está relacionada apenas com a resolução em energia do detector $(\Delta R)$, a largura do pico de espalhamento Compton é 
determinada por vários fatores (CESAREO et al., 1992): i) a resolução em energia do detector, ii) a distribuição de momentos dos elétrons no material espalhador iii) a aceptância angular do detector $i v$ ) o múltiplo espalhamento. Considerando que dentre esses fatores apenas o segundo fornece informação sobre a amostra espalhadora permitindo o uso da LMA para caracterização do material, é desejável que os outros fatores sejam minimizados. Neste trabalho o efeito da resolução em energia do detector foi diminuído usando um detector com uma boa resolução em energia $(\approx 0,31 \mathrm{keV}$ na energia experimental de $17,44 \mathrm{keV})$. Os efeitos da aceptância angular do detector e do múltiplo espalhamento foram minimizados respectivamente pelo sistema de colimação do detector e pela pequena espessura de amostra analisada.

Experimentalmente a largura a meia altura da curva de espalhamento Compton foi determinada a partir dos espectros (distribuição em energia), ajustando-se duas gaussianas, uma de largura fixa ( $\Delta R=0,31 \mathrm{keV}$, que corresponde à resolução em energia do detector) para o pico de espalhamento Rayleigh e outra para o pico de espalhamento Compton. A resolução em energia $\Delta R$ do detector foi obtida experimentalmente através de ajuste gaussiano, da curva do espectro de radiação monoenergética incidente no detector.

\subsection{IMAGENS POR ESPALHAMENTO COMPTON}

Nesta subsecção será apresentada a metodologia empregada para as simulações computacionais das técnicas de imagens por espalhamento realizadas neste trabalho.

\subsubsection{Arranjo esquemático das simulações tomográficas}

A figura 3.7 representa esquematicamente o arranjo usado para as simulações computacionais da tomografia por espalhamento: 


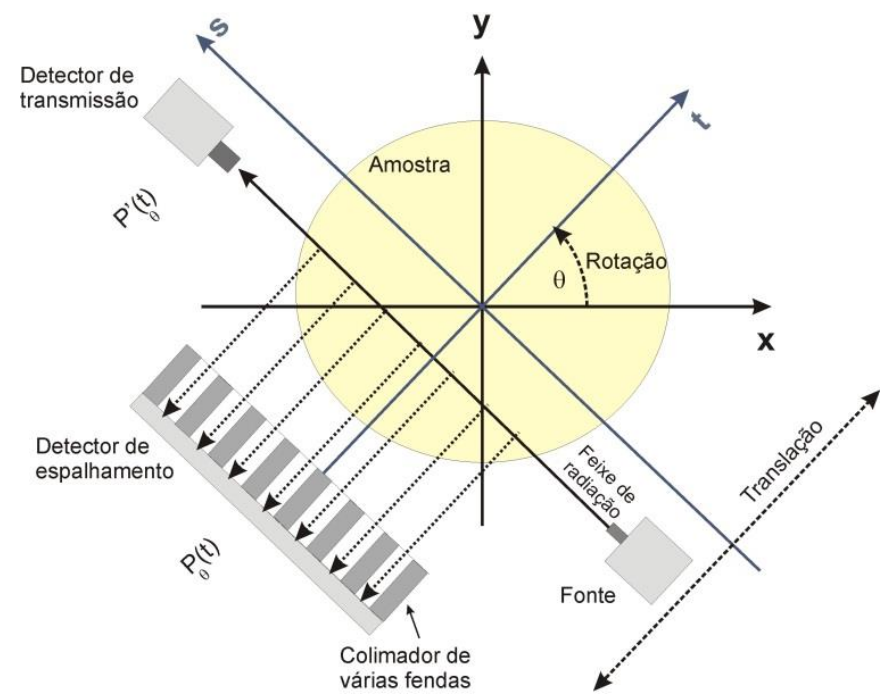

Figura 3.7: Arranjo esquemático usado nas simulações de tomografia por espalhamento.

Os detectores de transmissão e de espalhamento são responsáveis respectivamente pela obtenção das projeções transmissão $P^{\prime}{ }_{\theta}(t)$ e espalhamento $P_{\theta}(t)$. O ângulo de detecção dos fótons espalhados é fixo em $90^{\circ} \mathrm{com}$ uma pequena aceptância angular determinada pelas várias fendas do colimador do detector de espalhamento. Uma projeção completa (de transmissão ou espalhamento) é obtida com a translação completa da amostra ao longo da direção t. A translação da amostra permite que o ângulo sólido de detecção do feixe espalhado permaneça constante em cada passo da translação embora o problema de reconstrução possa ser analogamente tratado usando uma amostra fixa com o sistema fonte/detector de transmissão sofrendo translação. Para reconstrução das imagens de transmissão e espalhamento são obtidas projeções completas para vários ângulos de rotação ( 0 a $2 \pi)$.

\subsubsection{Tomografia por transmissão}

A reconstrução tomográfica por transmissão é necessária para determinação das propriedades de atenuação (mapa dos coeficientes de atenuação linear $\mu(x, y)$ ) do objeto analisado, que serão usadas para correção das imagens tomográficas de espalhamento Compton.

As projeções obtidas em cada ângulo de rotação podem ser definidas em função do número de fótons transmitidos $\left(N_{t}\right)$ detectados pelo detector de transmissão:

$$
P_{\theta}^{\prime}(t)=\ln \left(\frac{N_{0}}{N_{t}}\right)=\int \mu(x, y) d s
$$


ou no sistema de coordenadas $(x, y)$ :

$$
P^{\prime}{ }_{\theta}(t)=\iint \mu(x, y) \delta(x \cos \theta+y \operatorname{sen} \theta-t) d x d y
$$

onde a relação entre os sistemas de coordenadas $(x, y)$ e $(s, t)$ é dada pela equação 2.26.

Para reconstrução tomográfica a partir das projeções obtidas para cada ângulo pode se usar o método da retroprojeção filtrada, explicado nos fundamentos teóricos deste trabalho.

\subsubsection{Tomografia por espalhamento}

O número de fótons espalhados inelásticamente em uma região infinitesimal de volume $d V$ do objeto será dado de forma análoga à expressão 3.2 como:

$$
N_{\text {in }}=N_{0} n_{a t} S(x, y)\left(\frac{d \sigma}{d \Omega}\right)_{K N} \Delta \Omega_{d e t} d V \varepsilon A(x, y, \theta)
$$

sendo a atenuação $A(x, y, \theta)$ dada por:

$$
A(x, y, \theta)=\exp \left(-\int_{s} \mu_{1}(x, y) d s\right) \times \exp \left(-\int_{t} \mu_{2}(x, y) d t\right)
$$

onde $\exp \left(-\int_{s} \mu_{1}(x, y) d s\right)$ e $\exp \left(-\int_{t} \mu_{2}(x, y) d t\right)$ representam respectivamente as atenuações ao longo do caminho do feixe incidente (da superfície do objeto ao elemento de espalhamento $d V$ ) e ao longo do caminho do feixe espalhado (do elemento $d V$ até a superfície do objeto na direção do detector). Em situações em que a energia incidente for aproximadamente igual a energia de espalhamento os coeficientes de atenuação linear se aproximam $\mu_{1}(x, y) \approx \mu_{2}(x, y)$, podendo ser representados simplesmente por $\mu(x, y)$.

Escrevendo $d V$ como a.ds, onde $a$ é a área do feixe incidente, agrupando os termos constantes $\left(N_{0}, \Delta \Omega_{\text {det }}, \varepsilon, a\right)$ em $k$ e definindo o coeficiente linear de espalhamento inelástico como $\mu_{i n}(x, y)=n_{a t} S(x, y)\left(\frac{d \sigma}{d \Omega}\right)_{K N}=\rho_{e}(x, y)\left(\frac{S}{z}\right)_{x, y}\left(\frac{d \sigma}{d \Omega}\right)_{K N}$ temos:

$$
N_{\text {in }}=k \mu_{\text {in }}(x, y) A(x, y, \theta) d s
$$


Cabe ressaltar que o número de fótons espalhados inelasticamente $\left(N_{i n}\right)$ depende número de elementos espalhadores (elétrons) por unidade de volume (densidade eletrônica) do material espalhador. Assim sendo a distribuição espacial do coeficiente linear de espalhamento inelástico $\mu_{i n}(x, y)$ também está relacionada com a distribuição espacial da densidade eletrônica no material $\rho_{e}(x, y)$. De fato, para altos valores de momentos transferidos (alta energia incidente e/ou alto valor de ângulo de espalhamento) temos que a função de espalhamento incoerente $S$ tende ao número atômico $Z$ e o coeficiente linear de espalhamento inelástico será simplesmente dado por $\mu_{i n}(x, y)=\rho_{e}(x, y)(d \sigma / d \Omega)_{K N}$.

As projeções $P_{\theta}(t)$ obtidas em cada ângulo de rotação podem ser definidas em função do número de fótons espalhados inelasticamente $\left(N_{i n}\right)$ detectados pelo detector de espalhamento como:

$$
P_{\theta}(t)=k \int \mu_{i n}(x, y) A(x, y, \theta) d s
$$

$\mathrm{ou}$

$$
P_{\theta}(t)=k \iint \mu_{i n}(x, y) A(x, y, \theta) \delta(x \cos \theta+y \operatorname{sen} \theta-t) d x d y
$$

As expressão 3.16 é análoga a expressão 3.11 exceto pela presença do fator de atenuação $A(x, y, \theta)$ dependente do ângulo de rotação $\theta$. Assim sendo a retroprojeção filtrada das projeções $P_{\theta}(t)$ obtidas em cada ângulo não permite obter a função $\mu_{i n}(x, y)$ e sim uma função $I(x, y)$ alterada pelos efeitos da atenuação da radiação dentro do objeto.

Este problema matemático, entretanto, pode ser simplificado aproximando o fator de atenuação $A(x, y, \theta)$ por sua média em todos ângulos de rotação (BRUNETTI; GOLOSIO, 2001):

$$
\bar{A}(x, y)=\frac{1}{2 \pi} \int_{0}^{2 \pi} A(x, y, \theta) d \theta
$$

Desta forma a expressão 3.17 pode ser reescrita como:

$$
P_{\theta}(t)=k \iint I(x, y) \delta(x \cos \theta+y \operatorname{sen} \theta-t) d x d y
$$

onde $I(x, y)=\mu_{\text {in }}(x, y) \bar{A}(x, y)$. 
Neste caso a retroprojeção filtrada das projeções $P_{\theta}(t)$ permite obter a função $\tilde{I}(x, y)$, onde o acento $\sim$ indica que a função $I(x, y)$ foi obtida pelo processo de retroprojeção. Assim a imagem reconstruída de $\mu_{i n}(x, y)$ é então obtida por:

$$
\tilde{\mu}_{i n}(x, y)=\frac{\tilde{I}(x, y)}{k \bar{A}(x, y)}
$$

\subsubsection{Estrutura do programa usado na simulação de espalhamento Compton}

Na figura 3.8 é apresentado um diagrama da estrutura do programa utilizado para as simulações da tomografia de espalhamento.

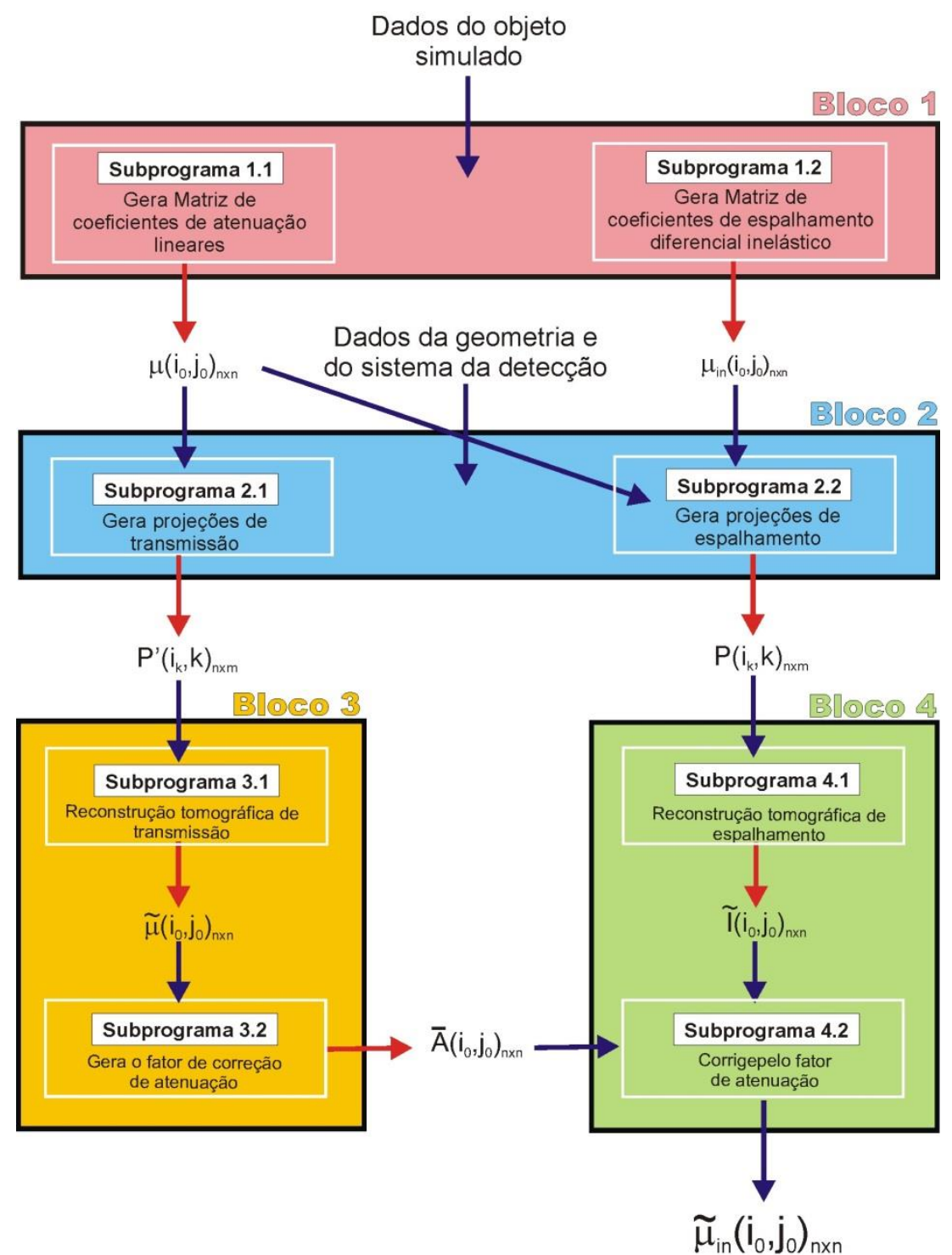

Figura 3.8: Estrutura do programa usado nas simulações de tomografia por espalhamento. 
O programa usado na simulação foi desenvolvido utilizando o software Matlab e está organizado em quatro blocos de subprogramas:

\section{Bloco 1: Obtenção dos objetos simulados}

O bloco 1 é constituído de dois subprogramas (subprogramas 1.1 e 1.2) responsáveis pela obtenção das matrizes $\mu\left(i_{0}, j_{0}\right)$ e $\mu_{i n}\left(i_{0}, j_{0}\right)$ que simulam respectivamente as propriedades de atenuação e espalhamento dos objetos a serem reconstruídos pela tomografia. Os sub-índices das coordenadas discretas matriciais $i_{0}$ e $j_{0}$ indicam elas são dadas no sistema de referência em um ângulo de rotação de $0^{\circ}$.

Este bloco de subprogramas possui como parâmetros de entrada os dados dos objetos simulados como diâmetro, valores de coeficientes de atenuação linear, $\mu$, e de coeficientes lineares de espalhamento inelástico, $\mu_{i n}$, dos tecidos mamários, etc.

As matrizes objetos $\mu\left(i_{0}, j_{0}\right)$ e $\mu_{i n}\left(i_{0}, j_{0}\right)$ foram simuladas atribuindo-se respectivamente valores de coeficientes de atenuação linear ou de coeficientes lineares de espalhamento inelástico de tecidos mamários para cada pixel $\left(i_{0}, j_{0}\right)$ de dimensões $\Delta \mathrm{s} \times \Delta \mathrm{t} \mathrm{cm}^{2}$. Os valores de coeficientes de atenuação linear dos tecidos mamários, para cada energia estudada, foram calculados usando o programa XCOM (BERGER et al., 1998). Os valores de coeficientes lineares de espalhamento inelástico dos tecidos mamários foram calculados usando dados de densidades eletrônicas médias dos tecidos obtidos neste trabalho e os valores de (S/Z) foram obtidos através do modelo atômico independente (equação 3.7). Os dados das composições dos tecidos foram obtidos de Woodard e White (1986) para tecidos normais e de Poletti, Gonçalves e Mazzaro (2002a) para os tecidos neoplásicos.

Os parâmetros de saída deste bloco de subprogramas são as matrizes $\mu\left(i_{0}, j_{0}\right)$ e $\mu_{\text {in }}\left(i_{0}, j_{0}\right)$ de dimensões $n \times n$.

\section{Bloco 2: Obtenção dos projeções de transmissão e espalhamento}

O bloco 2 é constituído de dois subprogramas (subprogramas 2.1 e 2.2) responsáveis respectivamente pela obtenção das projeções de transmissão e de espalhamento.

Os parâmetros de entrada são as matrizes objetos $\mu\left(i_{0}, j_{0}\right)$ e $\mu_{i n}\left(i_{0}, j_{0}\right)$ obtidas do bloco 1 de programas e os dados da geometria do sistema e da detecção (distância fonte detectores, área do feixe $a$, fluxo de fótons incidentes $N_{o}$, número de projeções obtidas $m$, etc). 
As projeções de transmissão $P_{k}^{\prime}\left(i_{k}\right)$ foram obtidas pelo subprograma 2.1 usando a forma discreta da expressão 3.11:

$$
P_{k}^{\prime}\left(i_{k}\right)=\sum_{j_{k=0}}^{n-1} \mu\left(i_{k}, j_{k}\right) \Delta s
$$

onde os valores de $\mu\left(i_{k}, j_{k}\right)$ necessários para obtenção de cada projeção $P_{k}^{\prime}\left(i_{k}\right)$ foram obtidos através da rotação em um ângulo $\theta_{k}=k \times(2 \pi / m)$ da matriz objeto inicial $\mu\left(i_{0}, j_{0}\right)$, sendo $k$ um número inteiro variando de 0 a $m-1$, relacionado com o ângulo de rotação do sistema de coordenadas.

As projeções $P_{k}\left(i_{k}\right)$ de espalhamento foram obtidas pelo subprograma 2.2 usando a forma discreta da expressão 3.16:

$$
P_{k}\left(i_{k}\right)=k \sum_{j_{k}}^{n-1} \mu_{i n}\left(i_{k}, j_{k}\right) \cdot A\left(i_{k}, j_{k}, k\right) \Delta s
$$

onde $\mu_{i n}\left(i_{k}, j_{k}\right)$ foi obtido através da rotação de $\theta_{k}$ da matriz objeto inicial $\mu_{i n}\left(i_{0}, j_{0}\right)$ e a matriz de atenuação $A\left(i_{k}, j_{k}, k\right)$, de dimensões $(n \times n \times m)$, foi calculada usando a expressão discreta 3.23 (análoga a expressão contínua 3.14):

$$
A\left(i_{k}, j_{k}, k\right)=\exp \left(-\sum_{j_{k}{ }^{\prime}=0}^{j_{k}} \mu\left(i_{k}, j_{k}{ }^{\prime}\right) \Delta s\right) \times \exp \left(-\sum_{i_{k}{ }^{\prime}=0}^{i_{k}} \mu\left(i_{k}{ }^{\prime}{ }^{\prime} j_{k}\right) \Delta t\right)
$$

Os parâmetros de saída deste bloco de subprogramas são as matrizes bidimensionais $P\left(i_{k}, k\right)$ e $P^{\prime}\left(i_{k}, k\right)$ de dimensões $n \times m$, conhecidas como senogramas, formados pelas projeções em cada ângulo de espalhamento $\theta_{k}$.

A simulação possibilita avaliar os efeitos da resolução espacial do sistema, relacionada com a largura do feixe incidente $b$. Para tanto, cada projeção $P_{k}^{*}\left(i_{k}^{*}\right)$ foi calculada pela soma de $b / \Delta t$ linhas de projeções $P_{k}\left(i_{k}\right)$ :

$$
P_{k}^{*}\left(i_{k}^{*}\right)=\sum_{i_{k}=i_{k}^{\min }}^{i_{k}^{\max }} P_{k}\left(i_{k}\right)
$$


onde $i_{k}^{\min }=i_{k}^{*}\left(\frac{b}{\Delta t}\right)$ e $i_{k}^{\max }=\left(i_{k}^{*}+1\right) \frac{b}{\Delta t}-1$. Neste caso as matrizes de saída passam a ter dimensões $n^{\prime} \times m$, onde $n^{\prime}=n(\Delta t / \mathrm{b})$.

A capacidade de simulação da natureza estocástica do processo de detecção da radiação também foi incluída neste bloco de subprogramas, permitindo-se somar às projeções um ruído aleatório de distribuição de Poisson de média igual ao valor da projeção (contagem no detector).

\section{Bloco 3: Obtenção da correção de atenuação}

Este bloco de subprogramas tem como função obter a atenuação média usada para correção de atenuação na reconstrução tomográfica de espalhamento. É constituído de dois subprogramas (3.1 e 3.2). O subprograma 3.1 permite reconstruir o mapa de coeficientes de atenuação linear a partir das projeções de transmissão. Tem como entrada a matriz $P^{\prime}\left(i_{k}, k\right)$ das projeções de transmissão e como saída a matriz $\tilde{\mu}\left(i_{0}, j_{0}\right)$, onde o acento $\sim$ indica a obtenção de $\mu\left(i_{0}, j_{0}\right)$ pelo método da retroprojeção filtrada.

O subprograma 3.2 utiliza a matriz $\tilde{\mu}\left(i_{0}, j_{0}\right)$ para obtenção da atenuação média $\bar{A}\left(i_{0}, j_{0}\right)$ usando a expressão 3.25 (forma discreta da equação 3.18 ):

$$
\bar{A}\left(i_{0}, j_{0}\right)=\frac{1}{m} \sum_{k=1}^{m} A\left(i_{0}, j_{0}, k\right)
$$

onde a matriz $A\left(i_{0}, j_{0}, k\right)$ é obtida conforme equação 3.23 no sistema de coordenadas $\left(i_{0}, j_{0}\right)$.

\section{Bloco 4: Reconstrução das imagens por espalhamento}

Este último bloco de subprogramas tem como função a reconstruir as imagens de espalhamento a partir das projeções de espalhamento e corrigi-las pelo efeito da atenuação.

É constituído de dois subprogramas (4.1 e 4.2). O subprograma 4.1 obtém a matriz $\tilde{I}\left(i_{0}, j_{0}\right)$ através da retroprojeção filtrada das projeções de espalhamento $P\left(i_{k}, k\right)$ usando o filtro de Shepp-Logan (SHEPP; LOGAN JR, 1974) ou o de Hamming (HERMAN, 1980), que 
é mais apropriado para as reconstruções com ruído (BRUNETTI; GOLOSIO, 2001; HERMAN, 1980).

O subprograma 4.2 corrige a matriz $\tilde{I}\left(i_{0}, j_{0}\right)$ pela atenuação média obtendo a matriz de coeficientes lineares de espalhamento inelástico, processo que corresponde a discretização da expressão 3.20 dado pela seguinte equação:

$$
\tilde{\mu}_{i n}\left(i_{0}, j_{0}\right)=\frac{\tilde{I}\left(i_{0}, j_{0}\right)}{k \bar{A}\left(i_{0}, j_{0}\right)}
$$

\subsubsection{Estudo das imagens obtidas}

O estudo da técnica de imagens por espalhamento Compton foi feito avaliando-se a qualidade das imagens obtidas em relação à energia incidente, ao objeto (dimensão e glandularidade do tecido que o compõe) e aos sistemas de irradiação e detecção (largura do feixe e ruído).

A figura 3.9 esquematiza o objeto simulado (composto por dois tipos de tecidos 1 e 2) e os diferentes parâmetros que influenciam os efeitos estudados na simulação.

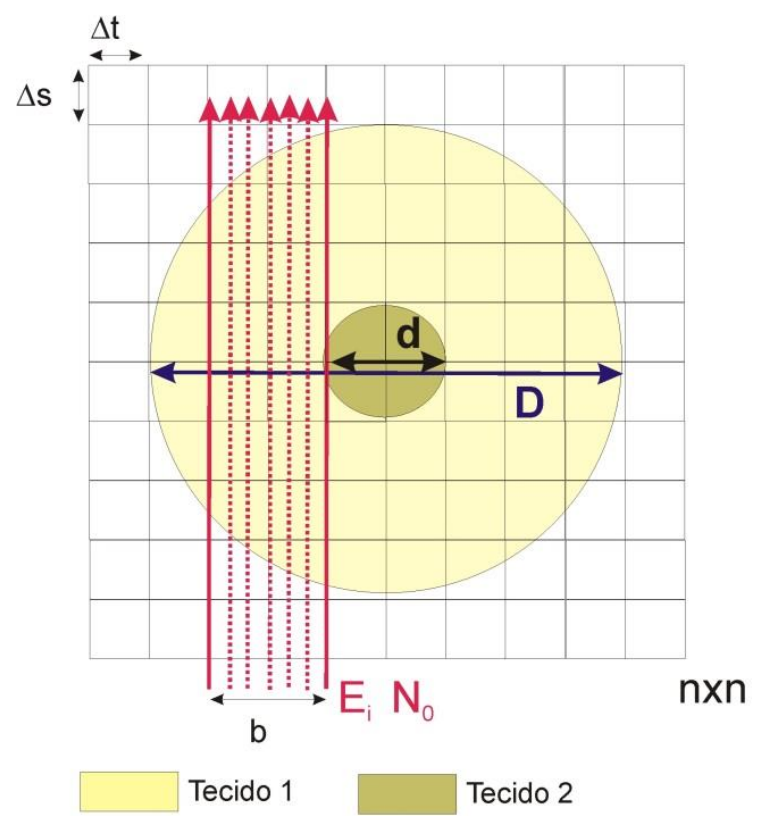

Figura 3.9: Definição de alguns parâmetros que influenciam as características das imagens reconstruídas 
O estudo dos efeitos energia incidente nas imagens foi feito comparando-se as imagens e os valores de coeficientes lineares de espalhamento inelástico (reais e obtidos pela reconstrução) ao longo da linha central da imagem para diferentes energias incidentes $\left(E_{i}\right)$.

O estudo da influência do objeto nas imagens obtidas foi feito em função de sua dimensão $(D)$ e da glandularidade (porcentagem de tecido fibroglandular em uma mistura de tecido fibroglandular e adiposo). Para tanto, simulou-se um carcinoma (tecido 2) rodeado por quatro diferentes misturas de tecidos de diferentes glandularidades.

O estudo do efeito da largura do feixe $b$ (relacionado à resolução espacial do sistema) foi feito variando-se a largura do feixe mantendo-se os demais parâmetros constantes.

Por fim foi avaliado o efeito do ruído estatístico das contagens de fótons na qualidade das imagens obtidas. O efeito do ruído depende da contagem fótons de espalhados que chegam ao detector que por sua vez depende dos parâmetros $N_{0}$ (número de fótons incidentes por unidade de área - fluxo), do volume da amostra irradiado (dependente da dimensão da amostra $D$ e da largura do feixe $b$ ), do tipo de tecido (coeficiente linear de espalhamento inelástico) e da atenuação na amostra (dependente tanto da dimensão da amostra $D$ quanto da energia incidente $E_{\mathrm{i}}$ ). Para avaliar este efeito foram comparadas imagens para diferentes níveis de ruído. 


\section{RESULTADOS E DISCUSSÕES}

\subsection{DENSIDADES ELETRÔNICAS DOS TECIDOS MAMÁRIOS}

\subsubsection{Resultados do teste de acurácia para as densidades eletrônicas}

A acurácia do método usado para determinação das densidades eletrônicas é mostrada na figura 4.1 pela distribuição dos valores de densidades eletrônicas experimentais versus calculados dos materiais de referência (etanol, glicerol, dimetilsulfóxido e polipropileno) em torno da linha de identidade, onde as barras de erros apresentam a combinação de incertezas associadas às incertezas estatísticas na contagem e incertezas nos valores das constantes obtidas pelo ajuste.

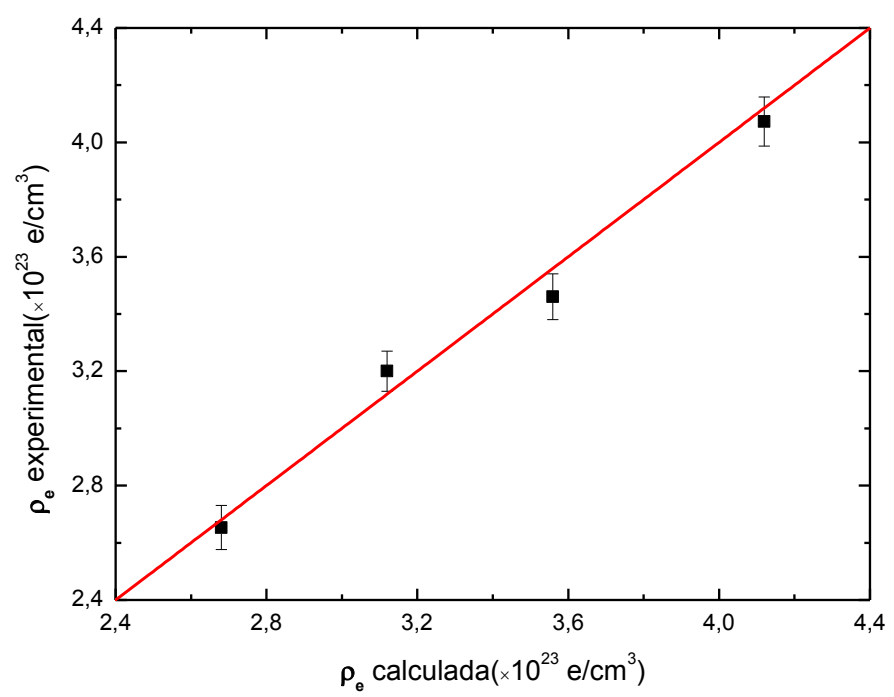

Figura 4.1: Densidade eletrônica experimental versus calculada para os materiais de referência.

Os valores de diferenças percentuais (acurácia relativa) são mostrados na tabela 4.1. Os valores obtidos são considerados pequenos (menores que 3,6\%) tendo em vista as incertezas experimentais. 
Tabela 4.1: Densidades eletrônicas reais e experimentais, utilizadas para verificar a acurácia do procedimento experimental

\begin{tabular}{lccc}
\hline $\begin{array}{l}\text { Materiais de } \\
\text { referência }\end{array}$ & $\begin{array}{c}\rho_{\mathrm{e}} \times 10^{23}\left(\mathrm{e} / \mathrm{cm}^{3}\right) \\
\text { Experimental }\end{array}$ & $\begin{array}{c}\rho_{\mathrm{e}} \times 10^{23}\left(\mathrm{e} / \mathrm{cm}^{3}\right) \\
\text { Calculada }\end{array}$ & $\begin{array}{c}\text { Acurácia relativa } \\
(\%)\end{array}$ \\
\hline Etanol & $2,65 \pm 0,09$ & 2,68 & 1,0 \\
Glicerol & $4,07 \pm 0,15$ & 4,12 & 1,1 \\
Dimetilsulfóxido & $3,43 \pm 0,11$ & 3,56 & 3,6 \\
Polipropileno & $3,22 \pm 0,012$ & 3,12 & $-3,2$ \\
\hline
\end{tabular}

\subsubsection{Resultados de densidades eletrônicas dos tecidos mamários}

A figura 4.2 apresenta o box plot dos valores de densidades eletrônicas obtidos para os diferentes tipos de tecidos estudados.

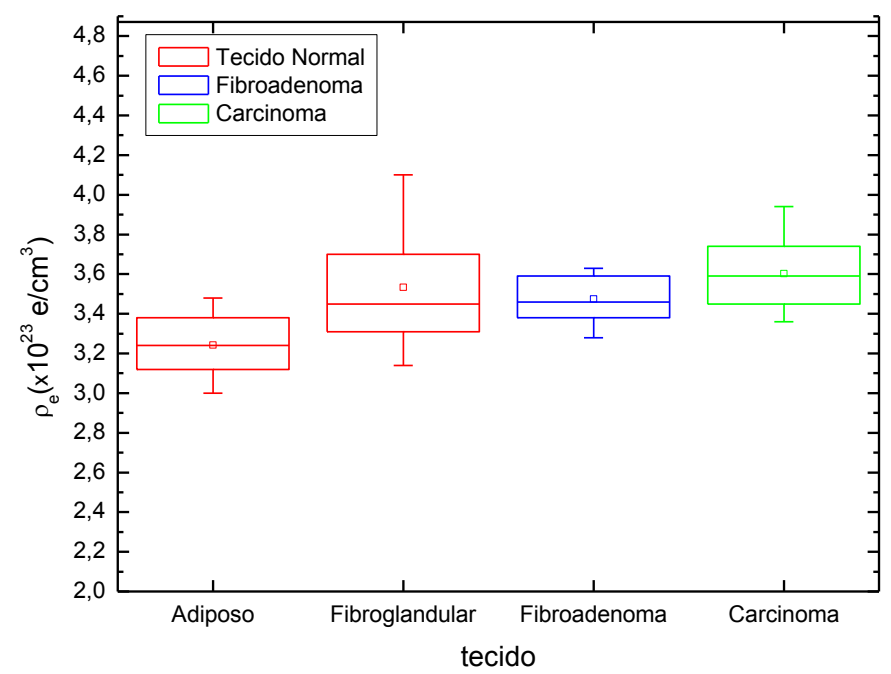

Figura 4.2: Box plot das densidades eletrônicas dos diferentes tipos de tecidos

Da figura é possível observar que as distribuições de densidades eletrônicas dos diferentes tecidos apresentam grande variação, mostrando sobreposição de valores entre os diferentes grupos. Estas variações são esperadas e atribuídas tanto a parâmetros gerais, associados à amostragem de diferentes pacientes, tais como alimentação, medicação, ambiente, idade e genética como a parâmetros específicos associados a características histológicas particulares de cada tipo de tecido, que pode explicar as grandes variações dos tecidos fibroglandulares, compostos de uma quantidade variável de lipídeos entre as fibras, e dos carcinomas, compostos por uma quantidade variável de fibras e células epiteliais malignas (ROSEN, 2009). Por outro lado os fibroadenomas apresentaram as menores variações, fato 
relacionado à regularidade espacial e homogeneidade de seus constituintes histológicos (ROSEN, 2009).

\subsubsection{Comparação dos valores de densidades eletrônicas obtidos com os presentes na literatura}

A tabela 4.2 apresenta os valores médios de densidades eletrônicas e os respectivos desvios padrões das amostras analisadas, cujos valores são comparados com os apresentados nos trabalhos existentes na literatura:

Tabela 4.2: Valores experimentais (média e desvio padrão) e teóricos de densidades eletrônicas de tecidos mamários presentes na literatura.

\begin{tabular}{|c|c|c|c|c|c|c|}
\hline \multirow[b]{3}{*}{$\begin{array}{l}\text { Tecido } \\
\text { mamário } \\
\end{array}$} & \multicolumn{5}{|c|}{ Experimental } & \multirow{2}{*}{$\begin{array}{c}\text { Teórico } \\
\text { ICRU44 } \\
(1989) \\
\end{array}$} \\
\hline & $\begin{array}{l}\text { Shrimpton } \\
\text { (1981) }\end{array}$ & $\begin{array}{l}\text { Al-Bahri and } \\
\text { Spyrou (1998) }\end{array}$ & $\begin{array}{l}\text { Ryan et al. } \\
\text { (2005) }\end{array}$ & $\begin{array}{l}\text { Antoniassi } \\
\text { (2008) }\end{array}$ & Este trabalho & \\
\hline & $\begin{array}{c}\rho_{\mathrm{e}} \\
\times 10^{23}\left(\mathrm{e} / \mathrm{cm}^{3}\right) \\
\end{array}$ & $\begin{array}{c}\rho_{\mathrm{e}} \\
\times 10^{23}\left(\mathrm{e} / \mathrm{cm}^{3}\right) \\
\end{array}$ & $\begin{array}{c}\rho_{\mathrm{e}}(\mathrm{DP}) \\
\times 10^{23}\left(\mathrm{e} / \mathrm{cm}^{3}\right) \\
\end{array}$ & $\begin{array}{c}\rho_{\mathrm{e}}(\mathrm{DP}) \\
\times 10^{23}\left(\mathrm{e} / \mathrm{cm}^{3}\right) \\
\end{array}$ & $\begin{array}{c}\rho_{\mathrm{e}}(\mathrm{DP}) \\
\times 10^{23}\left(\mathrm{e} / \mathrm{cm}^{3}\right) \\
\end{array}$ & $\begin{array}{c}\rho_{\mathrm{e}} \\
\times 10^{23}\left(\mathrm{e} / \mathrm{cm}^{3}\right) \\
\end{array}$ \\
\hline Adiposo & 3,10 & 3,46 & $3,24(0,14)$ & $3,21(0,14)$ & $3,24(0,16)$ & 3,18 \\
\hline Fibroglandular & NM & NM & NM & $\mathrm{NM}$ & $3,53(0,29)$ & 3,39 \\
\hline Fibroadenoma & NM & NM & $3,31(0,14)$ & $3,39(0,17)$ & $3,47(0,12)$ & NA \\
\hline Carcinoma & NM & 3,56 & $3,53(0,15)$ & $3,48(0,15)$ & $3,60(0,17)$ & NA \\
\hline
\end{tabular}

NM: não medido, NA: não apresentados

Verifica-se uma boa concordância (diferenças menores que 5\%) dos resultados deste trabalho (ANTONIASSI; CONCEIÇÃO; POLETTI, 2010), tanto com valores previamente obtidos usando uma fonte de radiação sincrotron (ANTONIASSI, 2008; ANTONIASSI; CONCEIÇÃO; POLETTI, 2012) como com os valores obtidos por Shrimpton (1981), Ryan et al. (2005) para todos os tipos de tecidos investigados e por Al-Bahari e Spyrou (1998) para os tecidos malignos, mas não para os tecidos adiposos, sendo o valor apresentado por eles significativamente maior que os nossos. Acreditamos que esta diferença possa ser explicada por uma superestimação sistemática dos valores apresentados por Al-Bahari e Spyrou (1998) devido ao processo de calibração bem como pela falta de correção por atenuação. Os valores médios obtidos neste trabalho, para os tecidos adiposos e fibroglandulares, também foram comparados com valores teóricos obtido através de dados de composição elementar dos tecidos apresentados por Woodard e White (1986) presentes no ICRU report 44 (ICRU, 1989), mostrando uma boa concordância com eles ( 2\% e 4\% respectivamente). 


\subsubsection{Comparações estatísticas entre as distribuições de densidades eletrônicas}

Análises estatísticas foram realizadas nas distribuições de valores de densidades eletrônicas obtidas experimentalmente a fim de quantificar as potencialidades do uso desta grandeza na diferenciação de amostras de acordo com sua classificação histológica.

Uma vez que nem todas as distribuições de densidades eletrônicas dos grupos de tecidos são normais ou simétricas, além de haver heterorocedasticidade (variâncias não homogêneas) entre elas, utilizou-se o teste de hipóteses não paramétrico de Kruskal-Wallis para as comparações estatísticas. Este teste verificou uma diferença estatisticamente significativa entre os grupos $\left(\chi^{2}=52,769, g l=3, p<0,001\right.$, onde $\chi^{2}$ dá a estatística do teste, $g l$ representa os graus de liberdade referente ao número $g$ de grupos, $g l=g$ - $l$, e $p$ o nível descritivo obtido).

Como complemento ao teste de Kruskal-Wallis, foi aplicado o teste de comparação múltipla de Dunn, que analisa simultaneamente pares de grupos, e permite revelar quais são diferentes entre si. Neste teste foram considerados significativamente diferentes grupos cujo resultado apresentasse um nível descritivo $p<0,1$. Os resultados deste teste podem ser observados na tabela 4.3 .

Tabela 4.3: Resultado do teste de comparação múltipla de Dunn.

\begin{tabular}{lcc}
\hline Comparação & Diferença & $p$ \\
\hline Adiposo $\times$ Fibroglandular & $\mathrm{S}$ & $p<0,01$ \\
Adiposo $\times$. Fibroadenoma & $\mathrm{S}$ & $p<0,01$ \\
Adiposo $\times$ Carcinoma & $\mathrm{S}$ & $p<0,01$ \\
Fibroglandular $\times$ Fibroadenoma & $\mathrm{NS}$ & $p>0,1$ \\
Fibroglandular $\times$ Carcinoma & $\mathrm{NS}$ & $p>0,1$ \\
Fibroadenoma $\times$ Carcinoma & $\mathrm{NS}$ & $p>0,1$ \\
\hline
\end{tabular}

(S: significativa $\mathrm{p}<0,1 ; \mathrm{NS}$ : não significativa $\mathrm{p}>0,1)$

Da tabela pode-se verificar que os tecidos normais adiposos se diferenciam de todos outros tipos de tecidos investigados. 


\subsection{NÚMERO ATÔMICO EFETIVO DOS TECIDOS MAMÁRIOS}

\subsubsection{Resultados da validação do método de determinação do número atômico efetivo usando a razão entre os espalhamentos Compton e Rayleigh}

A tabela 4.4 compara os valores de números atômicos efetivos determinados pelo o método proposto (espalhamento), usando as razões entre os espalhamentos Rayleigh e Compton e pelo método convencional de transmissão, baseado nas secções de choque totais (KUMAR; REDDY, 1997; SHIVARAMU, 2002). As incertezas experimentais apresentadas representam as incertezas estatísticas nos valores obtidos de $Z_{e f}$, as quais são a combinação das incertezas estatísticas associadas à contagem e aos procedimentos experimentais.

Tabela 4.4: Comparação entre os valores de $Z_{\text {ef }}$ determinados pelo método proposto (espalhamento) e pelo método convencional (transmissão) e respectiva exatidão relativa.

\begin{tabular}{lccc}
\hline $\begin{array}{l}\text { Material de } \\
\text { referência }\end{array}$ & $\begin{array}{c}Z_{e f} \\
\text { (Método de } \\
\text { espalhamento) }\end{array}$ & $\begin{array}{c}Z_{\text {ef }} \\
\text { (Método de } \\
\text { transmissão) }\end{array}$ & Diferença (\%) \\
\hline Água & $5,85 \pm 0,05$ & $5,90 \pm 0,09$ & $-0,9$ \\
Etanol & $5,26 \pm 0,06$ & $5,03 \pm 0,12$ & 4,4 \\
Isopropanol & $5,21 \pm 0,05$ & $4,96 \pm 0,08$ & 4,8 \\
Glicerol & $5,64 \pm 0,04$ & $5,65 \pm 0,07$ & $-0,2$ \\
Dimetilformamida & $5,36 \pm 0,05$ & $5,24 \pm 0,09$ & 2,2 \\
Acrilico & $5,53 \pm 0,05$ & $5,48 \pm 0,11$ & 0,9 \\
Nylon & $5,34 \pm 0,07$ & $5,09 \pm 0,11$ & 4,7 \\
\hline
\end{tabular}

Da tabela é observada uma boa concordância entre ambos os métodos (diferenças em torno de 5\%) mostrando que o método proposto pode ser usado, com a vantagem em relação ao método de transmissão de ser menos sensível a variações de espessuras na amostra e posicionamento (particularmente um problema em medidas de transmissão quando se usam tecidos biológicos), resultando em menores incertezas experimentais. 


\subsubsection{Resultados de número atômico efetivo dos tecidos mamários}

A figura 4.3 apresenta o box plot dos valores de número atômico efetivo $Z_{\text {ef }}$ obtidos para os diferentes tipos de tecidos estudados.

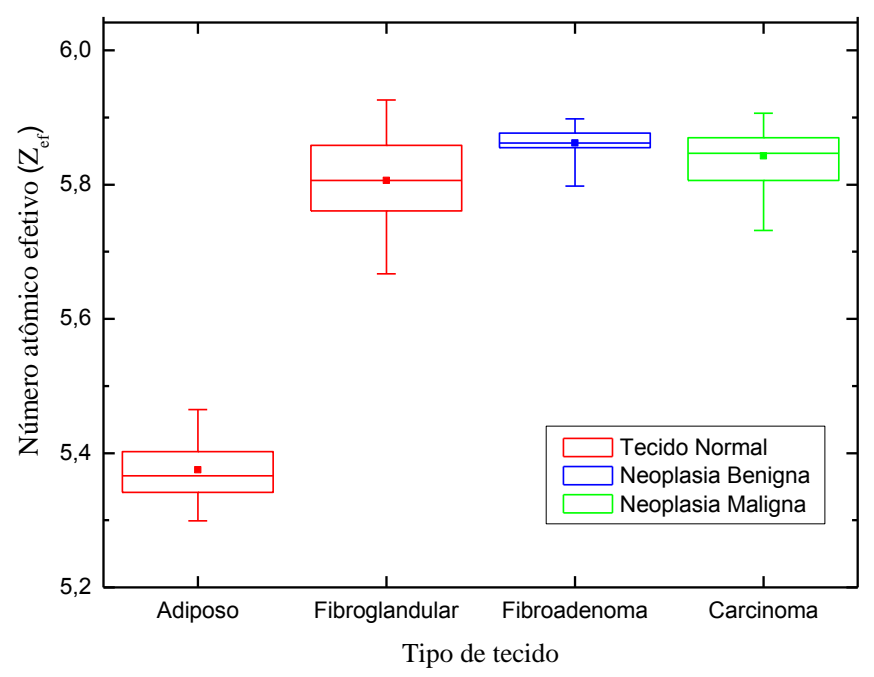

Figura 4.3: Box plot de $Z_{e f}$ dos diferentes tipos de tecidos

$\mathrm{Na}$ figura 4.3, semelhantemente aos resultados de densidades eletrônicas (figura 4.2), também são observadas distribuições com grande variação. As diferenças entre os tecidos adiposos e os demais são mais acentuadas e diferentemente dos resultados de densidades eletrônicas não apresentam sobreposição às distribuições de valores dos outros tipos de tecidos.

Os valores médios (M) de números atômicos efetivos de cada tipo de tecido e os intervalos $M+\sigma$ e $M-\sigma$ obtidos são mostrados na tabela 4.5:

Tabela 4.5: Intervalo dos valores médios de $Z_{e f}$ dos tecidos mamários

\begin{tabular}{|c|c|c|c|c|}
\hline & $\begin{array}{l}\text { Adiposo } \\
\quad\left(Z_{e f}\right)\end{array}$ & $\begin{array}{c}\text { Fibroglandular } \\
\qquad\left(Z_{e f}\right)\end{array}$ & $\begin{array}{l}\text { Fibroadenoma } \\
\qquad\left(Z_{e f}\right)\end{array}$ & $\begin{array}{c}\text { Carcinoma } \\
\left(Z_{e f}\right)\end{array}$ \\
\hline $\mathbf{M}-\sigma$ & 5,368 & 5,796 & 5,866 & 5,836 \\
\hline Média M & 5,375 & 5,806 & 5,862 & 5,843 \\
\hline$M+\sigma$ & 5,382 & 5,816 & 5,858 & 5,850 \\
\hline
\end{tabular}




\subsubsection{Comparação dos valores de número atômico efetivo obtidos com os presentes na literatura}

Os valores médios de $Z_{\text {ef }}$ obtidos neste trabalho (ANTONIASSI; CONCEIÇÃO; POLETTI, 2011), estão em boa concordância com valores teóricos de $Z_{e f}$ de tecidos adiposos $\left(Z_{e f}=5,2358\right)$ e fibroglandular $\left(Z_{e f}=5,7539\right)$ calculados usando o método convencional baseado nas secções de choque total (para15 keV) reportados por Shivaramu (2002), cujos valores são respectivamente $2,6 \%$ e $0,9 \%$ menores que os valores obtidos neste estudo. Valores experimentais de número atômico médio, definido como $\bar{Z}=\sum_{i} \omega_{i} Z_{i}$, reportados por Ryan e Farquharson (2010), embora não sendo a mesma grandeza física obtida neste estudo podem ser usados como uma fonte qualitativa de comparação. Seus resultados, em concordância com os resultados deste trabalho, também mostram que tecidos malignos apresentam maiores valores que os tecidos fibroglandulares. Não foram feitas comparações com os fibroadenomas uma vez que não há dados publicados sobre número atômico efetivo deste tipo de tecido na literatura. Entretanto, os resultados obtidos neste estudo mostram uma diferença de 8,4\% entre o número atômico efetivo dos tecidos adiposos e fibroadenomas.

\subsubsection{Comparações estatísticas entre as distribuições de número atômico efetivo}

Uma vez que as condições de normalidade e homocedasticidade das distribuições de $Z_{\text {ef }}$ foram confirmadas respectivamente pelos testes de Kolmogorov-Smirnov e de Bartlett foi utilizado o teste paramétrico de analise de variância (ANOVA) o qual apontou diferença estatisticamente significativa com $p<0,01$. Como complemento ao teste ANOVA, foi aplicado o teste de comparação múltipla de Bonferroni, com o intuito de comparar simultaneamente pares de grupos de tecidos e revelar quais são diferentes entre si. Foram considerados significativamente diferentes grupos que apresentaram no teste um nível descritivo $p<0,1$. Os resultados deste teste mostraram diferenças estatisticamente significativas entre os tecidos normais adiposos e todos outros tipos de tecidos $(p<0,01)$ e entre os tecidos fibroglandulares e fibroadenomas $(p<0,1)$. Os resultados do teste podem ser observados na tabela 4.6 : 
Tabela 4.6: Resultado do teste de comparação múltipla de Bonferroni.

\begin{tabular}{lcc}
\hline Comparação & Diferença & $p$ \\
\hline Adiposo $\times$ Fibroglandular & $\mathrm{S}$ & $p<0,01$ \\
Adiposo $\times$. Fibroadenoma & $\mathrm{S}$ & $p<0,01$ \\
Adiposo $\times$ Carcinoma & $\mathrm{S}$ & $p<0,01$ \\
Fibroglandular $\times$ Fibroadenoma & $\mathrm{NS}$ & $p<0,1$ \\
Fibroglandular $\times$ Carcinoma & $\mathrm{NS}$ & $p>0,1$ \\
Fibroadenoma $\times$ Carcinoma & $\mathrm{NS}$ & $p>0,1$ \\
\hline
\end{tabular}

(S: significativa $\mathrm{p}<0,1 ; \mathrm{NS}$ : não significativa $\mathrm{p}>0,1$ )

\subsection{LARGURA A MEIA ALTURA DAS CURVAS DE ESPALHAMENTO COMPTON DOS TECIDOS MAMÁRIOS}

\subsubsection{Espectro das medidas de espalhamento}

Na figura 4.4 são apresentados os espectros médios normalizados dos vários tipos de tecidos estudados.

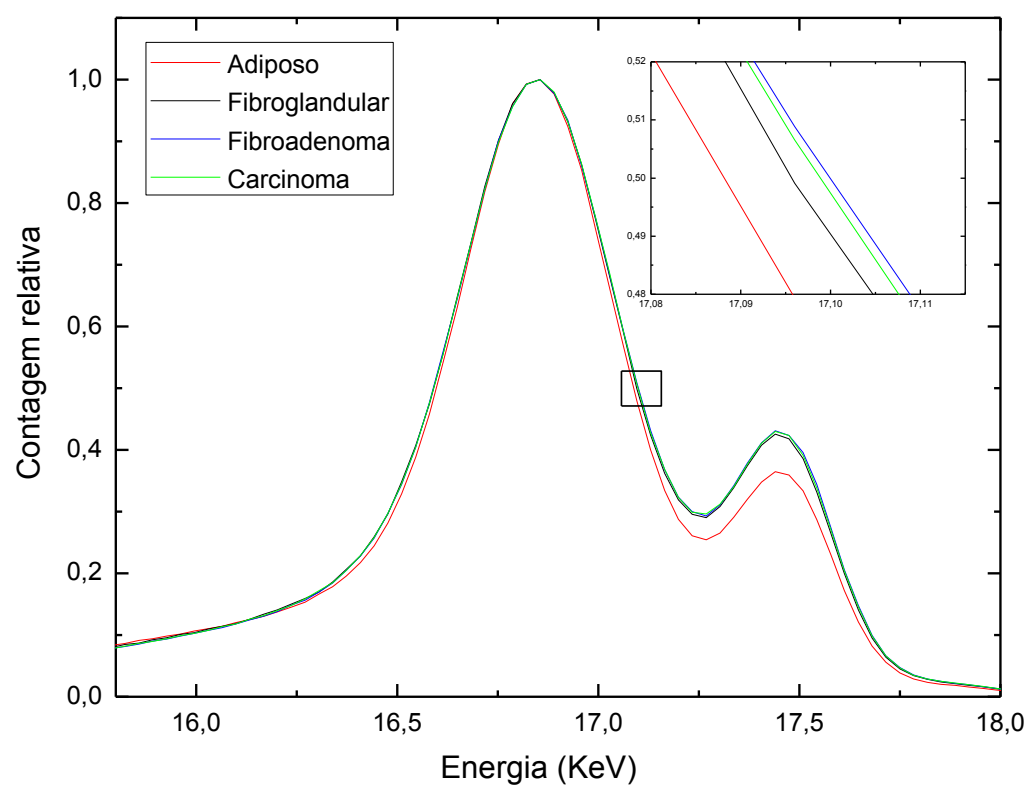

Figura 4.4: Espectro médio normalizado dos vários tipos de tecidos estudados.

O pico menor $(17,44 \mathrm{keV})$ de cada espectro corresponde a fótons espalhados elasticamente (Rayleigh) e sua largura é determinada pela resolução em energia do detector (CESAREO et al., 1992). O pico maior (16,86 keV) corresponde aos fótons que sofreram perda de energia devido ao espalhamento inelástico (Compton) nas amostras de tecidos 
mamários. Como pode ser observado na figura 4.4 existem diferenças entre as larguras dos picos inelásticos para os diferentes topos de tecidos investigados.

Com o objetivo de verificar os resultados de espectros obtidos, foram calculadas as secções de choque diferenciais duplas (RAO et al., 2004), mostradas na figura 4.5, usando os dados de composição de tecidos obtidos de Poletti, Gonçalves e Mazzaro (2002b) para os tecidos adiposos $(\mathrm{H} \mathrm{12,4 \% ,C} 76,5 \%, \mathrm{~N} 0,4 \%$ e $\mathrm{O} 10,7 \%)$ e fibroglandulares $(\mathrm{H} \mathrm{9,3 \% ,} \mathrm{C}$ $18,4 \%, \mathrm{~N} 4,4 \%$ e $\mathrm{O}$ 67,9\%) e de Poletti, Gonçalves e Mazzaro (2002a) para os carcinomas (H 9,9\%, C 19,4\%, N 4,7\% e O 66,0\%, média das composições).

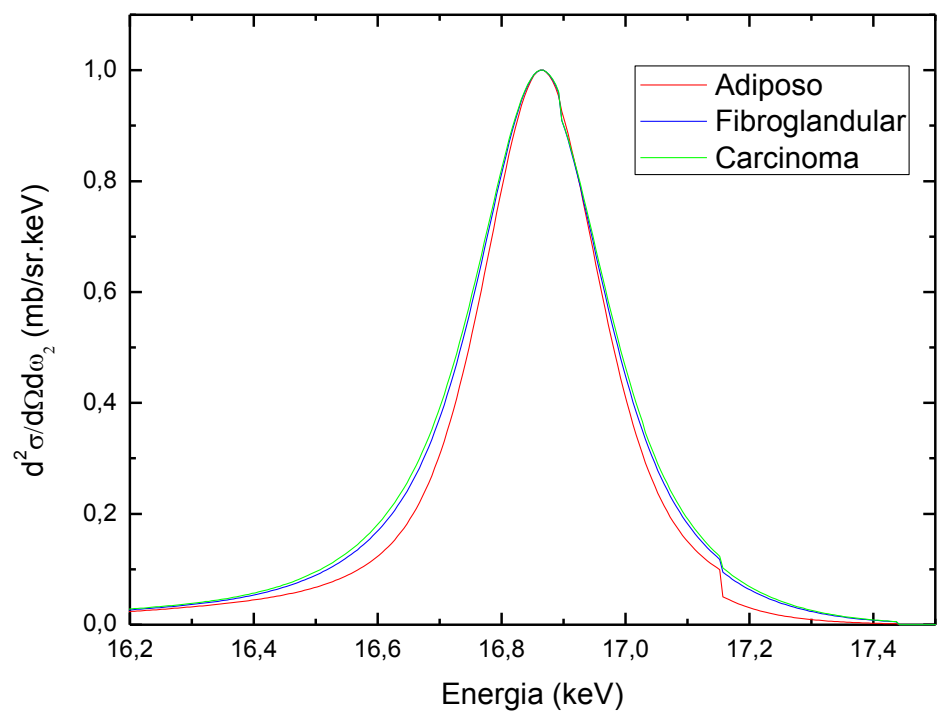

Figura 4.5: Secções de choques diferenciais duplas dos tecidos mamários.

Na figura 4.5 é possível observar que os tecidos adiposos apresentam a menor LMA enquanto os tecidos fibroglandulares e carcinomas apresentam valores similares, em conformidade com os espectros experimentais da figura 4.4. Além disso, os cálculos teóricos das secções de choque diferenciais duplas preveem uma diferença absoluta entre as LMA dos tecidos adiposos e demais tecidos (fibroglandulares e neoplásicos) da ordem de $0,026 \mathrm{keV}$, estando em boa concordância com os valores obtidos experimentalmente (em torno de $0,02 \mathrm{keV})$. 


\subsubsection{Resultados de $L M A$ dos tecidos mamários}

A figura 4.6 apresenta o box plot dos valores de LMA obtidos através dos espectros de espalhamento dos diferentes tipos de tecidos mamários.

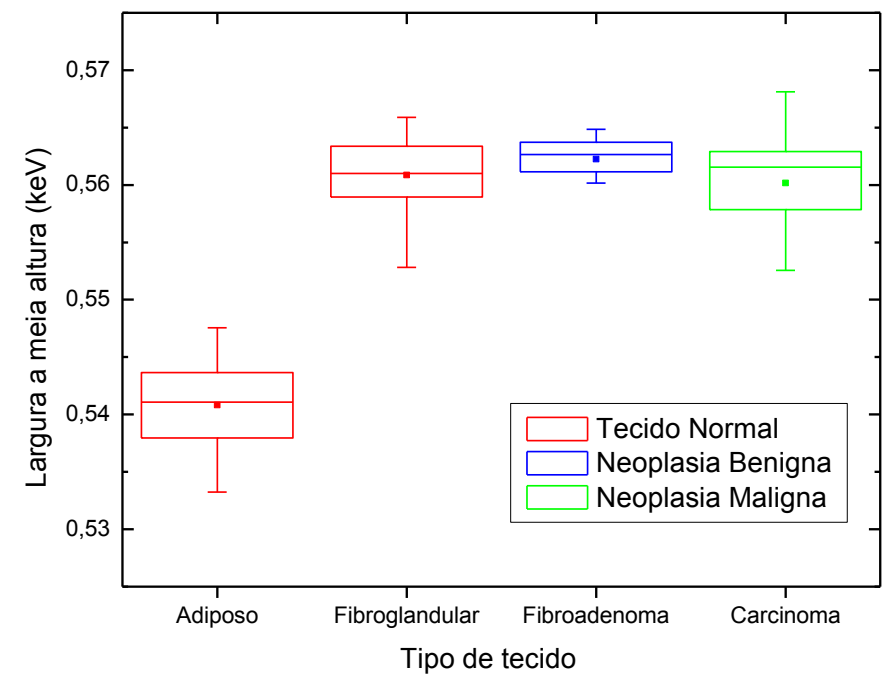

Figura 4.6: Box plot das LMA dos diferentes tipos de tecidos

Da figura 4.6 podem-se observar semelhanças entre as distribuições de $L M A$ e $Z_{e f}$ (figura 4.3). De fato, este comportamento é esperado, pois ambas as grandezas estão associadas a informações relacionadas às composições dos tecidos.

\subsubsection{Comparações estatísticas das distribuições de $L M A$}

Conforme explicado nos fundamentos teóricos deste trabalho (subseção 2.2.3.2, figura 2.7b) é esperado um aumento da largura da seção de choque diferencial dupla (curva de espalhamento Compton) com o aumento do número atômico do material espalhador. Desta forma é esperado que os valores de $L M A$ estejam associados aos valores de $Z_{e f}$. Para verificar o grau de correlação entre essas duas grandezas os valores experimentais de $L M A$ e de $Z_{e f}$, dos tecidos foram comparados, como mostrado na figura 4.7, que apresenta os valores de $L M A$ versus o $Z_{e f}$ das amostras. 


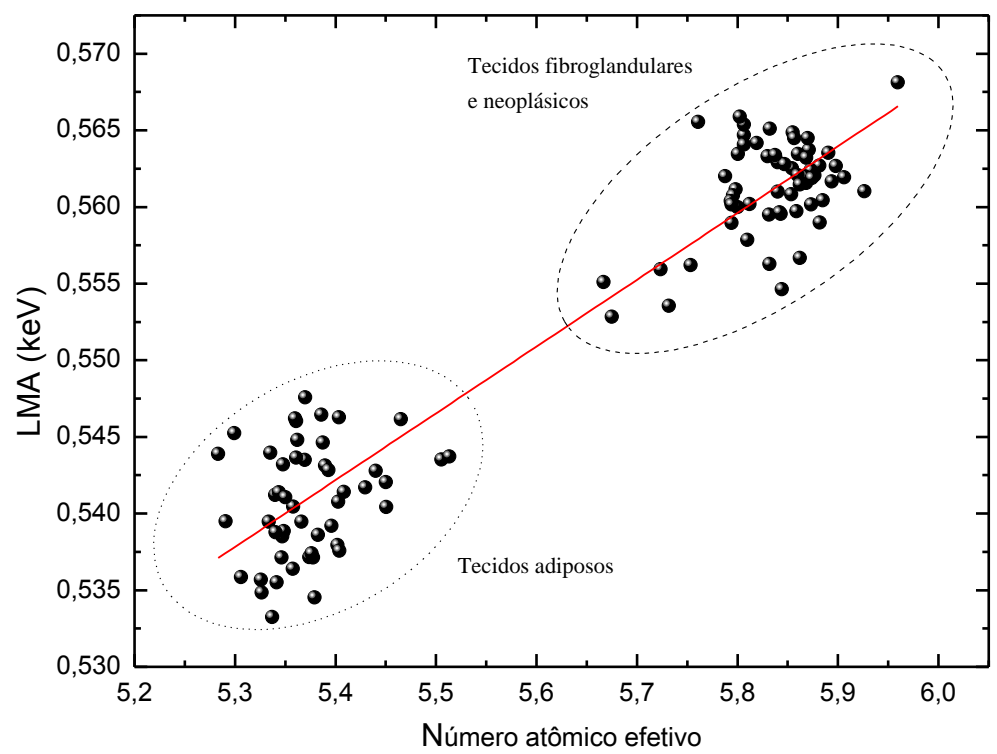

Figura 4.7: Distribuição das $L M A$ versus $Z_{e f}$ das amostras usadas no teste de correlação.

O teste de correlação de Pearson foi aplicado e revelou uma correlação significante entre as duas grandezas $(r=0.954 ; p<0.0001)$, evidenciando que a técnica baseada na $L M A$ também pode ser usada para obter informação sobre a composição dos tecidos mamários apresentando resultados análogos aos obtidos com o $Z_{e f}$.

Para verificação das diferenças de $L M A$ entre os diferentes tipos de tecidos mamários foi utilizado o teste paramétrico de análise de variância (ANOVA) o qual apontou diferença estatisticamente significativa com $p<0,01$. O teste post hoc de Bonferroni, foi usado para comparar simultaneamente pares de grupos, sendo considerados estatisticamente diferentes os grupos que apresentassem no teste um nível descritivo $p<0,1$. Os resultados deste teste mostraram diferenças estatisticamente significativas entre os tecidos normais adiposos e todos outros tipos de tecidos $(p<0,01)$, enquanto as outras comparações não apresentaram diferenças estatisticamente significativas. 


\subsection{RELAÇÕES ENTRE OS RESULTADOS DE $\rho_{E}, Z_{E F}$ E LMA OBTIDOS E HISTOLOGIA DOS TECIDOS MAMÁRIOS}

Dos resultados apresentados $\left(\rho_{e}, Z_{e f}\right.$ e LMA), tem-se que os tecidos normais adiposos apresentam menores valores quando comparados aos outros tipos de tecidos investigados, não apresentando sobreposição para os valores de $Z_{e f}$ e $L M A$. É bem sabido que os tecidos normais adiposos são compostos essencialmente por células especializadas em armazenar lipídeos, chamadas de adipócitos, ricas em carbono $(Z=6)$ de baixo número atômico e baixa densidade, enquanto os tecidos normais fibroglandulares e neoplásicos (carcinomas e fibroadenomas), de natureza conjuntiva (ricos em fibras de colágeno) ou epitelial, apresentam maior composição em oxigênio $(Z=8)$ de maior número atômico e densidade. Estas diferenças de composição dos tecidos mamários pode ser observadas na tabela 4.7 que compara as porcentagens em massa de carbono e oxigênio obtidas por Hammerstein et al. (1979), Poletti, Gonçalves e Mazzaro (2002a; 2002b) e Woodard and White (1986). Embora não haja valores publicados na literatura de composição de fibroadenomas, é possível inferir dos resultados de $Z_{\text {ef }}$ e $L M A$ obtidos neste trabalho que sua composição seja similar à dos tecidos fiboglandulares ou carcinomas.

Tabela 4.7: Composição química (porcentagem em massa) de carbono e oxigênio de tecidos mamários na literatura

\begin{tabular}{|c|c|c|c|c|c|c|}
\hline & \multicolumn{2}{|c|}{ Hammerstein et al. (1970) } & \multicolumn{2}{|c|}{ Poletti et al. $\left(2002^{a, b}\right)$} & \multicolumn{2}{|c|}{ Woodard and White (1986) } \\
\hline $\begin{array}{l}\text { Elemento } \\
\text { Químico }\end{array}$ & $\begin{array}{c}\mathrm{C}(\mathrm{Z}=6) \\
(\mathrm{massa} \%)\end{array}$ & $\begin{array}{c}\mathrm{O}(\mathrm{Z}=8) \\
(\mathrm{massa} \%)\end{array}$ & $\begin{array}{c}\mathrm{C}(\mathrm{Z}=6) \\
(\mathrm{massa} \%)\end{array}$ & $\begin{array}{c}\mathrm{O}(\mathrm{Z}=8) \\
(\mathrm{massa} \%)\end{array}$ & $\begin{array}{c}\mathrm{C}(\mathrm{Z}=6) \\
(\mathrm{massa} \%)\end{array}$ & $\begin{array}{c}\mathrm{O}(\mathrm{Z}=8) \\
(\mathrm{massa} \%)\end{array}$ \\
\hline Adiposo & 61,9 & 25,1 & $76,5 \pm 1,1^{b}$ & $\pm 1,3^{\mathrm{b}}$ & 59,8 & 27,8 \\
\hline Fibroglandular & 18,4 & 67,7 & $18,4 \pm 0,9^{b}$ & $67,9 \pm 2,0^{\mathrm{b}}$ & 33,2 & 52,7 \\
\hline Carcinoma & NM & NM & $19,36^{\mathrm{a}}$ & $65,98^{\mathrm{a}}$ & NM & NM \\
\hline
\end{tabular}

${ }^{\text {a }}$ Porcentagens médias obtidas de Poletti et al. (2002a)

${ }^{b}$ Porcentagens obtidas por Poletti et al. (2002b)

Estes resultados obtidos estão em boa concordância com as análises visuais das lâminas histológicas que apontaram a tendência de tecidos com elevada composição conjuntiva fibrosa e epitelial apresentarem maiores valores das grandezas $\left(\rho_{e}, Z_{e f}\right.$ e $\left.L M A\right)$ quando comparados com tecidos com maior fração adiposa em sua composição. No gráfico da figura 4.8 é esquematizado o comportamento histológico dos tecidos e sua relação com a distribuição de valores de $L M A$ e $Z_{e f}$. 


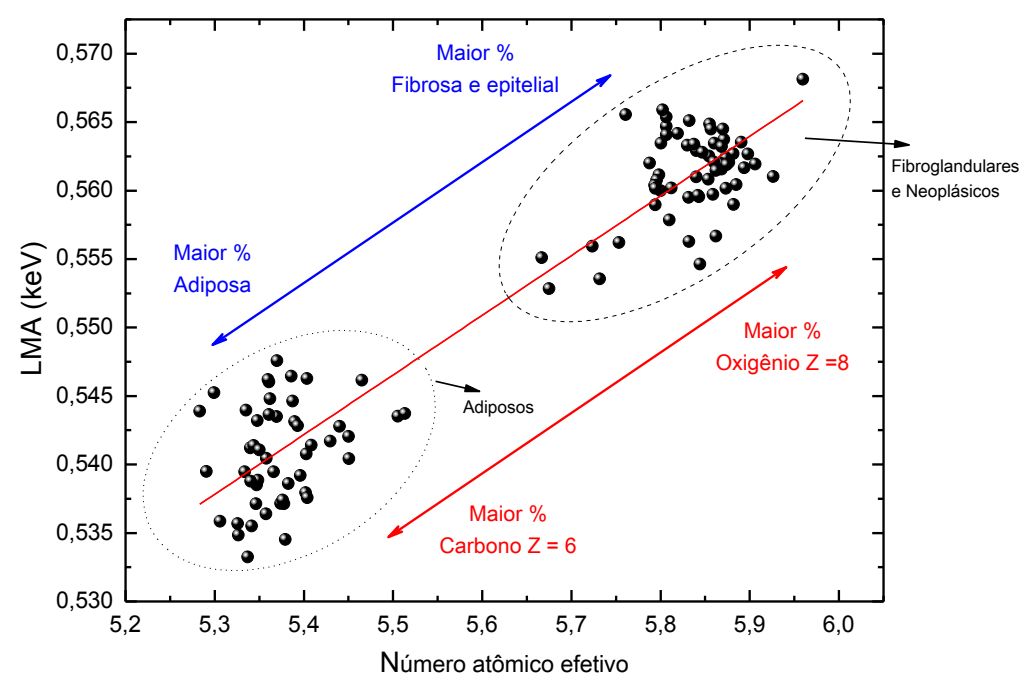

Figura 4.8: Histologia e composição dos tecidos comparadas com os valores obtidos de $L M A$ e $Z_{e f}$.

Do ponto de vista prático as técnicas estudadas se mostram sensíveis a diferenças entre a composição de tecidos adiposos (elevada composição de carbono, Z=6) e tecidos fibroglandulares/neoplásicos (elevada composição de oxigênio, Z=8). Estes resultados são particularmente importantes, pois variações na fração adiposo/fibroglandular ou a presença de uma neoplasia em uma região da mama (como, por exemplo, um carcinoma envolto em uma região composta por uma mistura de tecido adiposo) poderiam ser detectadas pelos métodos estudados.

Além dos fatores discutidos, também podem contribuir para os resultados obtidos outros tipos de fatores, associados ao metabolismo do tecido, cuja influência, no entanto, é difícil de ser quantificada, uma vez que diferentes processos estão relacionados à carcinogenese, como a proliferação celular e crescimento, tipo de células e tecidos, grau de malignidade, etc (ROSEN, 2009). 


\subsection{IMAGENS POR ESPALHAMENTO COMPTON}

\subsubsection{Influência da energia do feixe na imagem}

$\mathrm{Na}$ figura 4.9 são mostradas as imagens de espalhamento e os valores de coeficientes lineares de espalhamento inelástico $\left(\mu_{i n}\right)$ ao longo da linha central da imagem, para diferentes energias do feixe incidente.
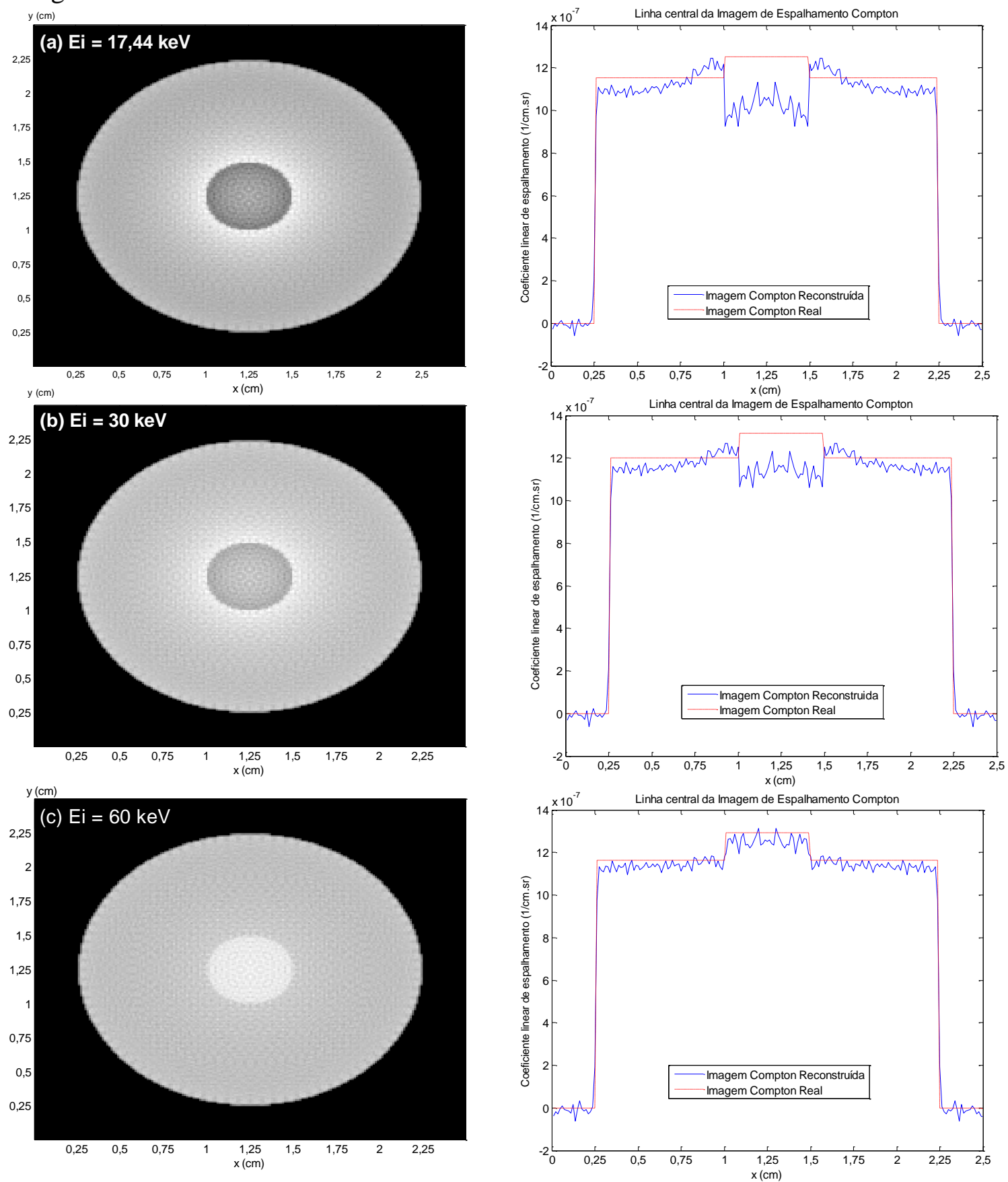

Figura 4.9: Imagens de espalhamento e valores de $\mu_{\text {in }}$, reais e reconstruídos, ao longo da linha central para $D=2 \mathrm{~cm}, d=0,5 \mathrm{~cm}$, tecido 1: adiposo, tecido 2: carcinoma, $n=200, m=180$, filtro: Shepp-

Logan e diferentes energias incidentes $E_{i}$ (a) $17,44 \mathrm{keV}$, (b) $30 \mathrm{keV}$ e (c) $60 \mathrm{keV}$. 
Observa-se nas figuras 4.9 que quanto maior a energia incidente $\left(E_{i}\right)$ mais os valores das imagens reconstruídas se aproximam dos valores reais, o que pode ser verificado através da figura 4.10 que compara as diferenças percentuais entre os dos valores de $\mu_{\text {in }}$ reais e obtidos pela reconstrução tomográfica ao longo das linhas centrais em função da energia incidente.

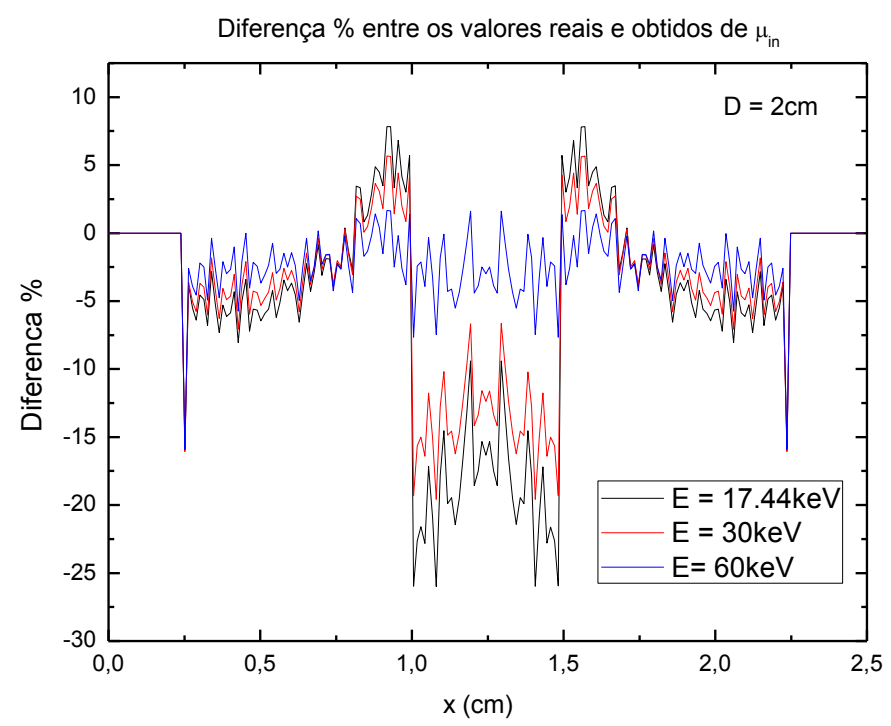

Figura 4.10: Diferenças $\%$ entre os valores de $\mu_{\text {in }}$ reais e obtido pela reconstrução tomográfica para diferentes energias incidentes.

Este comportamento se deve ao fato de que quanto maior a energia incidente menor é o coeficiente de atenuação linear dos tecidos e, portanto, menor será a atenuação da radiação no interior da amostra (BRUNETTI; GOLOSIO, 2001) fazendo com que a aproximação usada para correção de atenuação (equações 3.18 e 3.25) seja válida. Para o caso das imagens obtidas na figura 4.9, verificam-se resultados satisfatórios para energias acima de $60 \mathrm{keV}$.

\subsubsection{Influência da espessura e composição do objeto na imagem}

\subsubsection{Dimensão do objeto}

A figura 4.11 apresenta as imagens de espalhamento e os valores de coeficientes lineares de espalhamento inelástico ao longo da linha central da imagem, obtidos para diferentes dimensões $D$ do objeto. 

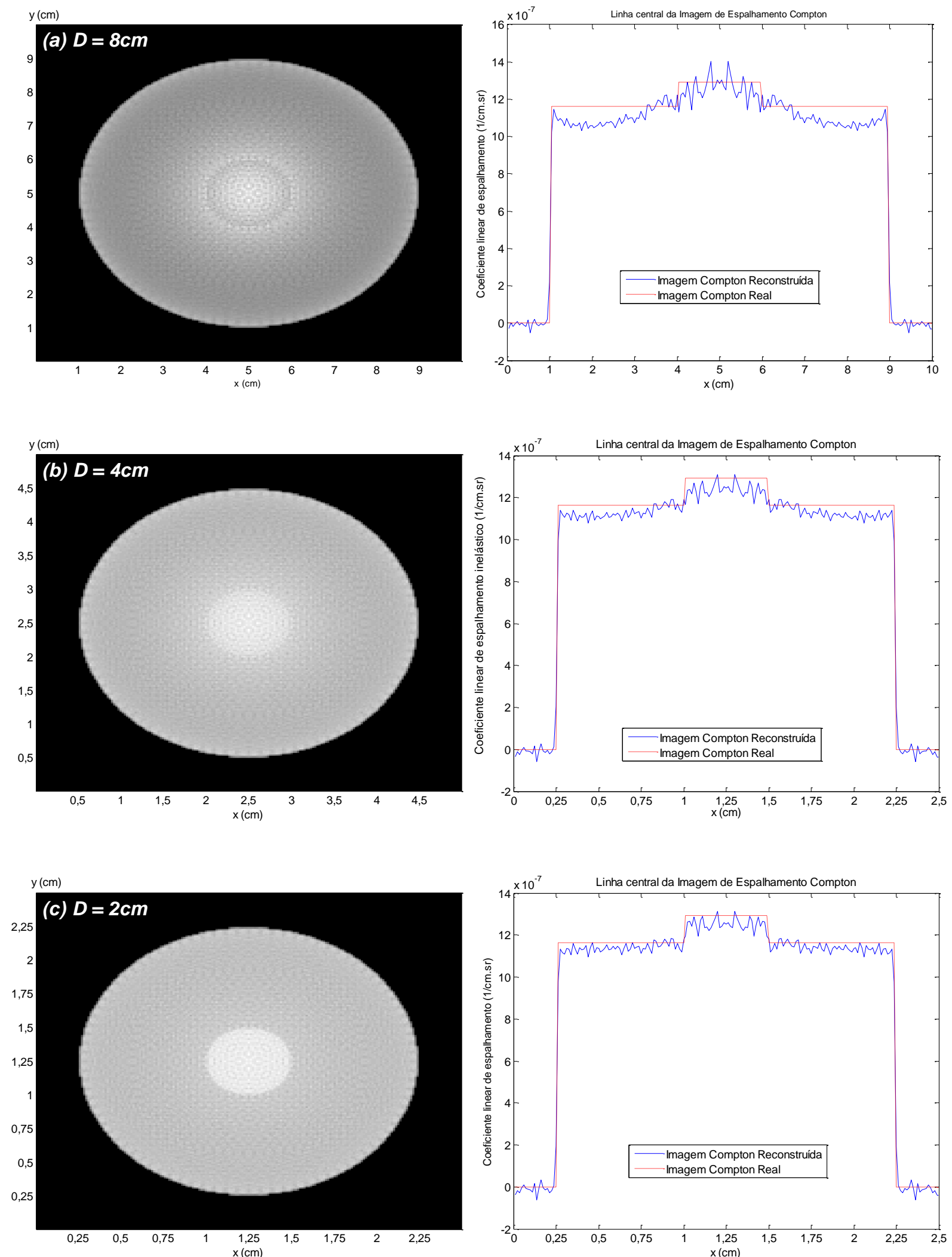

Figura 4.11: Imagens de espalhamento e valores de $\mu_{\text {in }}$, reais e reconstruídos, ao longo da linha central para $E_{i}=60 \mathrm{keV}$, tecido 1: adiposo, tecido 2: carcinoma, $n=200, m=180$, filtro: SheppLogan e diferentes diâmetro da amostra D (a) $8 \mathrm{~cm}$, (b) $4 \mathrm{~cm}$ e (c) $2 \mathrm{~cm}$. 
Observa-se na figura 4.11 que quanto maior a dimensão da amostra (diâmetro D) mais os valores das imagens reconstruídas se diferenciam dos valores reais, o que pode ser verificado através da figura 4.12 que compara as diferenças percentuais entre os valores de $\mu_{\text {in }}$ reais e obtidos pela reconstrução da imagem ao longo das linhas centrais em função do diâmetro d da amostra.

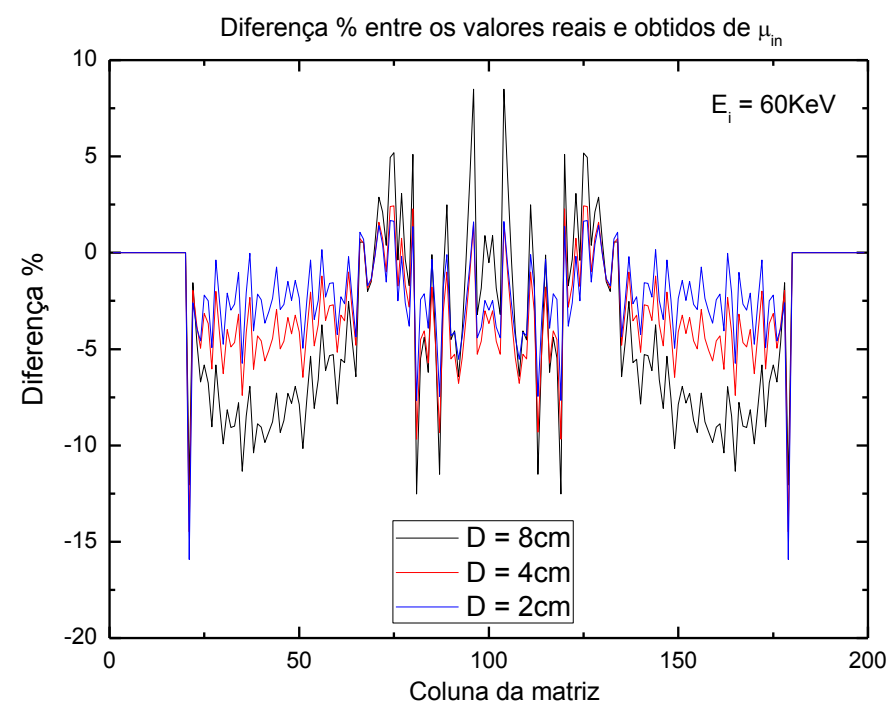

Figura 4.12: Diferenças \% entre os valores de $\mu_{\text {in }}$ reais e reconstruídos para diferentes diâmetro de amostra.

Este comportamento se deve ao fato de que quanto maior o diâmetro da amostra maior será a atenuação da radiação em seu interior e menos exata será a aproximação usada para correção de atenuação (equações 3.18 e 3.25 ).

\subsubsection{Glandularidade do tecido}

O contraste (diferença entre os valores de $\mu_{\text {in }}$ nas regiões de tecido tecidos 1 e 2 ) nas imagens reconstruídas foi verificado em função da glandularidade do tecido 1 (composto por uma mistura de tecido glandular e adiposo) que envolve o tecido 2 (carcinoma). A figura 4.13 apresenta as reconstruções tomográficas e os valores de coeficientes lineares de espalhamento inelástico obtidos ao longo da linha central para diferentes glandularidades $(g)$ : 

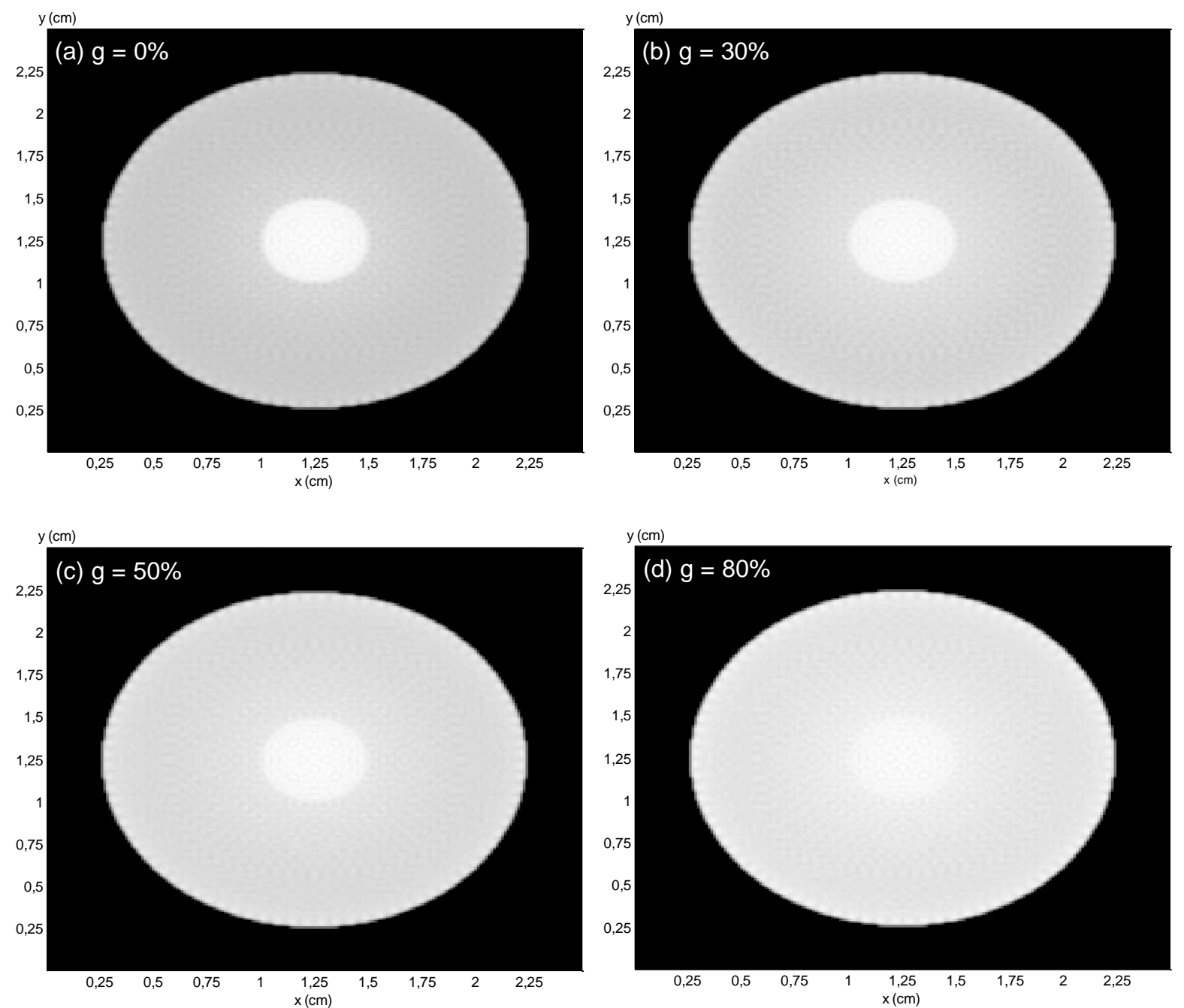

Figura 4.13: Imagens de espalhamento para $E_{i}=60 \mathrm{keV}, \mathrm{D}=2 \mathrm{~cm}, \mathrm{~d}=0,5 \mathrm{~cm}$, tecido 1 : adiposo/fibroglandular, tecido 2: carcinoma, $n=200, m=180$, filtro: Shepp-Logan e diferentes glandularidades do tecido 1 (a) $0 \%$, (b) $30 \%$, (c) $50 \%$ e (d) $80 \%$

Das figuras é possível observar que com o aumento da glandularidade do tecido 1 diminui-se o contraste entre as regiões de tecidos 1 e 2 . Esta redução ocorre devido à similaridade entre o coeficiente de atenuação linear e densidade eletrônica dos tecidos fibroglandular e carcinoma. O resultado obtido é semelhante ao observado na mamografia onde o contraste é menor em mamas mais densas (de maiores glandularidades), caso em que a detecção de neoplasias é dificultada. 


\subsubsection{Influência das condições geométricas de irradiação e detecção}

\subsubsection{Tamanho do feixe de irradiação}

A figura 4.14 apresenta as reconstruções tomográficas de espalhamento obtidas para diferentes larguras de feixe $b$. Não foi adicionado ruído às projeções nem considerados os efeitos da atenuação da amostra, a fim de se avaliar apenas o efeito da largura do feixe na resolução da imagem.
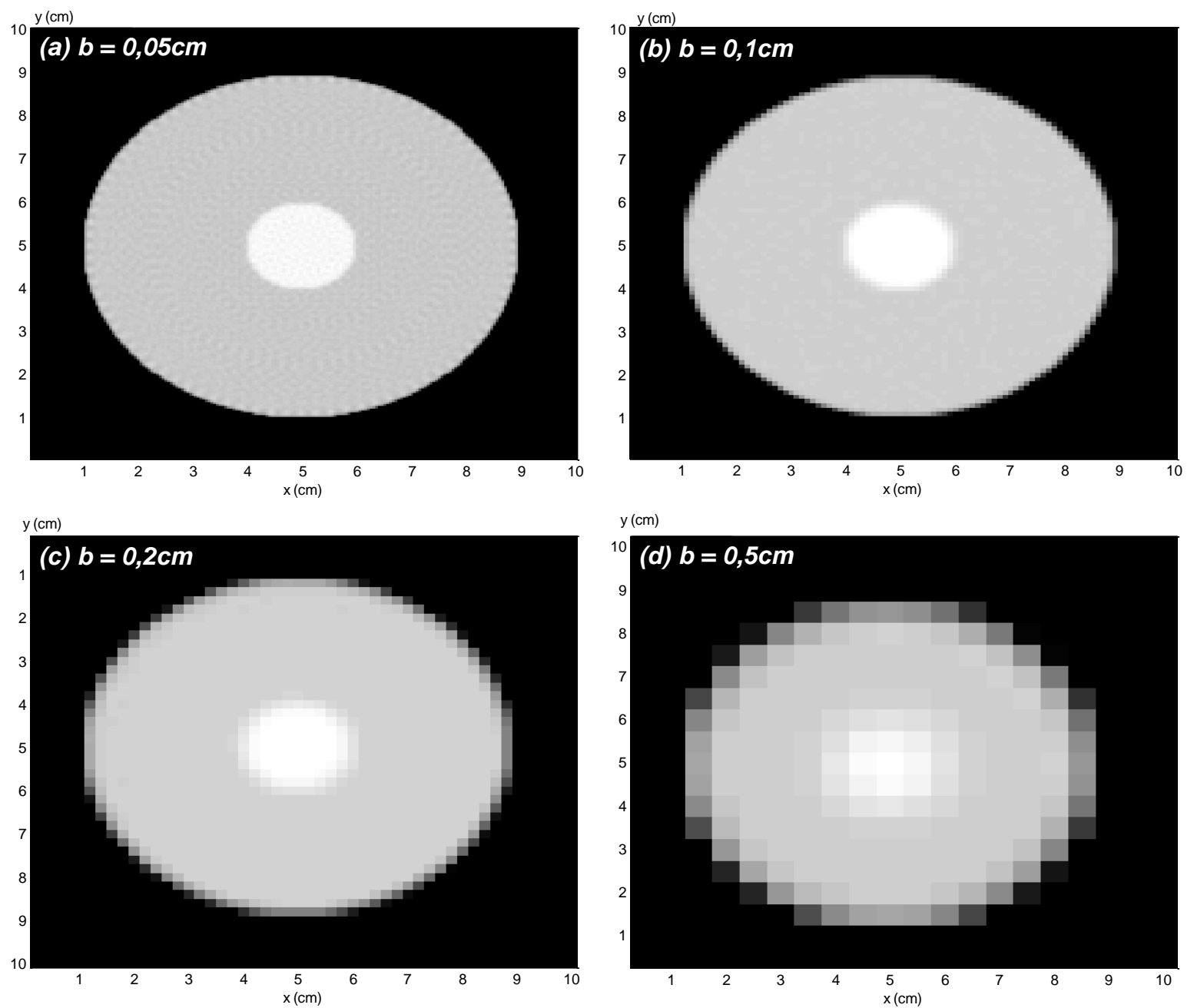

Figura 4.14: Imagens de espalhamento para $E_{i}=60 \mathrm{keV}, D=8 \mathrm{~cm}, d=2 \mathrm{~cm}$, tecido 1: adiposo, tecido 2: carcinoma, $n=200, m=180$, filtro: Shepp-Logan e diferentes larguras do feixe $b$ (a) $0,05 \mathrm{~cm}$ (b) $0,1 \mathrm{~cm}$ (c) $0,2 \mathrm{~cm}$ e (d) $0,5 \mathrm{~cm}$.

A partir da figura é possível observar o efeito da largura do feixe na resolução espacial das imagens. Quanto maior a largura do feixe menor é a resolução espacial da técnica e menor a dimensão $n$ ' $\times n$ ' imagem reconstruída. Assim sendo a largura do feixe é um fator que determinará as mínimas dimensões das estruturas a serem resolvidas (detectadas) pela técnica. 


\subsubsection{Ruído estatístico nas contagens}

Na figura 4.15 são mostradas as imagens de espalhamento obtidas para diferentes níveis de ruído devido às flutuações estatísticas nas contagens de fótons do detector.
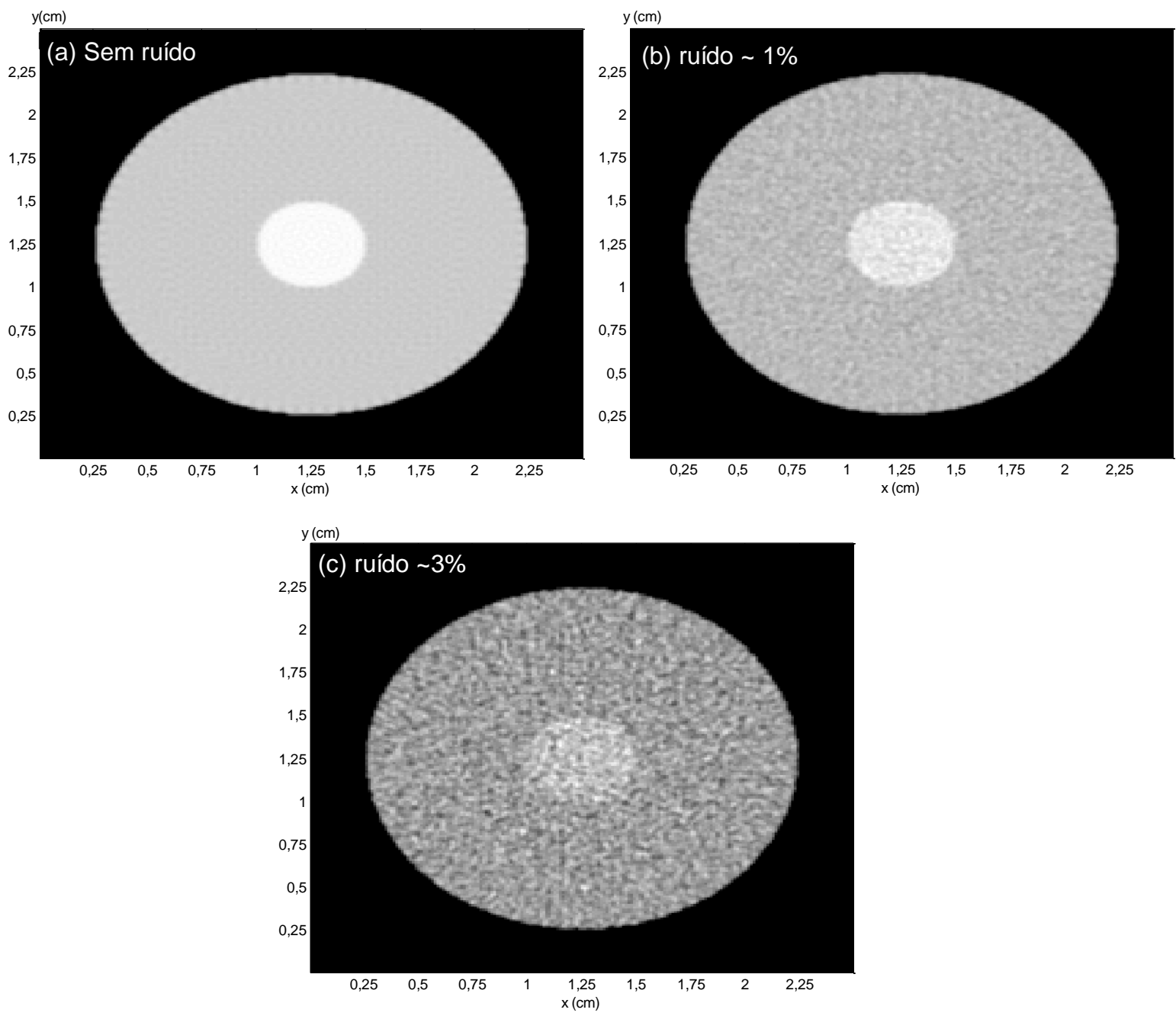

Figura 4.15: Imagens de espalhamento para $E_{i}=60 \mathrm{keV}, D=2 \mathrm{~cm}, d=0,5 \mathrm{~cm}$, tecido 1: adiposo, tecido 2: carcinoma, $n=200, m=180$, filtro: Hamming e diferentes níveis de ruído (a) sem ruído (b) ruído $\sim 1 \%$ (c) ruído $\sim 3 \%$

O ruído nas imagens depende do número de fótons que são detectados $\left(N_{d e t}\right)$ pelo detector de espalhamento ( ruído $\propto 1 / \sqrt{N_{d e t}}$ ). Observa-se na figura 4.15 que o efeito do ruído é significante, embora a qualidade das reconstruções ainda seja aceitável para os níveis de ruídos apresentados. 


\section{CONCLUSÕES E PERSPECTIVAS}

\subsection{SOBRE AS METODOLOGIAS DE OBTENÇÃO DE $\rho_{e}, Z_{e f}$ E $L M A$}

A verificação das metodologias de medidas e tratamento dos dados para determinação das densidades eletrônicas foi feita comparando os valores de $\rho_{e}$ obtidos para alguns materiais de referência com os valores reais calculados. As diferenças obtidas foram menores que $4 \%$. A verificação da metodologia de determinação do número atômico efetivo foi feita comparando-se valores de $Z_{\text {ef }}$ de diferentes compostos determinados a partir das razões (obtidas experimentalmente) entre os espalhamentos Rayleigh e Compton e valores de $Z_{e f}$ obtidos experimentalmente através de método convencional baseado no coeficiente de atenuação dos compostos. As diferenças encontradas, neste caso, foram menores que $5 \%$.

As metodologias experimentais para determinação de densidades eletrônicas $\left(\rho_{e}\right)$, largura a meia altura $(L M A)$ e número atômico efetivo $\left(Z_{e f}\right)$ geraram incertezas estimadas entre $4-6 \%$.

Os resultados de densidades eletrônicas e número atômico efetivo foram comparados com resultados previamente publicados na literatura. As diferenças encontradas em geral foram menores que $5 \%$ e $3 \%$ respectivamente.

\subsection{DOS RESULTADOS DE $P_{E}, Z_{E F}$ E $L M A$ OBTIDOS E POTENCIALIDADES DAS TÉCNICAS}

Os valores de densidade eletrônica $\left(\rho_{e}\right)$ e número atômico efetivo $\left(Z_{e f}\right)$ obtidos neste trabalho apresentam-se como uma boa fonte de dados sobre tecidos mamários, pois são resultados de procedimentos adequados de medidas e provêm da análise de um número grande de amostras, quando comparados à amostragem dos trabalhos existentes na literatura, apresentando, ainda, resultados experimentais inéditos de $\rho_{e}$ para tecidos normais fibroglandulares e de $Z_{e f}$ para fibroadenomas.

Os valores de LMA permitem obter informações sobre a composição dos tecidos apresentando correlação com os valores de número atômico efetivo indicando a possibilidade de uso destas grandezas de forma análoga. 
As distribuições de $\rho_{e}, L M A e Z_{e f}$ para um mesmo grupo de tecidos mostram que existe variabilidade, associadas a parâmetros externos (diferenças interindividuais) e parâmetros particulares associados ao tipo de tecido.

Os resultados também mostram que existem diferenças de $\rho_{\mathrm{e}}, Z_{e f}$ e $L M A$ entre os grupos de tecidos as quais estão associadas à composição e à histologia dos tecidos investigados.

Os resultados analisados mostram que as $\rho_{e}, Z_{e f}$ e $L M A$ são parâmetros úteis na caracterização de tecidos mamários. Assim sendo, as técnicas exploradas neste trabalho apresentam-se como uma promissora ferramenta no estudo e no diagnóstico de neoplasias mamárias, fornecendo informações complementares às técnicas de transmissão, que podem auxiliar o diagnóstico desse tipo de doença.

\subsection{DOS RESULTADOS DAS SIMULAÇÕES DE IMAGENS POR ESPALHAMENTO COMPTON}

O estudo da técnica de espalhamento Compton permitiu avaliar a qualidade das imagens obtidas em relação à energia incidente, ao objeto (dimensão e glandularidade do tecido que o compõe) e aos sistemas de irradiação e detecção (largura do feixe e ruído).

$\mathrm{O}$ estudo dos efeitos energia incidente nas imagens foi feito comparando-se as imagens e os valores de coeficientes lineares de espalhamento inelástico (reais e obtidos pela reconstrução) ao longo da linha central da imagem para diferentes energias incidentes. Os resultados evidenciaram o aumento da diferença entre os valores reais e simulados com a diminuição da energia incidente devido ao aumento dos efeitos da atenuação na amostra.

O estudo da influência do objeto nas imagens obtidas foi feito em função de sua dimensão e da glandularidade do tecido que o compõe. Os resultados mostraram o aumento da diferença entre os valores reais e obtidos pela reconstrução com o aumento da dimensão do objeto devido ao aumento dos efeitos da atenuação na amostra. O estudo das imagens de amostras formadas por duas regiões de tecidos (uma composta por uma mistura de tecido fibroglandular e adiposo e outra de carcinoma) evidenciou a diminuição do contraste obtido com o aumento da glandularidade da região composta pela mistura de tecidos fibroglandular e adiposo. 
Por fim os resultados mostraram a dependência da qualidade das imagens obtidas com a largura do feixe (que determina a resolução espacial) e com o ruído estatístico nas contagens de fótons no detector.

\subsection{PERSPECTIVAS}

Dos resultados obtidos neste trabalho abrem-se as seguintes perspectivas:

- Novos estudos sobre a sensibilidade em diferentes momentos transferidos das curvas de calibração envolvidas no método de determinação de $Z_{e f}$ podem ser desenvolvidos como o objetivo de otimização da técnica.

- Medir com melhor resolução em energia o espectro de espalhamento a fim de obter mais informações contidas na forma do espectro (pequenas diferenças de composição, descontinuidades no espectro).

- Estudar novas técnicas de imagens explorando a razão entre as intensidades de espalhamentos Rayleigh e Compton (número atômico efetivo) e a forma do espectro de espalhamento Compton (LMA). 


\section{REFERÊNCIAS BIBLIOGRÁFICAS}

AL-BAHRI, J. S.; SPYROU, N. M. Electron density of normal and pathological breast tissues using a compton scattering technique. Applied Radiation and Isotopes, v. 49, p. 1677-1684, 1998.

ANTONIASSI, M. Determinação das densidades eletrônicas de neoplasias mamárias utilizando o espalhamento Compton de raios X. Dissertação (Mestrado). Faculdade de Filosofia Ciências e Letras de Ribeirão Preto, Universidade de São Paulo, Ribeirão Preto, 2008.

ANTONIASSI, M.; CONCEIÇÃO, A. L. C.; POLETTI, M. E. Characterization of breast tissues using Compton scattering. Nuclear Instruments and Methods in Physics Research Section A: Accelerators, Spectrometers, Detectors and Associated Equipment, v. 619, n. 1-3, p. 375-378, 2010.

Study of effective atomic number of breast tissues determined using the elastic to inelastic scattering ratio. Nuclear Instruments and Methods in Physics Research Section A: Accelerators, Spectrometers, Detectors and Associated Equipment., v. 652, n. 1, p. 739-743, 2011.

Study of electron densities of normal and neoplastic human breast tissues by Compton scattering using synchrotron radiation. Applied Radiation and Isotopes, 2012. DOI: 10.1016/j.apradiso.2012.01.001.

ATTIX, F. H. Introduction to Radiological Physics and Radiation Dosimetry. Madison: John Wiley \& Sons, 1986.

BARROS, A. C. S. D. Doenças benignas da mama. In: BRASILEIRO FILHO, G. (Ed.). Bogliolo. 3ed. Rio de Janeiro: Guanabara Koogan, 2004.

BERGER, M. J. et al. XCOM: Photon Cross Sections Database,National Institute of Standards and Technology (NIST), $1998 . \quad$ Disponível em: < http://www.nist.gov/pml/data/xcom/index.cfm >.

BIGGS, F.; MENDELSOHN, L. B.; MANN, J. B. Hartree-Fock Compton profiles for the elements. Atomic Data and Nuclear Data Tables, v. 16, n. 3, p. 201-309, 1975.

BLOOM, H. J. G.; RICHARDSON, W. W. Histological grading and prognosis in breast cancer: A study of 1409 cases of which 359 have been followed for 15 years. British Journal of Cancer, v. 11, n. 3, p. 359-377, 1957.

BRADLEY, D. A.; GHOSE, A. M. Photon scattering in biomedically important elements. Physics in Medicine and Biology, v. 29, n. 11, p. 1385-1397, 1984.

BRUNETTI, A. et al. Geometrical factor influence on Compton profile measurement for biological samples. Nuclear Instruments and Methods in Physics Research Section A: Accelerators, Spectrometers, Detectors and Associated Equipment, v. 526, n. 3, p. 584592, 2004. 
BRUNETTI, A.; GOLOSIO, B. Software for X-ray fluorescence and scattering tomographic reconstruction. Computer Physics Communications, v. 141, n. 3, p. 412-425, 2001.

BRUSA, D. et al. Fast sampling algorithm for the simulation of photon Compton scattering. Nuclear Instruments and Methods in Physics Research Section A: Accelerators, Spectrometers, Detectors and Associated Equipment, v. 379, n. 1, p. 167-175, 1996.

CASTRO, C. R. F.; BARROSO, R. C.; LOPES, R. T. Scattering signatures for some human tissues using synchrotron radiation. X-Ray Spectrometry, v. 34, n. 6, p. 477-480, 2005.

CESAREO, R. et al. $90^{\circ}$ Compton and Rayleigh measurements and imaging. Radiation Physics and Chemistry, v. 61, n. 3-6, p. 339-342, 2001.

CESAREO, R. et al. A simple scanner for Compton tomography. Nuclear Instruments and Methods in Physics Research Section A: Accelerators, Spectrometers, Detectors and Associated Equipment, v. 487, n. 1-2, p. 188-192, 2002.

CESAREO, R. et al. Interaction of keV photons with matter and new applications. Physics Reports, v. 213, n. 3, p. 117-178, 1992.

CLARKE, R. L.; VANDYK, G. A new method for measurement of bone mineral content using both transmitted and scattered beams of gamma-rays. Physics in Medicine and Biology, v. 18, n. 4, p. 532-539, 1973.

COMPTON, A. H. The Spectrum of Scattered X-Rays. Physical Review, v. 22, n. 5, p. 409413, 1923.

CONCEIÇÃO, A. L. C.; ANTONIASSI, M.; POLETTI, M. E. Analysis of breast cancer by small angle X-ray scattering (SAXS). Analyst, v. 134, n. 6, p. 1077-1082, 2009.

Assessment of the differential linear coherent scattering coefficient of biological samples. Nuclear Instruments and Methods in Physics Research Section A: Accelerators, Spectrometers, Detectors and Associated Equipment, v. 619, n. 1-3, p. 67-70, 2010.

CONNER, A. L. et al. Gamma-Ray Attenuation-Coefficient Measurements. Physical Review A, v. 1, n. 3, p. 539-544, Mar 1970.

COOPER, M. J. Compton scattering and electron momentum determination. Reports on Progress in Physics, v. 48, n. 4, p. 415-481, 1985.

CROMER, D. T. Compton Scattering Factors for Aspherical Free Atoms. The Journal of Chemical Physics, v. 50, n. 11, p. 4857-4859, 1969.

CROMER, D. T.; MANN, J. B. Compton Scattering Factors for Spherically Symmetric Free Atoms. The Journal of Chemical Physics, v. 47, n. 6, p. 1892-1893, 1967.

DUMOND, J. W. M. Compton Modified Line Structure and its Relation to the Electron Theory of Solid Bodies. Physical Review, v. 33, n. 5, p. 643-658, May 1929. 
DUVAUCHELLE, P.; PEIX, G.; BABOT, D. Effective atomic number in the Rayleigh to Compton scattering ratio. Nuclear Instruments and Methods in Physics Research Section B: Beam Interactions with Materials and Atoms, v. 155, n. 3, p. 221-228, 1999.

Rayleigh to Compton ratio computed tomography using synchrotron radiation. NDT \& E International, v. 33, n. 1, p. 23-31, 2000.

EISENBERG, A. L. A.; KOIFMAN, S. Aspectos Gerais dos Adenocarcinomas de Mama, Estadiamento e Classificação Histopatológica com Descrição dos Principais Tipos. Revista Brasileira de Cancerologia, v. 46, n. 1, p. 63-77, 2000.

ELSHEMEY, W. M.; ELSAYED, A. A.; EL-LAKKANI, A. Characteristics of low-angle xray scattering from some biological samples. Physics in Medicine and Biology, v. 44, n. 12, p. 2907-2915, 1999.

FERNANDEZ, M. et al. Small-angle x-ray scattering studies of human breast tissue samples. Physics in Medicine and Biology, v. 47, n. 4, p. 577-592, 2002.

GATTI, E.; REHAK, P.; KEMMER, J. Proposal for a New Tomographic Device Providing Information on the Chemical Properties of a Body Section. IEEE Transactions on Medical Imaging, v. 5, n. 4, p. 207-221, 1986.

HAMMERSTEIN, G. R. et al. Absorbed radiation dose in mammography. Radiology, v. 130, n. 2, p. 485-491, 1979.

HANSON, J. A. et al. Compton scatter with polychromatic sources for lung densitometry. Medical Physics, v. 11, n. 5, p. 633-637, 1984.

HARDING, G. Inelastic photon scattering: Effects and applications in biomedical science and industry. Radiation Physics and Chemistry, v. 50, n. 1, p. 91-111, 1997.

HARDING, G.; HARDING, E. Compton scatter imaging: A tool for historical exploration. Applied Radiation and Isotopes, v. 68, n. 6, p. 993-1005, 2010.

HENDEE, W. R.; RITENOUR, E. R. Medical imaging physics. 4ed. Wiley-Liss, 2002.

HERMAN, G. T. Image reconstruction from projections: the fundamentals of computerized tomography. New York: Academic Press, 1980. ISBN 9780123420503.

HOLT, R. S. et al. Assessment of gamma ray scattering for the characterisation of biological material. Physics in Medicine and Biology, v. 28, n. 12, p. 1435-1440, 1983.

HUBBELL, J. H. et al. Atomic form factors, incoherent scattering functions, and photon scattering cross sections. Journal of Physical and Chemical Reference Data, v. 4, n. 3, p. 471-538, 1975.

ICRU.International Commission on Radiation Units \& Measurements. Report 44:Tissue Substitutes in Radiation Dosimetry and Measurement. Bethesda, 1989

INCA.Instituto Nacional de Câncer. Estimativa 2012: incidência de câncer no Brasil. 2011 
JOHnS, H. E.; CUnNInghaM, J. R. The Physics of Radiology. Springfield: Charles C. Thomas, 1983.

JUNQUEIRA, L. C.; CARNEIRO, J. Histologia Básica. 10ed. Rio de Janeiro: Guanabara Koogan, 2004.

KANE, P. P. Inelastic scattering of X-rays and gamma rays by inner shell electrons. Physics Reports, v. 218, n. 2, p. 67-139, 1992.

KANE, P. P. et al. Elastic scattering of [gamma]-rays and X-rays by atoms. Physics Reports, v. 140, n. 2, p. 75-159, 1986.

KERR, S. A. et al. Coherent scattering and the assessment of mineral concentration in trabecular bone. Physics in Medicine and Biology, v. 25, n. 6, p. 1037-1047, 1980.

KLEIN, O.; NISHINA, T. Über die Streuung von Strahlung durch freie Elektronen nach der neuen relativistischen Quantendynamik von Dirac. Zeitschrift für Physik A Hadrons and Nuclei, v. 52, n. 11-12, p. 853-868, 1929.

KNOLL, G. F. Radiation detection and measurements. Nova Iorque: Wiley \& Sons, 1989.

KUMAR, T. K.; REDDY, K. V. Effective atomic numbers for materials of dosimetric interest. Radiation Physics and Chemistry, v. 50, n. 6, p. 545-553, 1997.

LENTI, M. A 3-D imaging device using Compton scattering off the body. Nuclear Instruments and Methods in Physics Research Section A: Accelerators, Spectrometers, Detectors and Associated Equipment, v. 588, n. 3, p. 457-462, 2008.

LEWIS, R. A. et al. Breast cancer diagnosis using scattered X-rays. Journal of Synchrotron Radiation, v. 7, n. 5, p. 348-352, Sep 2000.

MACKENZIE, I. K. An axially symmetric gamma-ray backscatter system for DuMond spectrometry. Nuclear Instruments and Methods in Physics Research Section A: Accelerators, Spectrometers, Detectors and Associated Equipment, v. 299, n. 1-3, p. 377381, 1990.

MATSCHEKO, G.; CARLSSON, G. A.; RIBBERFORS, R. Compton spectroscopy in the diagnostic X-ray energy range: II. Effects of scattering material and energy resolution Physics in Medicine and Biology, v. 34, n. 2, p. 199-208, 1989.

MAUTNER, B. D.; SCHMIDT, K. V.; BRENNAN, M. B. New diagnostic techniques and treatments for early breast cancer. Seminars in Oncology Nursing, v. 16, n. 3, p. 185-196, 2000.

POLETTI, M. E. Análise do contraste, dose e desempenho de uma grade relacionada ao espalhamento na imagem mamográfica. Dissertação (Mestrado). Faculdade de Filosofia Ciências e Letras de Ribeirão preto, Universidade de São Paulo, Ribeirão Preto, 1997. 
POLETTI, M. E.; GONÇALVES, O. D.; MAZZARO, I. Coherent and incoherent scattering of 17.44 and $6.93 \mathrm{keV}$ x-ray photons scattered from biological and biological-equivalent samples: characterization of tissues. X-Ray Spectrometry, v. 31, n. 1, p. 57-61, 2002a.

X-ray scattering from human breast tissues and breast-equivalent materials. Physics in Medicine and Biology, v. 47, n. 1, p. 47-63, 2002 b.

PUUMALAINEN, P.; OLKKONEN, H.; SIKANEN, P. Assessment of fat content of liver by a photon scattering technique. The International Journal of Applied Radiation and Isotopes, v. 28, n. 9, p. 785-787, 1977.

PUUMALAINEN, P.; SIKANEN, P.; OLKKONEN, H. Measurement of stable iodine content of tissue by coherently and compton scattered photons. Nuclear Instruments and Methods, v. 163, n. 1, p. 261-263, 1979.

PUUMALAINEN, P. et al. A coherent/Compton scattering method employing an X-ray tube for measurement of trabecular bone mineral content. Physics in Medicine and Biology, v. 27, n. 3, p. 425-429, 1982.

RAO, D. V. et al. Doppler Broadening Calculations of Compton Scattering for Molecules, Plastics, Tissues, and Few Biological Materials in the X-Ray Region: An Analysis in Terms of Compton Broadening and Geometrical Energy Broadening. Journal of Physical and Chemical Reference Data, v. 33, n. 3, p. 627-712, 2004.

RIBBERFORS, R. Relationship of the relativistic Compton cross section to the momentum distribution of bound electron states. Physical Review B, v. 12, n. 6, p. 2067-2074, Sep 1975.

RIBBERFORS, R.; BERGGREN, K. F. Incoherent-x-ray-scattering functions and cross sections $(\mathrm{d} \sigma / \mathrm{d} \Omega)_{\text {incoh }}$ by means of a pocket calculator. Physical Review A, v. 26, n. 6, p. 3325-3333, Dec 1982.

ROSEN, P. P. Rosen's Breast Pathology. Third edition. Philadelphia: Lippincott Williams \& Wilkins, 2009.

RYAN, E. A.; FARQUHARSON, M. J. Breast tissue classification using x-ray scattering measurements and multivariate data analysis. Physics in Medicine and Biology, v. 52, n. 22, p. 6679-6696, 2007.

The differentiation between malignant and non-malignant breast tissues using elastic and inelastic scattering of synchrotron radiation. Nuclear Instruments and Methods in Physics Research Section A: Accelerators, Spectrometers, Detectors and Associated Equipment, v. 619, n. 1-3, p. 379-384, 2010.

RYAN, E. A.; FARQUHARSON, M. J.; FLINTON, D. M. The use of Compton scattering to differentiate between classifications of normal and diseased breast tissue. Physics in Medicine and Biology, v. 50, n. 14, p. 3337-3348, 2005.

SCHAUPP, D. et al. Small-Angle Rayleigh Scattering of Photons at High Energies: Tabulations of Relativistic HFS Modified Atomic Form Factors. Journal of Physical and Chemical Reference Data, v. 12, n. 3, p. 467-512, 1983. 
SCHMITT, F. Mama. In: COTRAN, R. S.;KUMAR, V., et al (Ed.). Robbins. 6ed. Rio de Janeiro: Guanabara Koogan, 2000.

SHEPP, L. A.; LOGAN JR, B. F. The Fourier reconstruction of a head section. IEEE Transactions on Nuclear Science, v. NS-21, n. 3, p. 21-43, 1974.

SHIVARAMU. Effective atomic numbers for photon energy absorption and photon attenuation of tissues from human organs. Medical Dosimetry, v. 27, n. 1, p. 1-9, 2002.

SHRIMPTON, P. C. Electron density values of various human tissues: in vitro Compton scatter measurements and calculated ranges. Physics in Medicine and Biology, v. 26, n. 5, p. 907-911, 1981.

SIU, K. K. W. et al. Identifying markers of pathology in SAXS data of malignant tissues of the brain. Nuclear Instruments and Methods in Physics Research Section A: Accelerators, Spectrometers, Detectors and Associated Equipment, v. 548, n. 1-2, p. 140146, 2005.

SPELLER, R. D. Tissue analysis using x-ray scattering. X-Ray Spectrometry, v. 28, n. 4, p. 224-250, 1999.

TARTARI, A. et al. Feasibility of in vivo tissue characterisation by Compton scattering profile measurements. Nuclear Instruments and Methods in Physics Research Section B: Beam Interactions with Materials and Atoms, v. 71, n. 2, p. 209-213, 1992.

TARTARI, A. et al. Photon backscattering tissue characterization by energy dispersive spectroscopy evaluations. Physics in Medicine and Biology, v. 39, n. 2, p. 219, 1994.

THEODORAKOU, C.; FARQUHARSON, M. J. Human soft tissue analysis using x-ray or gamma-ray techniques. Physics in Medicine and Biology, v. 53, n. 11, p. R111-R149, 2008.

TOMAL, A. et al. Experimental determination of linear attenuation coefficient of normal, benign and malignant breast tissues. Radiation Measurements, v. 45, n. 9, p. 1055-1059, 2010 .

VANUYTVEN, E.; PISTORIUS, S.; GORDON, R. A method for 3D electron density imaging using single scattered $\mathrm{x}$-rays with application to mammographic screening. Physics in Medicine and Biology, v. 53, n. 19, p. 5445-5459, 2008.

WALLER, I.; HARTREE, D. R. On the Intensity of Total Scattering of X-Rays. Proceedings of the Royal Society of London. Series A, Containing Papers of a Mathematical and Physical Character, v. 124, n. 793, p. 119-142, 1929.

WANG, J. H. et al. X-Ray Elastic and Inelastic Scattering Factors for Neutral Atoms Z = 292. Atomic Data and Nuclear Data Tables, v. 53, n. 2, p. 233-269, 1993.

WEBBER, C. E.; COATES, G. A clinical system for the in vivo measurement of lung density. Medical Physics, v. 9, n. 4, p. 473-477, 1982. 
WEBBER, C. E.; KENNETT, T. J. Bone density measured by photon scattering. I. A system for clinical use. Physics in Medicine and Biology, v. 21, n. 5, p. 760-769, 1976.

WOODARD, H. Q.; WHITE, D. R. The composition of body tissues. British Journal of Radiology, v. 59, n. 708, p. 1209-1218, 1986. 
APÊNDICE A - PRODUÇão BIBLIOGRÁFICA

Este apêndice apresenta os trabalhos desenvolvidos durante o doutorado. São apresentados os artigos científicos publicados e aceitos para publicação em periódicos bem como as comunicações e resumos publicados em anais de congressos.

\section{A.1 - Artigos publicados em periódicos}

- ANTONIASSI, M.; CONCEIÇÃO, A. L. C.; POLETTI, M. E. Study of effective atomic number of breast tissues determined using the elastic to inelastic scattering ratio. Nuclear Instruments and Methods in Physics Research Section A: Accelerators, Spectrometers, Detectors and Associated Equipment., v. 652, n. 1, p. 739-743, 2011.

- CONCEIÇÃO, A. L. C. et al. Multivariate analysis of the scattering profiles of healthy and pathological human breast tissues. Nuclear Instruments and Methods in Physics Research Section A: Accelerators, Spectrometers, Detectors and Associated Equipment, v. 652, n. 1, p. 870-873, 2011.

- ANTONIASSI, M.; CONCEIÇÃO, A. L. C.; POLETTI, M. E. Characterization of breast tissues using Compton scattering. Nuclear Instruments and Methods in Physics Research Section A: Accelerators, Spectrometers, Detectors and Associated Equipment, v. 619, n. 1-3, p. 375-378, 2010.

- CONCEIÇÃO, A. L. C.; ANTONIASSI, M.; POLETTI, M. E. Assessment of the differential linear coherent scattering coefficient of biological samples. Nuclear Instruments and Methods in Physics Research Section A: Accelerators, Spectrometers, Detectors and Associated Equipment, v. 619, n. 1-3, p. 67-70, 2010.

- CONCEIÇÃO, A. L. C. et al. Preliminary study of human breast tissue using synchrotron radiation combining WAXS and SAXS techniques. Applied Radiation and Isotopes, v. 68, n. 4-5, p. 799-803, 2010.

- CONCEIÇÃO, A. L. C.; ANTONIASSI, M.; POLETTI, M. E. Analysis of breast cancer by small angle X-ray scattering (SAXS). Analyst, v. 134, n. 6, p. 1077-1082, 2009. 
A.2 - Artigos aceitos para publicação em periódicos

- Antoniassi, M., CONCEICÃO, A. L. C., POLETTI, M. E. Study of electron densities of normal and neoplastic human breast tissues by Compton scattering using synchrotron radiation. Applied Radiation and Isotopes, aceito para publicação, 2012.

- TOMAl, A., CUNHA, D.M., ANTONIASSI, M., POLETTI, M.E. Response functions of $\mathrm{Si}(\mathrm{Li}), \mathrm{SDD}$ and CdTe detectors for mammographic x-ray spectroscopy. Applied Radiation and Isotopes. Aceito para publicação, 2011.DOI: 10.1016/j.apradiso.2011.11.044.

A.3 - Resumos publicados em anais de congressos

- ANTONiASSI, M., CONCEIÇÃO, A. L. C., POLETTI, M. E. Compton scattering spectrum as a source of information of normal and neoplastic breast tissues composition In: 8th International Topical Meeting on Industrial Radiation and Radioisotope Measurement Applications (IRRMA-8), 2011, Kansas City. Proceedings of 8th International Topical Meeting on Industrial Radiation and Radioisotope Measurement Applications (IRRMA-8). , 2011. p.68 - 68.

- ANTONiASsi, M., CONCEIÇÃO, A. L. C., POLETTI, M. E. Study of electron density of normal and neoplastic breast tissues determined using the Compton scattering of synchrotron radiation In: 8th International Topical Meeting on Industrial Radiation and Radioisotope Measurement Applications (IRRMA-8), 2011, Kansas City. Proceedings of 8th International Topical Meeting on Industrial Radiation and Radioisotope Measurement Applications (IRRMA-8). , 2011. p.146 - 146.

- ANTONiASSI, M., CONCEIÇÃO, A. L. C., POLETTI, M. E. Breast tissues electron densities determined by Compton scattering: A preliminary study using synchrotron radiation In: 10th International Conference on Biology and Synchrotron Radiation, 2010, Melbourne. Proceedings of 10th International Conference on Biology and Synchrotron Radiation., 2010.

- ANTONiAssi, M., CONCEIÇÃO, A. L. C., POLETTI, M. E. Study of effective atomic number of breast tissues determined using the elastic to inelastic scattering ratio In: Symposium on Radiation Measurements and Applications, 2010, Ann Arbor. Proceedings of Symposium on Radiation Measurements and Applications (SORMA XII). , 2010. p.172 - 172

- ANTONiASSI, M., CONCEIÇÃO, A. L. C., POLETTI, M. E. Determinação do número atômico efetivo de tecidos mamários usando a radiação espalhada In: XV Congresso Brasileiro de Física Médica, 2010, Aracaju. Cd room do XV Congresso Brasileiro de Física Médica. , 2010.

- ANTONiASsi, M., CONCEIÇÃO, A. L. C., POLETTI, M. E. Characterization of breast tissues using Compton scattering In: 11th International Symposium on 
Radiation Physics, 2009, Melbourne. Proceedings of 11th International Symposium on Radiation Physics. , 2009. p.160 - 160

- ANTONiAssi, M., CONCEIÇÃO, A. L. C., TOMAL, A., COSTA, J. J. G., POLETTI, M. E. Determination of effective atomic number of breast tissues using the Rayleigh to Compton scattering ratio In: 11th International Symposium on Radiation Physics, 2009, Melbourne. Proceedings of 11th International Symposium on Radiation Physics. , 2009. p.161 - 16.

- Antoniassi, M., CONCEIÇÃO, A. L. C., POletTi, M. E. Análise do espalhamento Rayleigh e Compton para o diagnóstico de neoplasias mamárias In: XIV Congresso Brasileiro de Física Médica, 2009, São Paulo. Cd room do XIV Congresso Brasileiro de Física Médica (XIV CBFM). , 2009. 
ANEXO A - APROVAÇÃO PELO COMITÊ DE ÉTICA E PESQUISA DO HC-FMRP

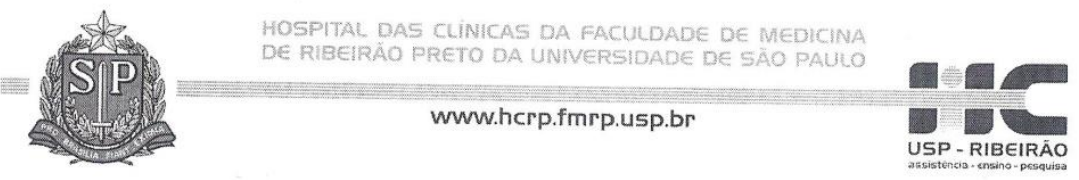

Ribeirão Preto, 27 de maio de 2009

Oficio $\mathrm{n}^{\circ} 1629 / 2009$

$\mathrm{CEP} / \mathrm{MGV}$

Prezados Senhores,

O trabalho intitulado "O ESPALHAMENTO COMPTON DE RAIOS X NO DIAGNÓSTICO DE NEOPLASIAS MAMÁRIAS” foi analisado pelo Comitê de Ética em Pesquisa, em sua $287^{\text {a }}$ Reunião Ordinária realizada em 25/05/2009 e enquadrado na categoria: APROVADO, de acordo com o Processo HCRP n 4306/2009.

Este Comitê segue integralmente a Conferência Internacional de Harmonização de Boas Práticas Clinicas (IGH-GCP), bem como a Resolução no 196/96 CNS/ MS.

Lembramos que devem ser apresentados a este CEP, o Relatório Parcial e o Relatório Final da pesquisa.

Atenciosamente.

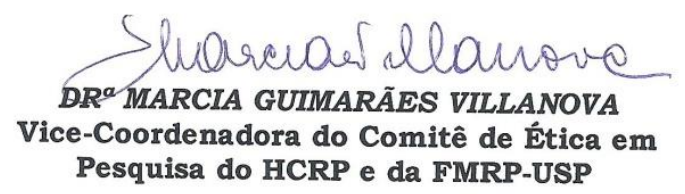

Ilustríssimos Senhores

MARCELO ANTONIASSI

PROF. DR. MARTIN EDUARDO POLETTI (Orientador)

Faculdade de Filosofia, Ciências e Letras de Ribeirão Preto-USP

Comitê de Ética em Pesquisa HCRP e FMRP-USP - Campus Universitário
FWA - 00002733 ; IRB - 00002186 e Registro SISNEP/CONEP n 4

Fone (16) 3602-2228 - E-mail : cep@hcrp.fmrp.usp.br

Monte Alegre 14048-900 Ribeirão Preto SP 